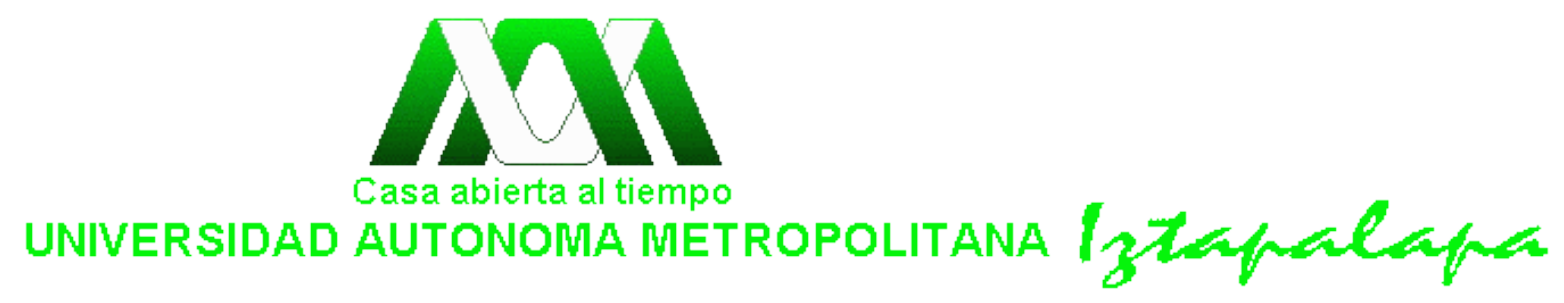

Maestría en Biología de la Reproducción Animal

\title{
Efecto del sulfonato de perfluorooctano (PFOS) en la vía de señalización de la esteroidogénesis en el ovario murino
}

TESIS

Que para obtener el grado de maestro en Biología de la Reproducción Animal

Presenta:

Bióloga Experimental Olivia Grisell Hernández García

Comité:

Director

Dr. Humberto González Márquez

Asesores

Dra. Yvonne Claudine Ducolomb Ramírez

Dr. Enrique Othón Hernández González

México, D.F. 13 de noviembre del 2015 


\title{
Miembros del Comité Tutoral
}

\section{Director}

\author{
Dr. Humberto González Márquez \\ Universidad Autónoma Metropolitana UAM-Iztapalapa \\ Departamento Ciencias de la Salud. División Ciencias Biológicas y de la Salud \\ Profesor titular: "C" \\ Laboratorio de Expresión Génica \\ Correo: hgm@xanum.uam.mx
}

\section{Asesores}

Dra. Yvonne Claudine Ducolomb Ramírez

Universidad Autónoma Metropolitana UAM-Iztapalapa

Departamento Ciencias de la Salud. División Ciencias Biológicas y de la Salud

Profesor titular: "C"

Laboratorio de Biología Celular

Correo: duco@xanum.uam.mx

Dr. Enrique Othón Hernández González

Centro de Investigaciones y Estudios Avanzados Cinvestav- Zacatenco

Departamento de Biología Celular

CINVESTAV: "3C"

Laboratorio 51

Correo: eothon@cell.cinvestav.mx 


\section{Agradecimiento a CONACYT}

En el Programa de la Maestría en Biología de la Reproducción Animal de la Universidad Autónoma Metropolitana que está incluido en el Programa Nacional de Posgrados de Excelencia del CONACyT (PNPC) registro 003797.

Numero de CVU 508882 y becario otorgado por CONACyT: 302757. 
Este trabajo fue realizado en el laboratorio de "Expresión Génica" S-248 de la Universidad Autónoma Metropolitana- Iztapalapa. Departamento Ciencias de la Salud. División Ciencias Biológicas y de la Salud. Con el apoyo del proyecto "Efecto de compuestos perfluorados en la ovogénesis temprana, la maduración de gametos y la fertilización de gametos y la fertilización en mamíferos y la fertilización en mamíferos in vitro"

Número de proyecto CONACyT: CB-2012-01-180043 


\section{Miembros del jurado del examen}

Los miembros del jurado designados por la división de Ciencias Bilógicas y de la Salud de la Universidad Autónoma Metropolitana- Iztapalapa, abajo firmantes, aprobaron la Tesis titulada: "Efecto del sulfonato de perfluorooctano (PFOS) en la vía de señalización de la esteroidogénesis en el ovario murino" que presentó: Olivia Grisell Hernández García el día: 13 de noviembre del 2015.

\section{Presidente}

Dra. Yvonne Claudine Ducolomb Ramírez

Universidad Autónoma Metropolitana UAM-Iztapalapa. Departamento Ciencias de la Salud. División Ciencias Biológicas y de la Salud.

Correo: duco@xanum.uam.mx

\section{Secretario}

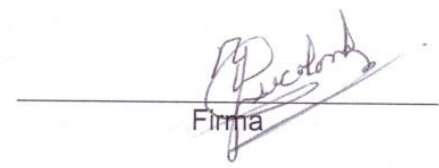

Dr. Enrique Othón Hernández González

Centro de Investigaciones y Estudios Avanzados del IPN, Zacatenco. Departamento de Biología Celular.

Correo: eothon@cell.cinvestav.mx

\section{Vocal}

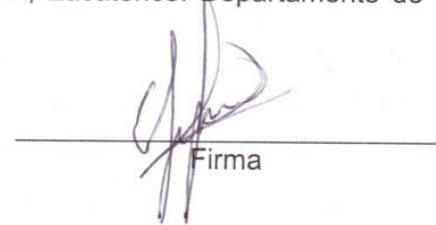

Dr. Edmundo Bonilla González

Universidad Autónoma Metropolitana UAM-Iztapalapa. Departamento Ciencias de la Salud. División Ciencias Biológicas y de la Salud.

Correo: mundo@xanum.uam.mx

\section{Vocal}

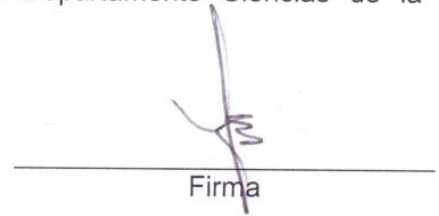

Dra. Elizabeth Hernández Pérez

Universidad Autónoma Metropolitana UAM-Iztapalapa. Departamento Ciencias de la Salud. División Ciencias Biológicas y de la Salud.

Correo: sila@xanum.uam.mx

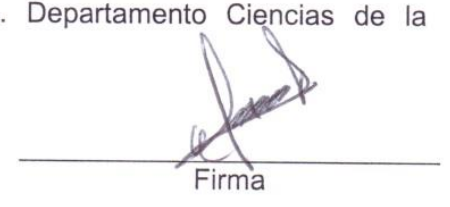




\section{Agradecimientos}

Dr. Humberto González y Dr. Enrique Othón Hernández: Gracias por abrirme las puertas de sus laboratorios y depositar en mí su confianza.

Dra. Yvonne Ducolomb: Gracias por guiarme en la realización de este trabajo.

Dra. Beatriz Buentello "miss Bety": por guiarme y enseñarme tanto, mucho éxito en todos sus proyectos.

Dra. Angeles Aguilar: por el apoyo y palabras que siempre me ha dado, GRACIAS.

Mstra. Ana Lilia Roa "Anita”: por enseñarme y ayudarme.

Dr. Pablo Damián, por su apoyo y entrega en el posgrado, gracias por la confianza que deposita en nosotros, éxito.

A los Doctores: José Miguel Betancourt Rule, Reyna Fierro que los éxitos se sigan cosechando.

Dr. Edmundo Bonilla y Dra. Elizabeth Hernández por los consejos y observaciones aportadas para la mejora del presente trabajo, por el apoyo y los buenos deseos

A mis compañeros de laboratorio: Jany, Marcos a las "Vikies": Indra e Ivonne y los "Ivanes": Iván Bahena e Iván Oseguera, GRACIAS por llenar de risas y alegría mis días en el laboratorio.

A mis compañeros Mario y Alex Domínguez: por darme su apoyo, palabras de aliento y cuidar de mí cuando lo necesité. GRACIAS.

A mi amigo Alejandro "Alex" Alonso, deseo que nuestra amistad dure muchos años más.

A mi hermana Guadalupe Elisa "Tampis", GRACIAS; en esta ocasión te tocó aguantarme como hermana y como compañera, gracias por ayudarme, te quiero mucho.

A mi tía Hermelinda, gracias por preguntar: ¿cómo voy, cómo van los experimentos y mis ratones? Y demás. Que Dios la llene de salud. 


\section{Dedicatoria}

A mi familia: mi papá, mamá, mi hermana

Por cuidarme, protegerme, enseñarme y llenarme de lo más

valioso: el amor

A ustedes les dedico todos mis logros y éxitos

A mi papá, por ayudarme a levantar de las caídas y sacudirme

el polvo para poder seguir, por todo el apoyo.

A mi mamá, por su apoyo incondicional, por todas las palabras de aliento y de amor que me das.

A ustedes les debo todo lo que soy, GRACIAS por darme la familia que tenemos, son mi ejemplo a seguir.

A mi hermana, "la Tampis" por su apoyo como hermana y compañera de aventuras, por ser la mejor hermana que me pudieron dar, tienes mucho que dar, sigue adelante y no dejes que nadie te diga lo contrario.

A mi abuelita, por ser un ejemplo de fortaleza y perseverancia, que Dios te mantenga con nosotros muchos años más y llena de salud.

Y a Dios por permitirme ser parte de ustedes y por ser mi todo.

Papá, mamá "tampis" y abuelita, los amo

"Porque donde ustedes tengan su tesoro, allí también estará su corazón"

San Lucas 12:34 
"El conocimiento no debe comenzar por la puerta falsa de la inteligencia, sino por la de los sentidos" Daniel Cosío Villegas 


\section{Resumen}

El sulfonato de perfluorooctano (PFOS) es un compuesto alifático en el que se sustituyeron los hidrógenos por flúor, se le considera un contaminante persistente que causa daños en los organismos, se emplea en la elaboración de productos textiles, de cuidado personal y envases alimentarios de uso diario. En el suero de humanos expuestos y no expuestos ocupacionalmente, se ha detectado en concentraciones de 400 a 900 y 3 a $30 \mathrm{ng} / \mathrm{ml}$ respectivamente. Se ha reportado que el PFOS puede ser considerado como disruptor endócrino, sin embargo, no se ha estudiado su efecto en las proteínas EGFR, ERK 1/2 y StAR, involucradas en la vía de señalización de la esteroidogénesis en las células de la granulosa (CG) y de la teca (CT). Es por ello que, en este estudio, se administró a ratones hembras en dosis de 0, 1.4, 10 y $21 \mu \mathrm{mol} / \mathrm{kg}$ de PFOS durante 8 días a partir del día 13 postnatal. El PFOS no modificó el peso corporal de las hembras tratadas, sin embargo, se encontró un aumento en la longitud de los ovarios de hembras tratadas con $10 \mu \mathrm{mol} / \mathrm{kg}$. Por otro lado, indujo una disminución del EGFR en las CG aunque provocó incremento en las CT. El p-EGFR no se modificó significativamente en las CT; sin embargo, en las CG el PFOS se incrementó levemente. EI PFOS no causó alteraciones significativas en la expresión de ERK 1/2 en las CG, pero se pudo observar una tendencia de aumento en la dosis de 1.4 y $10 \mu \mathrm{mol} / \mathrm{kg}$ mientras que en las CT se observó una disminución en la dosis de $10 \mu \mathrm{mol} / \mathrm{kg}$. Por otro lado, el efecto de PFOS sobre p-ERK 1/2 fue de incrementarlo en las CG en $10 \mu \mathrm{mol} / \mathrm{kg}$ y en las CT se observó una disminución en esta misma dosis. Y por último, en cuanto a la presencia de StAR en las CT se observó que las hembras tratadas con las dosis 1.4 y $21 \mu \mathrm{mol} / \mathrm{kg}$ tuvieron una tendencia al aumento mientras que las tratadas con $10 \mu \mathrm{mol} / \mathrm{kg}$ mostraron una disminución, sin embargo, no se encontraron diferencias significativas. Es importante realizar más experimentos para evaluar otros parámetros que nos ayuden a dilucidar el mecanismo de PFOS sobre la actividad y presencia de las proteínas estudiadas, tanto a nivel molecular como proteínico, algunos de los experimentos que se proponen son: evaluar la expresión del RNAm de PPAR $\gamma$, MMPs, ERK 1/2, CREB y SF-1. 


\section{Abstract}

Perfluorooctane sulfonate (PFOS) is an aliphatic compound wherein the hydrogen is replaced by fluorine, it is considered a persistent pollutant that causes damage to organisms, and it is used in the manufacture of textiles, personal care and food packaging for daily use. In the serum of humans exposed and no exposed occupationally has been detected at concentrations 400 a 900 y 3 a $30 \mathrm{ng} / \mathrm{ml}$ respectively. It has been reported that PFOS can be considered as an endocrine disruptor. However, its effect on proteins like EGFR, ERK 1/2 y StAR involved in the signaling pathway of steroidogenesis in granulosa cells (CG) and thecal cell (CT) has not been studied yet. In this study, female mice were administered with doses of $0,1.4,10$ and $21 \mu \mathrm{mol} / \mathrm{kg}$ of PFOS for 8 days in the $13 \mathrm{rd}$ postnatal day. PFOS did not change the body weight of the female mice administered, however it was found an increase in the length of female mice ovaries treated with $10 \mu \mathrm{mol}$ $/ \mathrm{kg}$. Furthermore, it induced a decrease of EGFR in the CG but an increase in CT. p-EGFR was not significantly changed in CT; however, in CG it increased slightly. The PFOS did not cause significant alterations in the expression of ERK 1/2 in CG, but it is observed a tendency of increasing in 1.4 and $10 \mu \mathrm{mol} / \mathrm{kg}$, while in CT it was observed a decrease in $10 \mu \mathrm{mol} / \mathrm{kg}$. Moreover, the effect of PFOS caused an increase on p-ERK $1 / 2$ in $C G$ in the dose $10 \mu \mathrm{mol} / \mathrm{kg}$, while a decrease was observed in CT with same dose. Finally, it was observed that the CT of females treated with PFOS 1.4 and $21 \mu \mathrm{mol} / \mathrm{kg}$, have a tendency to increase in StAR content while those treated with $10 \mu \mathrm{mol} / \mathrm{kg}$ reduced its content, however no significant differences were found. Further experiments are necessary to evaluate other parameters that help to elucidate the molecular mechanism of PFOS toxicity, some of the experiments proposed are: to evaluate the expression of the mRNA of PPAR $\gamma$, MMPs, ERK 1/2, CREB y SF-1. 


\section{Índice}

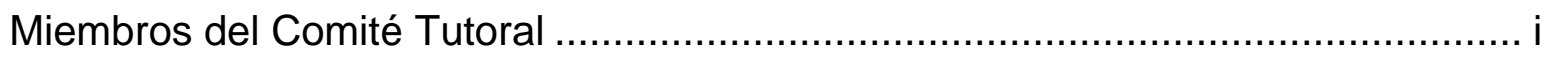

Agradecimiento a CONACyT ........................................................................

Miembros del jurado del examen .................................................................iv

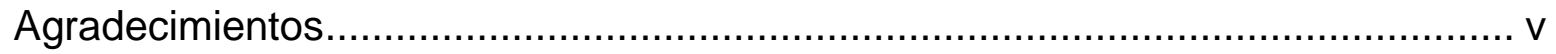

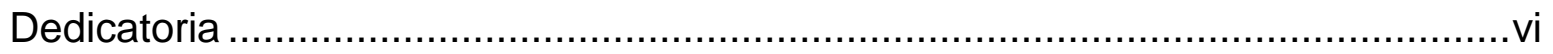

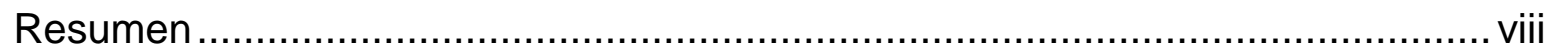

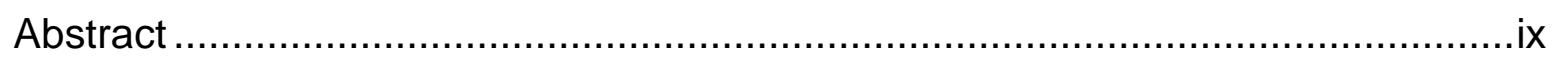

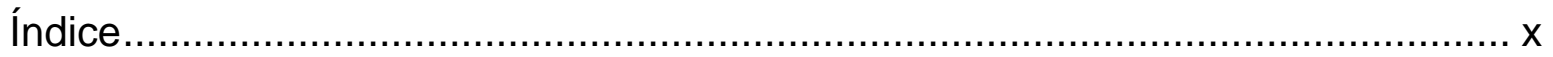

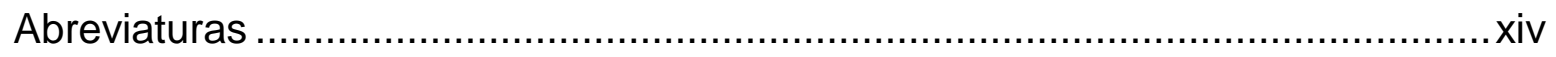

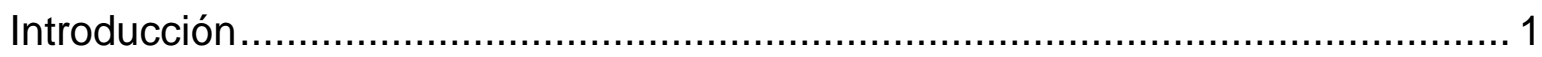

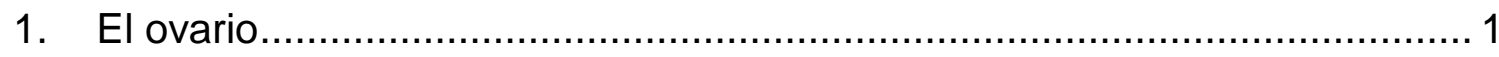

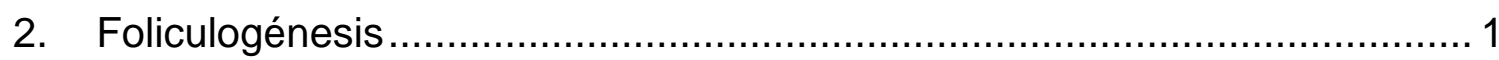

2.1 Foliculogénesis en murinos ...................................................... 2

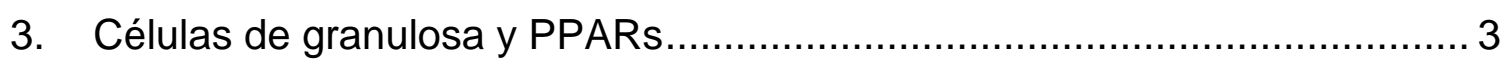

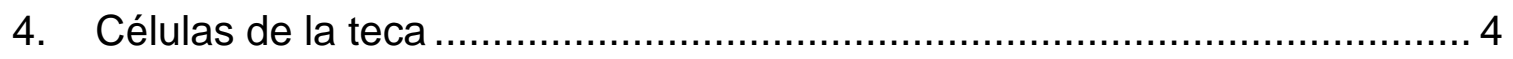

5. Biosíntesis de hormonas esteroides ....................................................... 5

6. Vía de señalización de esteroides .......................................................... 6

6.1 Receptor del factor de crecimiento epidérmico (EGFR) ….................. 7

6.2 Cinasa regulada extracelularmente (ERK 1/2) .............................. 8

6.3 Proteína reguladora de la esteroidogénesis aguda (StAR) ….............. 9

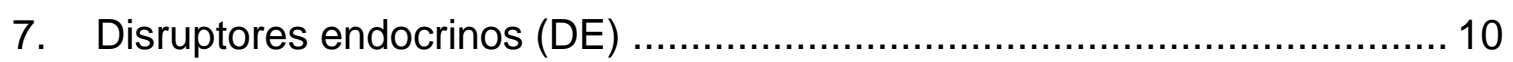

8. Compuestos perfluorados................................................................. 10

8.1 Efectos de los compuestos perfluorados ........................................ 11

9. Sulfonato de perfluorooctano (PFOS) .................................................. 12 
9.1 Concentraciones de PFOS en poblaciones y alteraciones fisiológicas 14

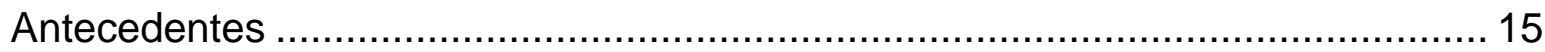

10. Efecto de PFOS sobre la actividad de EGFR, ERK 1/2 y StAR ............. 16

10.1 Actividad del EGFR en un modelo in vivo expuesto a PFOS .............. 17

10.2 Actividad de la ERK 1/2 en modelos expuestos a PFOS ................... 17

10.3 Actividad de StAR en modelos expuestos a PFOS …........................ 18

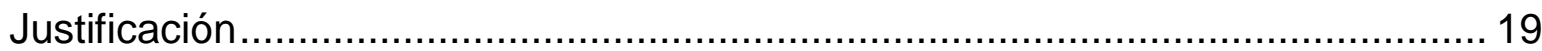

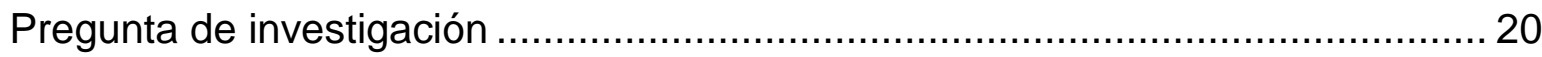

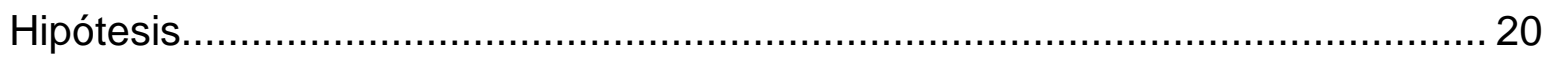

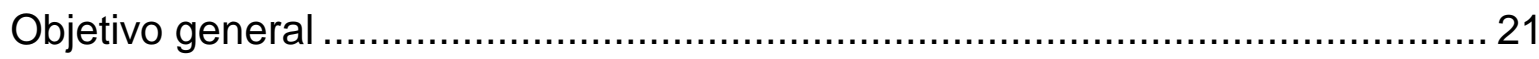

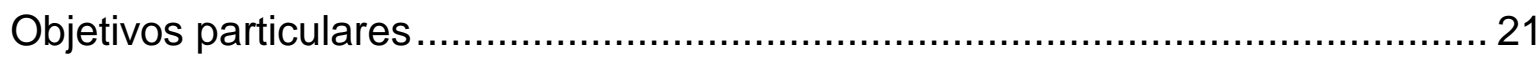

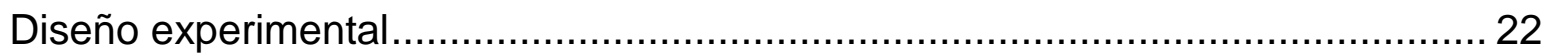

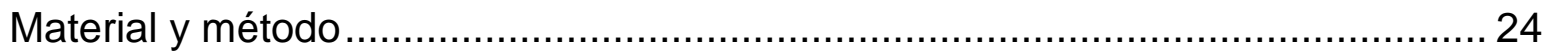

11. Obtención de los individuos para la administración de PFOS.................24

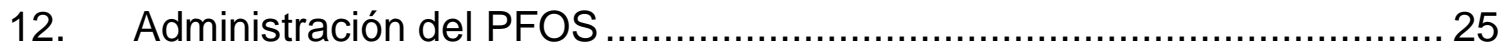

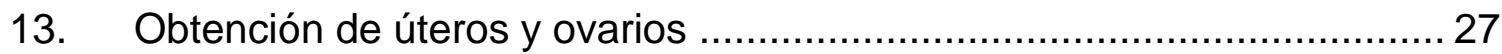

14. Obtención de células de la granulosa y de la teca ................................2 27

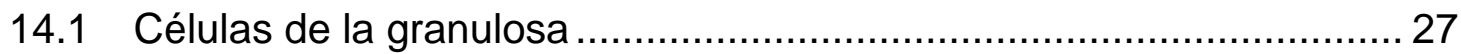

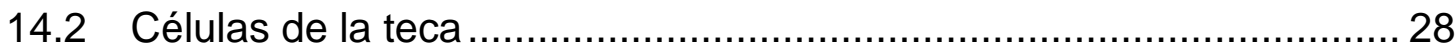

14.3 Extracción de las proteínas de las CG y CT ......................................... 28

14.4 Aislamiento de las células de la granulosa y de la teca......................2 29

15. Inmunodetección de las proteínas fosforiladas y totales de EGFR, ERK

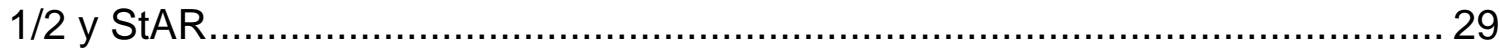

15.1 Desnudamiento de membranas de nitrocelulosa ("stripping") .............30

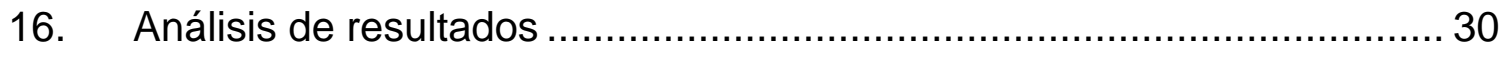


Resultados

17. EL PFOS no afecta el peso corporal de las hembras tratadas ............... 31

18. Evaluación de los ovarios y úteros de animales expuestos al PFOS...... 32

19. Aislamiento de las células de la granulosa y de la teca .......................... 34

20. Actividad de proteínas involucradas en la vía de señalización de la esteroidogénesis

20.1 Diferencias entre el efecto del PFOS sobre la presencia de EGFR en las $C T$ y $C G$ 35

20.2 Diferencias entre el efecto del PFOS sobre la presencia de $p$-EGFR en las CT y CG. 36

20.3 Efecto del PFOS sobre la relación de p-EGFR / EGFR en las

CG y $C T$ 38

20.4 Diferencias entre el efecto del PFOS sobre la presencia la Cinasa regulada extracelularmente (ERK 1/2) en las CG y CT. 40

20.5 Diferencias entre el efecto del PFOS sobre la presencia de $p$-ERK 1/2 en las $C G$ y $C T$ 41

20.6 Efecto del PFOS sobre la relación de p-ERK 1/2 / ERK 1/2 43

20.7 Efecto del PFOS sobre la presencia de la proteína reguladora de la esteroidogénesis aguda (StAR) 45

Discusión 47

21. EL PFOS no afecta el peso corporal de las hembras tratadas 47

22. Evaluación macroscópica de los úteros y ovarios de animales expuestos al PFOS 47

23. Actividad de proteínas involucradas en la vía de señalización de la esteroidogénesis. 49

23.1 Efecto del PFOS sobre la presencia del Receptor del factor de crecimiento epidérmico (EGFR) 
23.1 Efecto del PFOS sobre la presencia de la Cinasa regulada extracelularmente (ERK 1/2) .............................................................. 51

23.1 Efecto del PFOS sobre la presencia de la proteína reguladora de la esteroidogénesis aguda (StAR) ........................................................... 53

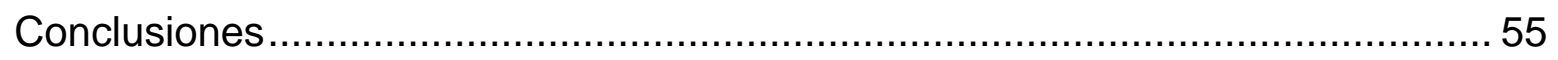

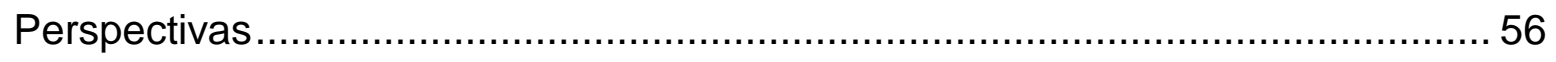

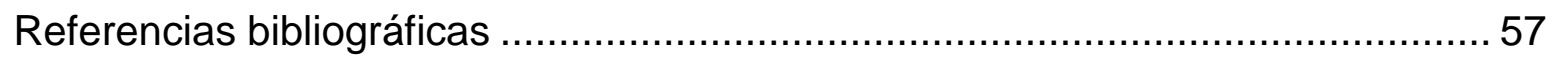




\section{Abreviaturas}

AMPc: Adenosín monofosfato

AP-1: Activador de la proteína 1

CG: Células de la granulosa

CPF: Compuestos perfluorados

CREB: Proteína fijadora de los elementos de respuesta a AMPc

CT: Células de la teca

D.O: Densitometría óptica

DE: Disruptores endocrinos

DHEA: Dehidroepiandrosterona

DMEM-F12: Medio Dulbecco modificado por Eagle, mezcla de nutriente HAM- F12

$E_{2}:$ Estradiol

eCG: Gonadotropina Coriónica equina

EGFR: Receptor del factor de crecimiento

ERK: MAP cinasas reguladas extracelularmente

esr1: Gene del Receptor de estrógenos $\alpha$

FSH: Hormona folículo estimulante

FSHR: Receptor de FSH

GFD9: Factor de diferenciación de crecimiento 9

GH: Hormona del crecimiento

GnRH: Hormona liberadora de gonadotropinas 
GPCRs: Receptores acoplados a proteínas G

IGF-1: Factor de crecimiento insulínico- 1

LH: Hormona Luteinizante

LHR: Receptor de LH

MAPK: Proteínas cinasas activadas por mitógenos

MMP: metaloproteasas

$\mathrm{P}_{4}$ : Progesterona

PFAAs: Ácidos perfluoralquilos

PFDA: Perfluorodecanoato

PFDoA: Perfluorododecanoato

PFHX: Perfluorhexano

PFNA: Amonio de perfluorooctanoato

PFOA: Ácido perfluorooctanoico

PFOS: Sulfonato de perfluorooctano

PFUna: Pefluoroundecanoato

Pgr: Gen que codifica para el Receptor de progesterona

PKA: Proteína cinasa dependiente de AMPc

PKC: Proteína cinasa C

PPARs: Receptores activados de proliferación de peroxisomas

ptgs2: Gen que codifica para Prostaglandina-endoperóxido sintasa 2

RE: Receptor estrogénico 
RSG: Rosiglitazona

SF-1: Factor esteroidogénico- 1

StAR: Proteína Reguladora de la Esteroidogénesis Aguda

$\mathrm{T}_{2}$ : Testosterona

$\mathrm{T}_{3}$ : Triyodotironina

$\mathrm{T}_{4}$ : Tiroxina (T4)

TZD: Tiazolidinedionas 


\section{Introducción}

\section{El ovario}

Las funciones principales de los ovarios son producir ovocitos maduros (ovogénesis) para la fertilización y la producción de hormonas esteroides para mantener las funciones del tracto genital. Los ovarios son órganos pares de forma ovalada que se encuentran suspendidos en la cavidad abdominal de las hembras, sostenidos por tejido conectivo y su tamaño varía según la especie. El ovario es una estructura sólida que tiene en su interior una parte medular integrada por tejido conectivo, vasos sanguíneos y linfáticos, músculo liso y fibras nerviosas. Rodeando la médula se localiza la corteza, que es la región donde están los folículos y dentro de éstos se encuentran los ovocitos (Trejo et al., 2005). Los folículos son la fuente principal de las hormonas secretadas por el ovario. Cada folículo está formado por el ovocito, las células de la granulosa, una membrana basal, las células de la teca interna que contiene fibroblastos, células endoteliales y las células de la teca externa que contienen células similares a los fibroblastos y son más vascularizadas (Hatzirodos et al., 2014, Rajkovic et al., 2006). Los ovocitos son células germinales con una carga genética diferente a las células somáticas por efectos del entrecruzamiento genético que se produce durante la etapa de paquiteno de la primera división meiótica, los ovocitos se encuentran rodeados de las células de la granulosa y de la teca (Trejo et al., 2005).

\section{Foliculogénesis}

La unidad funcional del ovario es el folículo, constituido por células de la granulosa y de la teca interna y externa que rodean al ovocito en crecimiento, funcionando como soporte nutricional, además de llevar a cabo la síntesis de hormonas esteroides (Gómez-Chang et al., 2012, Sanderson, 2006). 
La foliculogénesis es un proceso muy selectivo donde, usualmente, solo un folículo asume la dominancia. El folículo primordial está compuesto por un ovocito detenido en profase I, rodeado por una sola capa de células de la granulosa planas, por fuera de la cual se halla una membrana basal que separa ambas estructuras del tejido adyacente (Bethencourt, 2004). En el folículo primario se observa una proliferación de células foliculares que se diferencian en la capa de las células de la granulosa, de una morfología aplanada y cuboide, en el folículo secundario aumenta el número de células de la granulosa por mitosis, las células externas de la membrana basal que rodean a las células de la granulosa forman la capa concéntrica conocida como la teca, la teca interna comienza su diferenciación y la zona pelúcida se forma a partir de una capa de glicoproteínas (Bethencourt, 2004, Trejo et al., 2005). Bajo la influencia sinérgica de los estrógenos, se produce un aumento en la producción del fluido folicular que se acumula en los espacios intercelulares de las células de la granulosa, lo que formará una cavidad denominada antro, formando así el folículo antral. El aumento del fluido folicular conduce al desplazamiento del ovocito hacia la periferia, que queda rodeado por células de la granulosa, cuya capa más interna en contacto con la zona pelúcida forma la corona radiata (Bethencourt, 2004, Rosell, 2004). El folículo de Graaf, es el folículo maduro, se caracteriza por ser el folículo de mayor tamaño. El ovocito empieza a separarse del resto del folículo rodeado solamente por la corona radiata y será expulsado (Figura 1) (Bethencourt, 2004).

\subsection{Foliculogénesis en murinos}

Uno 02 días después del nacimiento, un número de folículos primordiales aparecen, mientras que el número de grupos de células germinales disminuye. En el día postnatal 3, una clase de folículos primarios es perceptible por la presencia de células de la granulosa de forma cúbica y el crecimiento del ovocito, en esta etapa numerosos folículos primordiales remplazan los quistes de las células germinales en la periferia del ovario. En el día postnatal 7, las células germinales han desaparecido en su mayoría y se encuentran folículos primordiales en mayor cantidad y los folículos primarios y secundarios se encuentran en la zona medular del ovario. En el día postnatal 14 se observan mayor cantidad de folículos 
secundarios. Los folículos degeneran por la falta de FSH y en el día 21, hay mayor cantidad de folículos y el ovocito alcanza su diámetro final de aproximadamente 70 $\mu \mathrm{m}$ y se encuentra rodeado por varias capas de células de la granulosa y áreas dispersas de líquido intersticial, que posteriormente formarán la cavidad antral (Rajkovic et al., 2006).

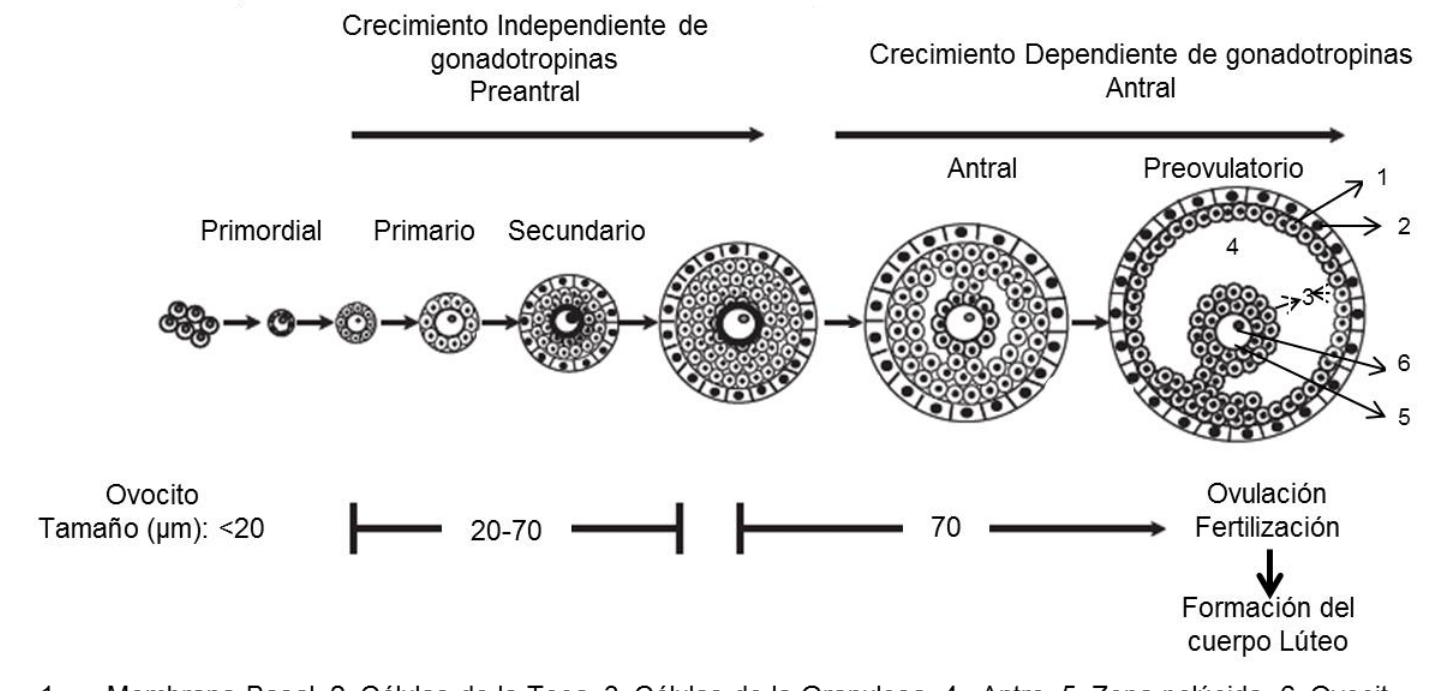

1. Membrana Basal, 2. Células de la Teca, 3. Células de la Granulosa, 4. Antro, 5. Zona pelúcida, 6. Ovocito

Fig. 1. Representación esquemática de los estadios en la foliculogénesis. Modificado de (Rajkovic et al., 2006).

\section{Células de granulosa y PPARs}

Las células de la granulosa (CG) derivan del mesodermo y adquieren una forma epitelial durante la foliculogénesis. Estas células en un folículo primordial poseen una morfología y bioquímica heterogénea entre las capas de células, con respecto a su cercanía con el ovocito y células de la teca (Amsterdam et al., 1992). Las CG, son el principal tipo de células en el ovario, proveen el microambiente para el desarrollo del ovocito y proporcionan estructura y soporte (Qiu et al., 2013b).

Los receptores activados de proliferación de peroxisomas (peroxisome proliferatoractivated receptors, PPARs) son una familia de receptores hormonales nucleares, pertenecientes a la superfamilia de los receptores de esteroides, son activados por varios factores, tales como herbicidas, plastificantes industriales, insulina y ácidos 
grasos; existen 3 isoformas: PPAR $\alpha$, PPAR $\delta$, PPAR $\gamma$. Los PPARs están involucrados en las funciones del ovario, tales como la síntesis de esteroides, angiogénesis, remodelación de tejido y regulación del ciclo celular; además preservan las funciones del cuerpo lúteo, es decir, la producción de progesterona para dar soporte a la implantación y gestación (Froment et al., 2006, Komar et al., 2001). Los PPARs regulan la actividad y expresión de la aromatasa. La activación de los PPARs también inhibe la producción de progesterona en cultivos de células de granulosas porcinas, esto es debido al hecho de que los PPARs tienen la capacidad de reducir la actividad de la 3-hidroxiesteroide deshidrogenasa (Komar et al., 2001).

Cada PPAR se transcribe a partir de un gene diferente. El gen que codifica para PPAR $\gamma$ se encuentra localizado en el brazo corto del cromosoma 3, consiste de 9 exones con aproximadamente $100 \mathrm{~kb}$. Se ha demostrado que la disminución en la actividad de los PPAR $\gamma$ se relaciona con la disminución en la biosíntesis de hormonas en el ovario, por lo que se considera un factor importante en la fertilidad (Sahmani et al., 2012).

El PPAR $\gamma$ es la isoforma predominante que se expresa en las células de la granulosa, este receptor se detecta en los folículos primarios y secundarios y su expresión aumenta conforme crece el folículo y disminuye después del pico de $\mathrm{LH}$, lo que indica que tiene un papel importante en las células de la granulosa durante la esteroidogénesis (Froment et al., 2006).

\section{Células de la teca}

Las células de la teca (CT) son reclutadas a partir de las células del estroma ovárico, su diferenciación en CT interna y externa se considera que es controlada por factores paracrinos que son secretados por las CG. Se ha sugerido que después del estado de folículo primario, las células troncales que se encuentran en el estroma son inducidas a la proliferación por factores de las células troncales, como el factor de crecimiento insulínico- 1 (IGF-1) que son secretados por las células de la granulosa y los factores secretados por el ovocito, tales como el 
factor de diferenciación de crecimiento 9 (Growth Diferentiation Factor, GFD9) (Hatzirodos et al., 2014). Las funciones de las CT son: estructura de soporte y reguladores ováricos de los folículos en desarrollo, proveer andrógenos a las células de la granulosa para producir estrógenos y estimular el crecimiento de los primeros folículos mediante la secreción de andrógenos (Qiu et al., 2013b).

\section{Biosintesis de hormonas esteroides}

Los procesos fisiológicos desde la vida fetal hasta la adultez están regulados por una variedad de hormonas, como la hormona del crecimiento $(\mathrm{GH})$, el cortisol, la tiroxina (T4) y la triyodotironina (T3), la testosterona (T2), la progesterona (P4), androsterona y el estradiol (E2) entre otras. En específico las hormonas esteroides se producen en las glándulas suprarrenales, testículos y ovarios y responden al estímulo de las hormonas tróficas: hormona folículo estimulante (FSH) y hormona luteinizante (LH) y a factores ambientales y genéticos (Manna et al., 2009, Miller y Auchus, 2011).

La producción de esteroides en el ovario es crítica para el desarrollo normal y la función de tejidos y órganos en las hembras, en los que se incluyen: vagina, útero, mama, esqueleto y ovario. En el ovario este proceso implica varias vías de señalización en múltiples tipos de células somáticas (Jamnongjit y Hammes, 2006). En los ovarios de los mamíferos, la esteroidogénesis se lleva a cabo por las células de granulosa y de la teca y por influencia de las hormonas LH y FSH. En este proceso los andrógenos se sintetizan a partir del colesterol en las células de la teca que son estimuladas por la acción de la LH posteriormente, éstos son transformados en estrógenos por las células de la granulosa estimuladas por la FSH (Jamnongjit y Hammes, 2006). En las células de la teca se expresan principalmente los receptores de LH y la enzima CYP17, que convierte la pregnenolona en dehidroepiandrosterona (DHEA) y la progesterona en androstenediona; mientras que en las células de la granulosa se expresan principalmente los receptores de FSH y la aromatasa (CYP19) que convierte los andrógenos en estrógenos (Figura 2) (Jamnongjit y Hammes, 2006). Por otro lado, 
el proceso de esteroidogénesis también requiere de la participación de la proteína Reguladora de la esteroidogénesis Aguda (StAR por sus siglas en inglés; masa molecular $30 \mathrm{kDa}$ ) que transporta el colesterol desde la membrana mitocondrial externa hacia la interna, donde se encuentran las enzimas esteroidogénicas. StAR se expresa en las células de la teca y es una proteína limitante de la producción de esteroides, por lo que es necesaria para el funcionamiento adecuado del ovario en hembras adultas (Jamnongjit y Hammes, 2006).

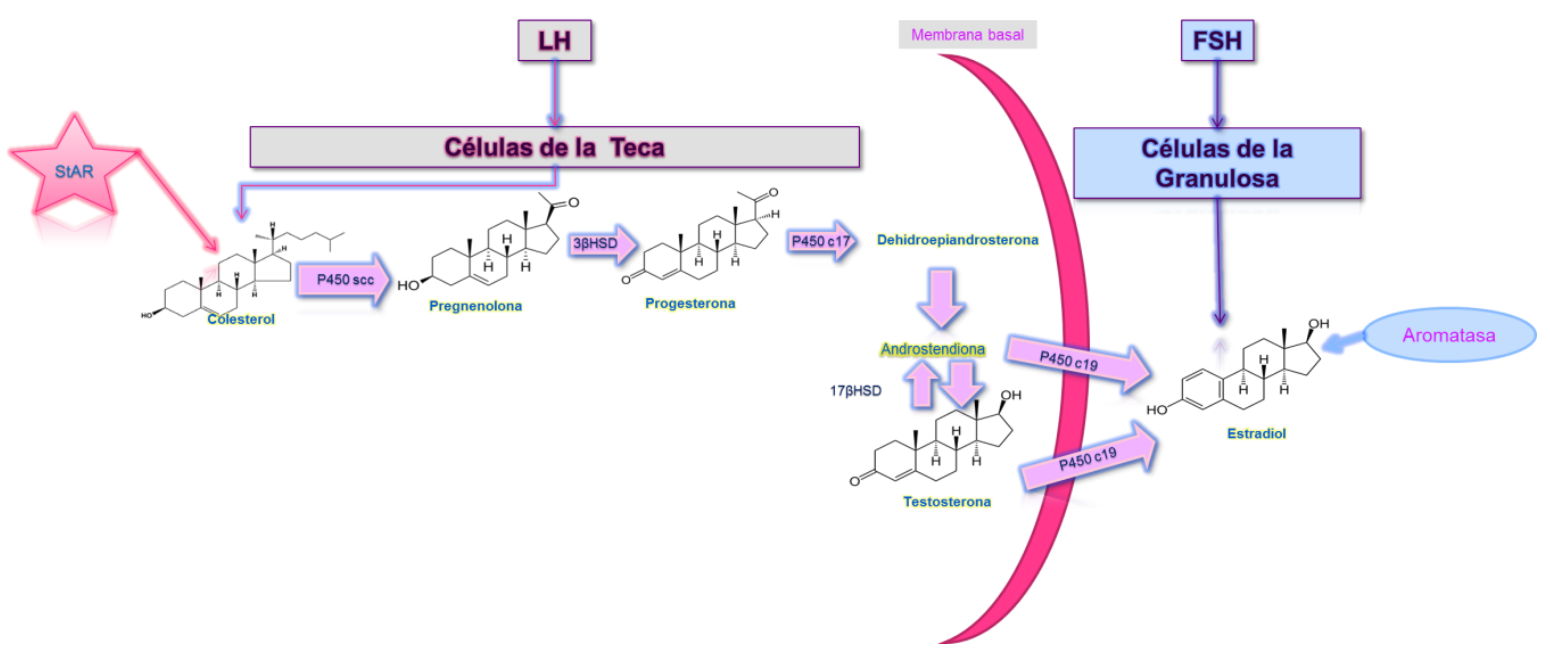

Fig. 2. Resumen de la biosíntesis de esteroides en el ovario. CG; células de la granulosa, CT: células de la teca, FSH, Hormona folículo estimulante, LH, Hormona luteinizante, StAR: proteína reguladora de la esteroidogénesis aguda.

\section{Vía de señalización de esteroides}

La secreción de la hormona liberadora de gonadotropinas $(\mathrm{GnRH})$, que es sintetizada en el hipotálamo, estimula la secreción pulsátil de $\mathrm{LH}$ y $\mathrm{FSH}$, que se unen a sus receptores, que están acoplados a proteínas $G$ y al receptor del factor de crecimiento (EGFR, anfiregulina y epirregulina), todo esto promueve finalmente, la esteroidogénesis (Figura 3) (Carbajal et al., 2011, Woods et al., 2007). En el ovario, la esteroidogénesis inicia en las células de la teca con la activación del receptor de LH (LHR) que estimula la producción de adenosín monofosfato cíclico (AMPc) y la señalización subsecuente de la proteína cinasa $A(P K A)$, mientras que en las células de la granulosa, la activación del receptor de FSH (FSHR) estimula 
la señalización de la proteína cinasa C (PKC). La activación de PKA y PKC activan al receptor del factor de crecimiento epidérmico (EGFR), promoviendo la activación de la vía de las cinasas reguladas extracelularmente (ERK 1/2). ERK 1/2 sub-regula la fosforilación de la proteína StAR, que es una proteína mitocondrial que se sintetiza rápidamente como respuesta a la estimulación hormonal, incrementando la producción de esteroides (Carbajal et al., 2011, Jamnongjit y Hammes, 2006, Sanderson, 2006). La vía mediada por las cinasas de proteínas activadas por mitógeno (MAPK) participa en la transducción de señales iniciadas por citocinas, como los factores de crecimiento epidérmico (EGF), cuyos receptores tienen actividad intrínseca de tirosina cinasa, lo que desencadena la activación secuencial de otras cinasas efectoras como MEKERK1/2. La función de MAPK implica la fosforilación de factores transcripcionales asociados con la biosíntesis de esteroides (Chang et al., 2012, Manna y Stocco, 2011).

\subsection{Receptor del factor de crecimiento epidérmico (EGFR)}

El desarrollo y función del ovario, folículos ováricos y ovocitos dependen de una interacción compleja entre hormonas y factores de crecimientos que regulan el progreso del ciclo celular y pueden desempeñar un papel en la morfogénesis y en el mantenimiento de la homeostasis y supervivencia celular (Sasseville et al., 2010, Zheng et al., 2009). Para el estudio de los factores de crecimiento, se han clasificado en familias, atendiendo a sus características estructurales y efectos biológicos: Familia del factor de crecimiento epidérmico, del factor de crecimiento fibroblástico, del factor de crecimiento plaquetario, del factor de crecimiento similar a insulina, del factor de crecimiento transformante $\beta$, y del factor de crecimiento hematopoyéticos (citocinas) (Díaz et al., 1998).

El primer factor de crecimiento que se descubrió fue el factor de crecimiento epidérmico, que se aisló de la glándula submaxilar del ratón (Cohen, 1962), pertenece a una familia de factores de crecimiento que son proteínas que poseen seis cisteínas y forman tres enlaces disulfuro. Estos enlaces son esenciales para mantener su estructura terciaria, esta familia tiene la capacidad de unirse al mismo 
receptor, el receptor de factor de crecimiento epidérmico (EGFR) el cual es una glicoproteína transmembranal de superficie de 170 kDa (Hunter et al., 1984). El EGFR tienen actividad de tirosina cinasa y dimeriza en la presencia de un ligando e induce la auto fosforilación en los residuos de tirosina. Este evento de activación desencadena la cascada de fosforilación de las MAPK (Light y Hammes, 2013).

\subsection{Cinasa regulada extracelularmente (ERK 1/2)}

Las cinasas de proteínas activadas por mitógeno (MAPK) ERK1 (PM $44 \mathrm{kDa}$ ) y ERK2 (PM $42 \mathrm{kDa}$ ) (ERK 1/2) se encuentran muy conservadas en las células de los eucariontes. Estas cinasas se unen a receptores transmembranales y a varias proteínas, integrando así las señales para el control de procesos celulares como la supervivencia y diferenciación celular. La cascada de señalización de ERK 1/2 juega un papel importante en la regulación de la esteroidogénesis regulada por las cinasa PKA y PKC (Manna y Stocco, 2011). La activación del receptor de LH lleva a un transactivación rápida del EGFR, proceso que es necesario para activar la cascada de señalización de ERK 1/2 (Light y Hammes, 2013). La función de MAPK implica la fosforilación de factores transcripcionales, lo que resulta en la activación, regulación de la expresión y fosforilación de StAR, en el residuo de serina 232, esta fosforilación es necesaria para la acción de StAR sobre el transporte de colesterol a la membrana interna de la mitocondria (Gómez-Chang et al., 2012). En mamíferos, en las células de la granulosa, ERK 1/2 es activada en respuesta a las gonadotropinas y es importante en la regulación de la esteroidogénesis ovárica inducida por gonadotropinas (Paul et al., 2010). La vía de señalización de ERK 1/2 también puede ser activada a través de la señalización directa rio abajo de la PKA. Trabajos realizados en ratones nulos para ERK 1/2, en las células de la granulosa durante la maduración, revelaron que estas cinasas se requieren para la detención del ciclo celular, la expansión de las células del cúmulo, la inducción de la meiosis en el ovocito, la ovulación y la diferenciación de las células de la granulosa en células lúteas durante la formación del cuerpo lúteo (Karlsson et al., 2010). 


\subsection{Proteína reguladora de la esteroidogénesis aguda (StAR)}

La transferencia de colesterol de la membrana externa mitocondrial a la interna es el paso limitante en la esteroidogénesis. Este paso es mediado por la StAR. En el ovario la esteroidogénesis de novo ocurre en las células de la teca, células de la granulosa luteinizadas y células lúteas (LaVoie et al., 2014). El efecto agudo de la FSH y LH, incrementa el contenido intracelular de AMPc activando a la PKA, que inicia la cascada de fosforilación de proteínas que termina en la fosforilación de StAR ésta aumenta su expresión por el efecto hormonal que promueve la esteroidogénesis en las gónadas (Gómez-Chang et al., 2012). Se ha observado una estrecha relación entre la síntesis de StAR y la síntesis de esteroides. La inhibición transcripcional o transduccional de la expresión de StAR produce una disminución de la biosíntesis de esteroides (Manna et al., 2009).

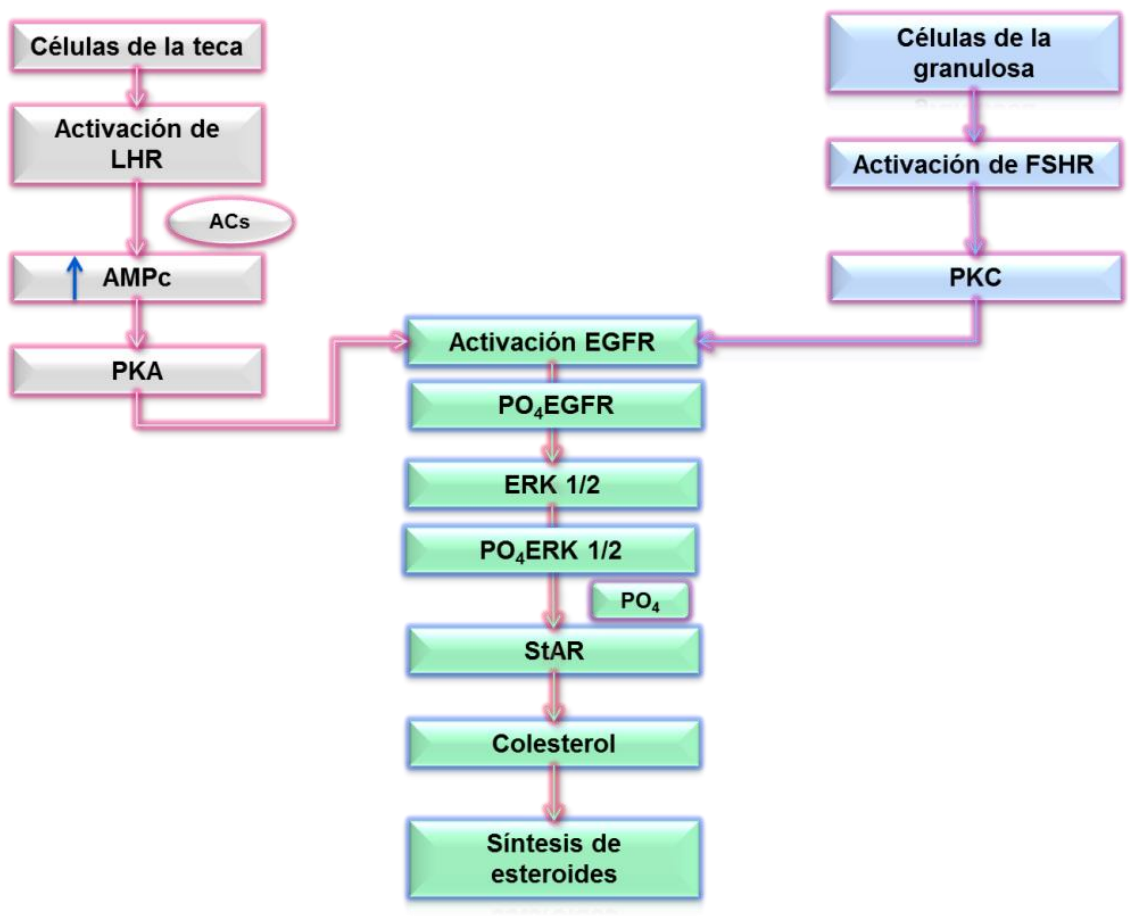

Fig. 3. Vía de señalización de la esteroidogénesis en el ovario. ACs: adenil ciclasa soluble, AMPC:

Adenosín monofosfato cíclico, EGF-R Receptor del Factor de crecimiento epidérmico, ERK1/2:

Cinasas reguladas por señales extracelulares, FSH-R: Receptor de Hormona Folículo estimulante, LH-R: Receptor de la hormona luteinizante, PKA: proteína cinasa A, PKC; Proteína cinasa C, PO4:

Fosforilación StAR: proteína de la regulación aguda de la esteroidogénesis. 


\section{Disruptores endocrinos (DE)}

Los DE son sustancias tóxicas que afectan la síntesis, secreción, transporte, unión, acción, o eliminación de hormonas presentes en el cuerpo (Basavarajappa et al., 2012). Algunos DE actúan de forma aditiva con las hormonas del organismo actuando en múltiples sitios y órganos blanco. También pueden interferir con los mecanismos de retroalimentación del sistema endocrino, pueden actuar como inhibidores o activadores de las enzimas clave o bien en los niveles de expresión de las enzimas involucradas en la biosíntesis de esteroides (Hampl et al., 2014). Entre estos compuestos se encuentran plaguicidas, cosméticos, solventes, pinturas, productos de uso farmacológico y otros contaminantes presentes en el medio como los compuestos perfluorados (CPF), que alteran la homeostasis endocrina en los organismos. Varios estudios han demostrado los vínculos entre la exposición a DE y problemas reproductivos, tanto en humanos como en animales (Heath et al., 2011).

\section{Compuestos perfluorados}

Los compuestos perfluorados (CPF) son compuestos sintéticos con propiedades repelentes al aceite y de baja tensión superficial, son insolubles en agua y en solventes orgánicos. Desde 1950, los CPF se han utilizado en productos textiles, industriales, de cuidado personal y envases alimentarios y que, al ser desechados, contaminan (Chen, 2012, Fei et al., 2009, Halldorsson et al., 2012). La fuente principal de los CPF en humanos se encuentra en la ingesta diaria. Los productos alimenticios pueden contaminarse directamente desde el envasado o por la bioacumulación en la cadena alimenticia; otras vías de exposición son el consumo de agua potable, inhalación de polvo al aire libre, y productos de consumo con recubrimiento de PFAAs resistentes al aceite y agua (Kjeldsen y BonefeldJorgensen, 2013, Petro et al., 2014).

Los CPF están constituidos por una cadena de 4 a 14 carbonos saturados de flúor y en el carbono terminal contienen un grupo sulfonato, amina o ácido carboxílico La familia de los CPF es muy amplia y a esta pertenecen algunos compuestos 
como: el sulfonato de perfluorhexano (PFHX), amonio de perfluorooctanoato (PFNA), perfluorodecanoato (PFDA), pefluoroundecanoato (PFUna), perfluorododecanoato (PFDoA), entre otros. Por su estabilidad química y resistencia a la biodegradación, generan problemas de salud, tanto en la vida silvestre como en los humanos. El uso y producción de los CPF incrementa la presencia de ácidos perfluoralquilos (PFAAs) en el ambiente (Halldorsson et al., 2012, Kjeldsen y Bonefeld-Jorgensen, 2013).

Los dos PFAAs que más se detectan en humanos y animales son los de 8 carbonos: el ácido perfluorooctanoico (PFOA) y el sulfonato de perfluorooctano (PFOS) (Halldorsson et al., 2012). En humanos y animales, estos compuestos son absorbidos fácilmente y eliminados pobremente, ya que tienen una vida promedio de 5 años, los PFAAs son distribuidos en el organismo, principalmente en el suero e hígado (Petro et al., 2014).

\subsection{Efectos de los compuestos perfluorados}

Los PFAAs tienen la capacidad de interactuar con los PPARs lo que provoca una alteración metabólica. Dentro del ovario en el microambiente folicular, los PFAAs se unen a los PPARs lo que interfiere con la esteroidogénesis $y$ subsecuentemente con el desarrollo del ovocito (Petro et al., 2014). En cultivos celulares de la línea de cáncer de seno (MCF-7), concentraciones de 1, 10 y 100 $\mu \mathrm{M}$ de PFOS y PFOA indujeron la proliferación celular. Veinticuatro horas después de la exposición a los PFAAs el porcentaje de células en fase $S$ se incrementó en comparación con el grupo control en el que las células permanecieron en la fase G0/G1 de ciclo celular (Maras et al., 2006).

Un estudio realizado en ratas macho a las que se les administró diariamente una dosis de PFOA $25 \mathrm{mg} / \mathrm{kg}$ de peso durante 15 días indujo la disminución de la concentración de testosterona tanto en plasma sanguíneo como en el líquido intersticial del testículo. Se observó además un incremento en la actividad aromatasa y un aumento en los niveles de estradiol en el suero induciendo la hiperplasia de las células de Leydig y formación de adenomas. Este estudio 
sugiere que los PFAAs son capaces de interferir en los procesos endocrinos de los seres vivos (Biegel et al., 1995).

\section{Sulfonato de perfluorooctano (PFOS)}

El sulfonato de perfluorooctano (PFOS) (Figura 4) es un anión, en el que todos los átomos de carbono se encuentran totalmente enlazados a átomos de flúor. Este compuesto se produce a partir de la hidrólisis de fluoruro de perfluorooctano sulfonilo $\left(\mathrm{C}_{8} \mathrm{~F}_{17} \mathrm{SO}_{2} \mathrm{~F}\right)$ y la degradación en el medio ambiente de la perfluorooctano sulfonamida $\left(\mathrm{C}_{8} \mathrm{~F}_{17} \mathrm{SO}_{2} \mathrm{NH}_{2}\right)$ y de ciertas $\mathrm{N}$-aquil- perfluorooctano sulfonamidas $\left(\mathrm{C}_{8} \mathrm{~F}_{17} \mathrm{SO}_{2} \mathrm{~N}(\mathrm{R})\right.$, que son precursores de productos comerciales, tales como: pinturas, ropa, calzado, lubricantes, ceras para pisos y coches y espumas para la extinción de incendios (Chang et al., 2012).

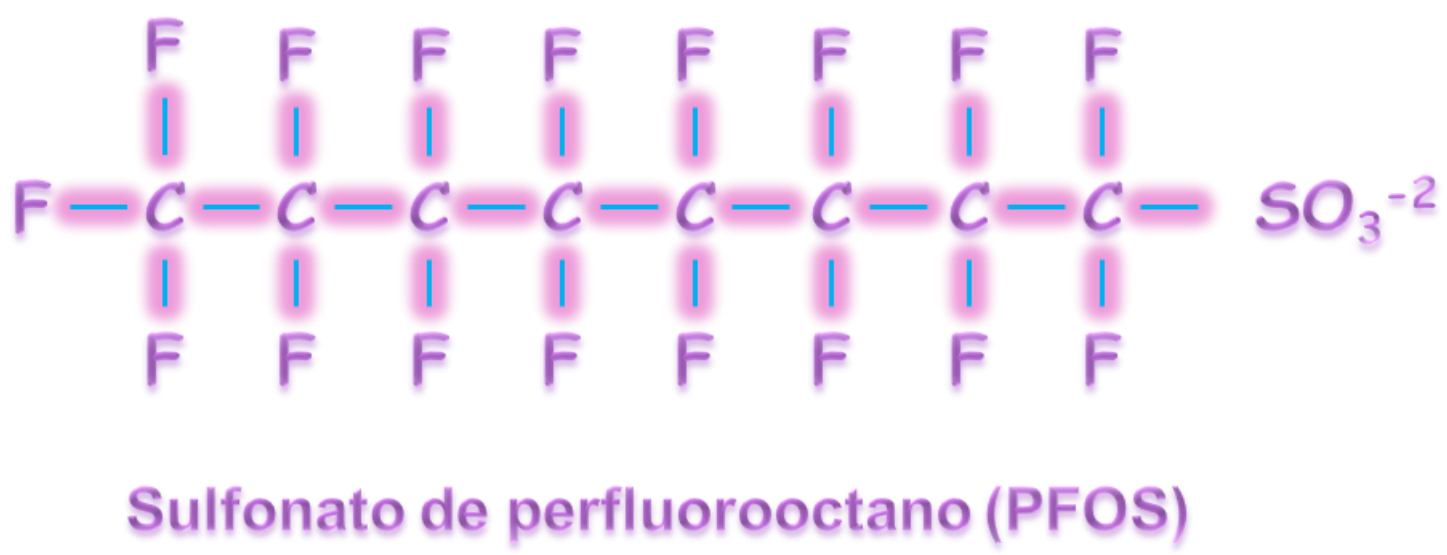

Fig.4. Estructura del sulfonato de perfluorooctano (PFOS).

EI PFOS generalmente se emplea en forma de sal o se incorpora a polímeros de moléculas de mayor tamaño (Programa de las Naciones Unidas para el Medio Ambiente, 2006). Las propiedades físicas y químicas de la sal de potasio del PFOS se muestran en la tabla 1. 
Tabla 1. Propiedades físicas y químicas de la sal de potasio de PFOS. Tomado de (Programa de las Naciones Unidas para el Medio Ambiente, 2006).

\section{Propiedad}

Apariencia a temperatura y presión

normales

Masa molecular

Punto de fusión

Punto de ebullición

\section{Valor}

Polvo blanco

$538 \mathrm{~g} / \mathrm{mol}$

$>400^{\circ} \mathrm{C}$

No mensurable

Se han realizado pocos estudios acerca de la farmacocinética del PFOS; sin embargo, se sabe que PFOS tiene una tasa de eliminación baja debido a un proceso de reabsorción renal saturable. En ratas macho la vida media de eliminación es de 33 días después de una dosis única de $400 \mu \mathrm{g} / \mathrm{kg}$ y de 80 días después de 12 semanas de tratamiento con una concentración de $425 \mathrm{ng} / \mathrm{g}$ (Chang et al., 2012).

En ratones dos grupos expuestos a una dosis única oral de PFOS de 1 o $20 \mathrm{mg} / \mathrm{kg}$ de peso corporal, los valores medios de eliminación fueron de 42.81 y 37.80 días en machos y en hembras respectivamente y en la concentración de $20 \mathrm{mg} / \mathrm{kg}$ la eliminación es de 36.42 y 30.35 días (Chang et al., 2012). En la tabla 2 se muestran los parámetros farmacocinéticos que se obtuvieron de ratones expuestos a PFOS.

Tabla 2 Parámetros farmacocinéticos en ratones $C D$-1 que recibieron una dosis oral única de PFOS de 1020 mg /kg, evaluados durante 20 semanas (141 días) (Chang et al., 2012).

\begin{tabular}{|c|ccc|}
\hline Parámetro & Sexo & $1 \mathrm{mg} / \mathrm{kg}$ & $20 \mathrm{mg} / \mathrm{kg}$ \\
\hline [PFOS] $_{\text {final }}$ en suero $(\boldsymbol{\mu g} / \mathbf{~ m l})$ & Macho & 0.344 & 5.15 \\
& Hembra & 0.276 & 3.47 \\
\hline $\mathbf{T}_{\mathbf{1 / 2}}$ & Macho & 42.81 & 36.42 \\
& Hembra & 37.8 & 30.45 \\
\hline Depuración $(\mathbf{C L})(\mathbf{m l} / \mathbf{~ d i ́ a / k g )}$ & Macho & 4.7 & 5 \\
& Hembra & 4.74 & 5.95 \\
\hline
\end{tabular}




\subsection{Concentraciones de PFOS en poblaciones $y$ alteraciones fisiológicas}

Entre los nuevos compuestos contaminantes persistentes, el PFOS se ubica en la novena posición de la lista de la convención de Estocolmo del 2009 (Wan, 2011). Estudios realizados en poblaciones no expuestas ocupacionalmente a PFOS en los Estados Unidos de Norteamérica, Colombia, Brasil, Bélgica, Italia, Polonia, India, Malasia y Corea, detectaron en suero concentraciones de 3 a $30 \mathrm{ng} /$ de este compuesto, en tanto que en poblaciones expuestas ocupacionalmente las concentraciones fueron de 400-900 ng/ml (Lopez- Doval et al., 2014).

EI PFOS en concentraciones de relevancia ambiental, afecta la actividad del sistema neuroendocrino, promueve la expresión del receptor de estrógenos y andrógenos, puede modular la biosíntesis de hormonas específicas y disminuye la expresión de enzimas y transportadores involucrados en la esteroidogénesis (Austin et al., 2003, Gorrochategui et al., 2014, Wan, 2011). Se ha reportado que tiene efectos adversos a nivel hepático y reproductivo en especies animales como roedores y mono Rhesus (Wan, 2011). En humanos los datos epidemiológicos sugieren una asociación entre la presencia y exposición a PFOS con alteraciones en la reproducción humana como la endometriosis (Petro et al., 2014).

EI PFOS afecta el ciclo estral en ratas, aumentando los niveles de corticosterona en suero, mientras que en el hipotálamo disminuye las concentraciones de leptina y norepinefrina, induce concentraciones bajas de glucosa y colesterol en suero, afecta la homeostasis del eje hipotálamo-hipófisis-testículo y del eje adrenal; en hembras, modifica las hormonas sexuales produciendo mayor incidencia de abortos en ratas preñadas. En rata y ratón, la exposición prenatal a dosis de PFOS altas $(5-20 \mathrm{mg} / \mathrm{kg}$ ) lleva a la muerte neonatal súbita, retardo en el crecimiento y desarrollo de las crías, además las crías hembras de ratón mostraron un incremento en el peso corporal (Austin et al., 2003, Fei et al., 2009, Lau et al., 2009, Zheng et al., 2009), por lo anterior, PFOS se considera un disruptor endocrino. 


\section{Antecedentes}

El PFOS es un compuesto utilizado ampliamente en la industria como agente surfactante, presenta resistencia al agua y al aceite por lo que es empleado para cubrir superficies en papeles y textiles (Austin et al., 2003, Biegel et al., 1995, Bijland et al., 2011). Debido a su estabilidad estructural química y su larga vida media se acumula en el ambiente, es pobremente eliminado y por tanto se acumula en los organismos silvestres, los humanos también están expuestos a este compuesto por contaminación, a través varias fuentes de exposición: el agua y la alimentación, y en el uso doméstico a través de pinturas y envolturas que protegen los alimentos (Austin et al., 2003).

EI PFOS es un agente contaminante que ha sido detectado en el hígado y plasma sanguíneo de animales silvestres a nivel global (Austin et al., 2003). En humanos se han reportado concentraciones altas de PFOS de un intervalo de 0.1-30.4 ng/ml en el fluido folicular y de $2.8-12.5 \mathrm{ng} / \mathrm{ml}$ en suero sanguíneo de mujeres con problemas reproductivos. Las concentraciones detectadas por (Petro et al., 2014) son mayores a las de otros DE, como el bisfenol- $A$ y el DDT. Esto podría deberse a la capacidad de los PFAAs de unirse a proteínas, tales como B-lipoproteínas y albumina y así transportarse al suero, y a su gran estabilidad (Petro et al., 2014).

En estudios in vivo se ha demostrado que el PFOS altera la producción de andrógenos, testosterona y estrógenos en truchas arcoíris y carpitas cabezona. En roedores se ha demostrado que la exposición a PFOS se correlaciona con bajo peso corporal de las crías y aumento en la muerte neonatal (Ankley et al., 2005, Austin et al., 2003, Benninghoff, 2011, Biegel et al., 1995). En ratones macho de la cepa CD-1 expuestos a PFOS por 7, 14 y 21 días en dosis de 0,1, 5, $10 \mathrm{mg} / \mathrm{kg}$, se observó que en el día 21 disminuyeron la concentración de $T_{2}$ en suero y la cuenta espermática (Wan, 2011). Estudios in vitro en cultivos primarios de tilapia expuestos a el PFOS por $72 \mathrm{~h}$ demostraron que induce la producción de estrógenos (Liu et al., 2007). En adrenales humanas (línea celular H295R) se observó que PFOS es capaz de modular la esteroidogénesis de dichas células 
adrenocorticales, ya que la exposición a PFOS provoca un aumento en las concentraciones de estradiol $\left(\mathrm{E}_{2}\right)$, testosterona $\left(\mathrm{T}_{2}\right)$ y progesterona (Kraugerud et al., 2005).

En otro estudio, se investigó el papel de PFOS como DE, midiendo la actividad anti-estrogénica, anti androgénica y anti tiroidea utilizando genes reporteros empleando como modelo in vitro cultivos de la línea celular H295R y el modelo in vivo de embriones de pez cebra, logrando caracterizar así el efecto potencial de PFOS en las funciones de los receptores estrogénicos, androgénicos y tiroideos. Los resultados obtenidos a partir de la línea celular H295R indican que PFOS puede actuar como un agonista del receptor estrogénico (RE) y un antagonista del receptor de la hormona tiroidea, también se observó un incremento de $E_{2}$, así como una alteración en los niveles de expresión de genes involucrados en la esteroidogénesis y una disminución de $T_{2}$, causada por la inhibición de la conversión de progesterona a testosterona a través de la inhibición de CYP17. En el cultivo de embriones de pez cebra, se observó que los genes relacionados con el desarrollo de la tiroides, tales como: hhex y pax 8 tuvieron un aumento en su expresión dependiente de la concentración de PFOS, los genes de la producción de estrógenos en los que se incluyen esr1 y esr2b, se observó que esr1 tuvo un aumento en su expresión, mientras que esr2b tiene una disminución, y también se observó la disminución de las enzimas esteroidogénicas CYP17, CYP19 y CYP19b. Llegando así a la conclusión de que PFOS tiene como efectos en el sistema endocrino, interferir con los receptores nucleares, alterar la esteroidogénesis y afectar la expresión de genes relacionados con el sistema endocrino, tanto in vitro como in vivo (Du et al., 2012).

\section{Efecto de PFOS sobre la actividad de EGFR, ERK $1 / 2$ y STAR}

Existen estudios en los que se ha comprobado que el PFOS tiene un efecto dependiente de concentración sobre la actividad y fosforilación de las proteínas 
EGFR, ERK 1/2 y StAR, en células somáticas como: células de Sertoli, células de Leydig, células de cerebelo, y células cardiacas, entre otras.

\subsection{Actividad del EGFR en un modelo in vivo expuesto a PFOS}

Se ha evaluado el efecto de PFOS como xenobiótico en la vida temprana de ratas Sprague-Dawley, expuestas prenatalmente, las dosis empleadas fueron 0.1, $0.6 \mathrm{y}$ $2.0 \mathrm{mg} / \mathrm{kg} / \mathrm{d}$ vía oral del día 2- 21 de gestación. Las crías se mantuvieron vivas hasta el día 21 postnatal cuando fueron sacrificadas, se obtuvieron los extractos proteínicos de corazón, por medio de western blot se evaluó la actividad de proteínas en la que se incluye EGFR. En los resultados se observó que PFOS induce un incremento en la actividad de EGFR particularmente en la dosis de 2.0 $\mathrm{mg} / \mathrm{kg} / \mathrm{d}$, la expresión de EGFR en los grupos de concentraciones bajas e intermedias fue normal, lo que sugiere un proceso de desarrollo celular normal y en la dosis mayor produce un efecto tóxico (Xia et al., 2011).

\subsection{Actividad de la ERK $1 / 2$ en modelos expuestos a PFOS}

En un modelo in vitro de células de Sertoli, se estudió el daño en la disfunción reproductiva masculina causado por PFOS. Las concentraciones empleadas fueron de 5-60 $\mu \mathrm{M}$, a fin de determinar el efecto de PFOS sobre la vía de señalización de la MAPK, se empleó un inhibidor específico de esta vía de señalización y se evaluaron las proteínas relacionadas en la vía de las MAPK. Se observó un aumento en la expresión de la fosforilación de ERK. Con base en los resultados obtenidos se llegó a la conclusión de que PFOS activa proteínas de la vía de señalización de las MAPK: la p38 y a ERK (Qiu et al., 2013a).

En dos estudios realizados por el mismo grupo de trabajo, se ha estudiado el efecto de PFOS en la vía de señalización de las MAPKs en cultivos de células granulares del cerebelo; estas células se aislaron a partir de ratas de 7 días de edad postnatal, el cultivo se mantuvo por un periodo de 7 días y posteriormente las células se trataron por $24 \mathrm{~h}$ con PFOS en concentraciones de 0, 3, 10 y $30 \mu \mathrm{M}$ (Lee et al., 2012, Lee et al., 2013). Primero se estudió la actividad de PKC y sus

isoformas $\alpha, \beta$ II y $\varepsilon$ en los cultivos expuestos con las concentraciones de 0,3 y 30 
$\mu \mathrm{M}$; se observó la inducción en la translocación de PKC de una manera dosis dependiente, estos resultados sugieren la alteración de la fosforilación, que es un paso clave para la vía de señalización de las MAPKs (Lee et al., 2012). Mientras que en la segunda investigación el tratamiento con PFOS 10 y $30 \mu \mathrm{M}$ por 24 hrs disminuyó la viabilidad de manera dosis dependiente. La fosforilación de ERK incrementó a partir de los 5 min de exposición a PFOS y se mantuvo hasta las $6 \mathrm{~h}$ y posteriormente regreso a nivel basal sin cambios en el nivel, la fosforilación de ERK incrementó de manera concentración dependiente (Lee et al., 2013).

\subsection{Actividad de STAR en modelos expuestos a PFOS}

El grupo de trabajo de (Wan, 2011) evaluó el efecto de PFOS en el testículo de ratón de la cepa CD-1, los ratones fueron expuestos en dosis de $0,1,5$, y 10 $\mathrm{mg} / \mathrm{kg}$ por 7,14 y 21 días, en éste estudio se evaluaron las concentraciones plasmáticas de testosterona, así como la cuenta espermática y los niveles de transcripción de los genes que codifican para enzimas esteroidogénicas, dentro de las que se incluye StAR. Los resultados reportados fueron una disminución significativa en los niveles de testosterona y bajo conteo espermático en los ratones expuestos en la dosis mayor y la expresión génica de StAR disminuyó en el grupo de 21 días de tratamiento y con dosis de 5 y $10 \mathrm{mg} / \mathrm{kg}$.

Otros estudios han evaluado el efecto de PFOS en la función de las células de Leydig fetales de ratas Sprague-Dawley. Las ratas fueron expuestas prenatalmente en dosis de 5 y $20 \mathrm{mg} / \mathrm{kg} / \mathrm{d}$, vía oral desde el día 11 de gestación hasta el 19, las ratas fueron sacrificadas en el día 20 de gestación y se obtuvieron las células de Leydig, se evaluó la producción de $T_{2}$, expresión de genes y proteínas, en la que se incluye StAR. En cuanto a los resultados obtenidos se observó una disminución significativa de la expresión de RNAm de StAR en el grupo de $20 \mathrm{mg} / \mathrm{kg}$ y por tanto en la actividad de la proteína StAR también se encontró una disminución en esta concentración (Zhao et al., 2014). 


\section{Justificación}

Los CPF son contaminantes persistentes que se han detectado en humanos y animales a nivel mundial; en poblaciones no expuestas las concentraciones de estos compuestos en el suero sanguíneo se han detectado en un rango de 3-30 $\mathrm{ng} / \mathrm{ml}$ y en poblaciones expuestas estas concentraciones aumentan (400-900 ng/ $\mathrm{ml}$ ). Estudios epidemiológicos de toxicología reproductiva han demostrado un vínculo entre la exposición a xenoestrógenos y un aumento en la frecuencia de anomalías en la reproducción en animales y humanos. Hay trabajos que indican que los CPF pueden actuar como DE e interferir en los procesos reproductivos.

El CPF que más se encuentra en los organismos es el PFOS, este compuesto se ha detectado principalmente en hígado y fluidos como plasma sanguíneo, leche materna semen y fluido folicular, este hecho podría deberse a la capacidad de los CPF de unirse a proteínas, como lipoproteínas y albumina y transportarse para unirse a órganos blanco en el cuerpo. Específicamente en el caso de las hembras, este compuesto podría afectar los eventos que se llevan a cabo en los folículos, donde las interacciones entre las hormonas, factores de crecimiento y las células somáticas que rodean el ovocito (células de la granulosa y de la teca) son esenciales para generar un ovocito competente.

Se sabe que PFOS puede actuar como DE y afectar la expresión génica y la actividad de StAR, del EGFR y la vía de señalización de las MAPK, específicamente de la cinasa ERK 1/2, la cual es un punto clave para la activación de la proteína StAR, que es el paso limitante para la esteroidogénesis. Hasta la fecha no se ha realizado un estudio donde se evalúe el efecto del PFOS sobre las proteínas antes mencionadas en las células de la granulosa y de la teca por lo cual es importante dilucidar el efecto que tiene este compuesto y su mecanismo de acción en la vía de señalización en la esteroidogénesis.

Para esto el murino es un excelente modelo de estudio, ya que presenta un ciclo de vida corto, es fácil de manipular y las herramientas moleculares son accesibles para estudiar las proteínas involucradas en la esteroidogénesis en el ovario. 


\section{Pregunta de investigación}

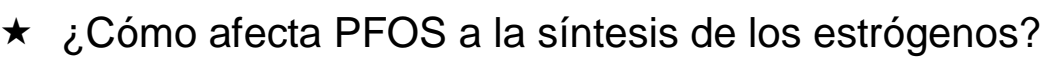

$\star$ ¿Altera PFOS la expresión de EGFR, ERK 1/2 y StAR?

\section{Hipótesis}

Si PFOS es un disruptor endocrino, entonces, al administrase a hembras murinas, producirá modificaciones en la actividad de las proteínas EGFR; ERK 1/2 y StAR, involucradas en la vía de señalización de la esteroidogénesis en las células de la granulosa y de la teca. 


\section{Objetivo general}

Determinar los efectos de PFOS sobre la vía de señalización relacionada con las proteínas EGFR, ERK 1/2 y StAR, que regulan la esteroidogénesis en las células de la granulosa y de la teca.

\section{Objetivos particulares}

$\star$ Determinar el efecto de la administración del PFOS en el peso corporal de los individuos expuestos.

$\star$ Determinar si la exposición al PFOS altera las características morfológicas del útero y ovarios.

$\star$ Aislar las células de la teca y de la granulosa.

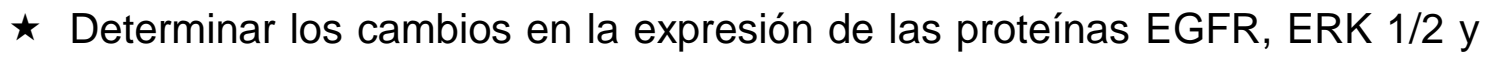
StAR, en extractos proteínicos de células de la teca y de la granulosa. 


\section{Diseño experimental}

Obtención de individuos de estudio:

Las hembras para el ensayo se obtuvieron a partir de dos unidades reproductivas de la cepa CD1 que constaron de dos hembras y un macho cada una, proporcionados por el bioterio de la UAM- Iztapalapa.

Una semana después del nacimiento las crías fueron sexadas y se ajustaron las camadas a un tamaño de 7- 9 crías: seis-ocho hembras y un macho; a los 13 días postnatal se inició a administrar el tratamiento diariamente durante 8 días, vía oral con una cánula acoplada a una jeringa de $1 \mathrm{ml}$. Cada dosis se ajustó al peso corporal de cada individuo.

Preparación del compuesto perfluorado:

Se preparó el vehículo a partir de una emulsión de lecitina de soya y aceite de cacahuate en proporción 1:10. De esta mezcla se tomaron 4 volúmenes y se adicionó 1 volumen de agua, para obtener la emulsión que se sónico por 10 minutos. El sulfonato de perfluorooctano (sal de potasio de PFOS) de pureza $98 \%$, se preparó con el vehículo para tener una solución stock de $21 \mu \mathrm{M}$. A partir de la que se prepararon dosis de 1.4, 10, y $21 \mu \mathrm{mol} / \mathrm{kg}$ (Figura 5) (Johansson et al., 2008b).

Los animales se dividieron en cuatro grupos experimentales:

Grupo control: Hembras a las que únicamente se les administró el vehículo N=9.

Grupo 1: Hembras a las que se les administró [1.4 $\mu \mathrm{mol} / \mathrm{kg}](0.75 \mathrm{mg} / \mathrm{kg}) \mathrm{N}=12$.

Grupo 2: Hembras a las que se les administró [10 $\mu \mathrm{mol} / \mathrm{kg}](5.38 \mathrm{mg} / \mathrm{kg}) \mathrm{N}=12$.

Grupo 3: Hembras a las que se les administró [21 $\mu \mathrm{mol} / \mathrm{kg}](11.3 \mathrm{mg} / \mathrm{kg}) \mathrm{N}=13$. 


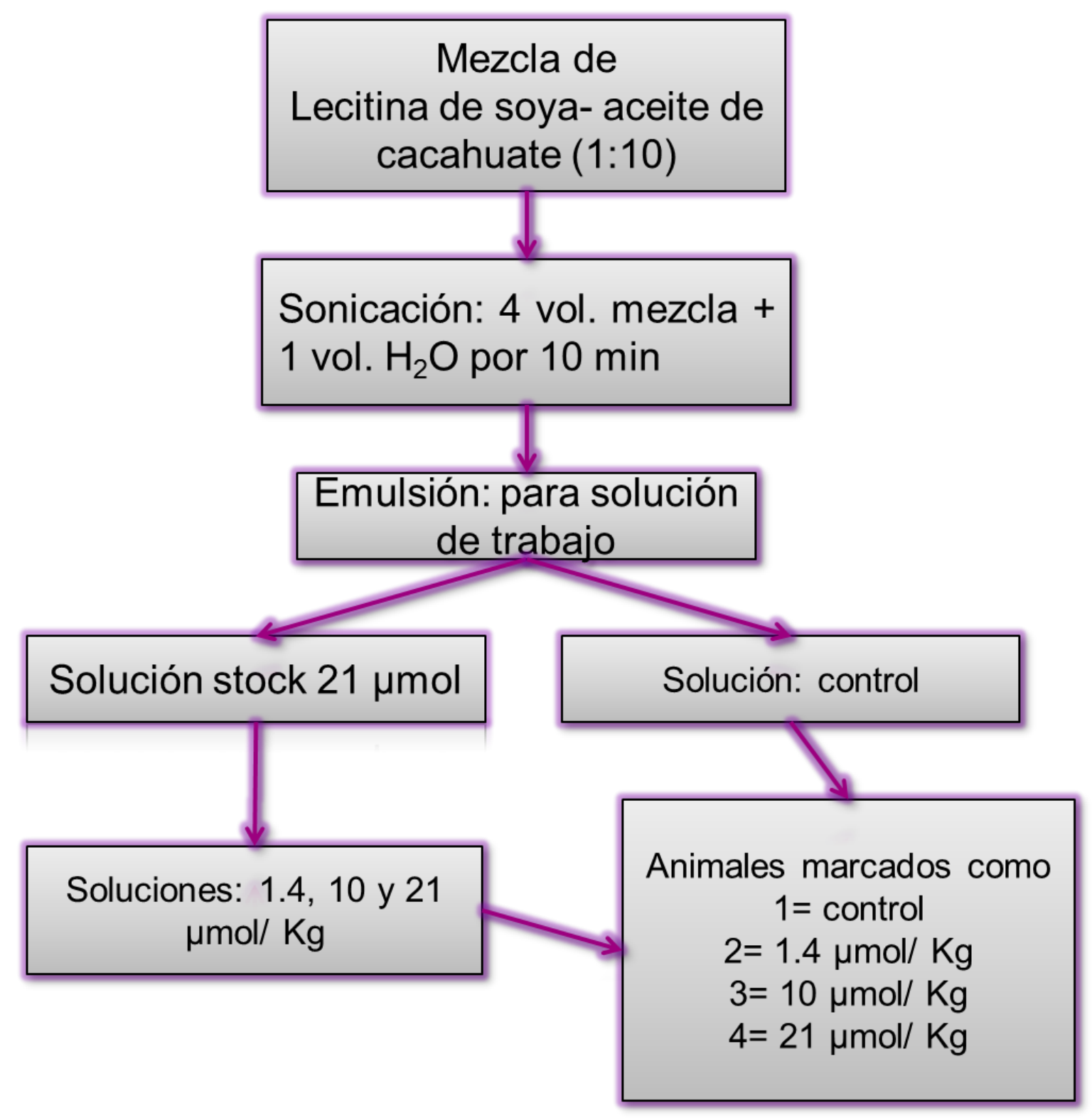

Fig. 5. Diagrama del diseño experimental empleado en el estudio. 


\section{Material y método}

A menos que se indique lo contrario, los reactivos empleados fueron de la marca Sigma-Aldrich (EUA) y los medios de cultivo de la marca In Vitro S.A. (México).

\section{Obtención de los individuos para la administración de PFOS}

Los individuos empleados para el estudio, se obtuvieron a partir de dos unidades reproductivas de ratón cepa CD 1, que estaban formadas por 2 hembras y un macho por caja; los animales en edad reproductiva fueron proporcionados por el bioterio de Universidad Autónoma Metropolitana- Iztapalapa y se mantuvieron bajos las condiciones de la Norma Oficial Mexicana NOM-062-ZOO-1999 (SAGARPA, 2001) y con agua y alimento ad libitum; el ciclo estral de las hembras fue evaluado por método visual. En este método se observaron los cambios morfológicos de la vagina.

Proestro: se caracteriza por presentar los labios vaginales inflamados, húmedos y de color rosa, la apertura de la vagina es amplia. Estro: la vagina se torna menos rosa y húmeda y la inflamación de los labios disminuye. Metaestro: la apertura vaginal es pequeña y los labios vaginales son blancos. Diestro: la apertura vaginal es muy pequeña y los labios parecen estar cerrados (Figura 6) (Byers et al., 2012). 


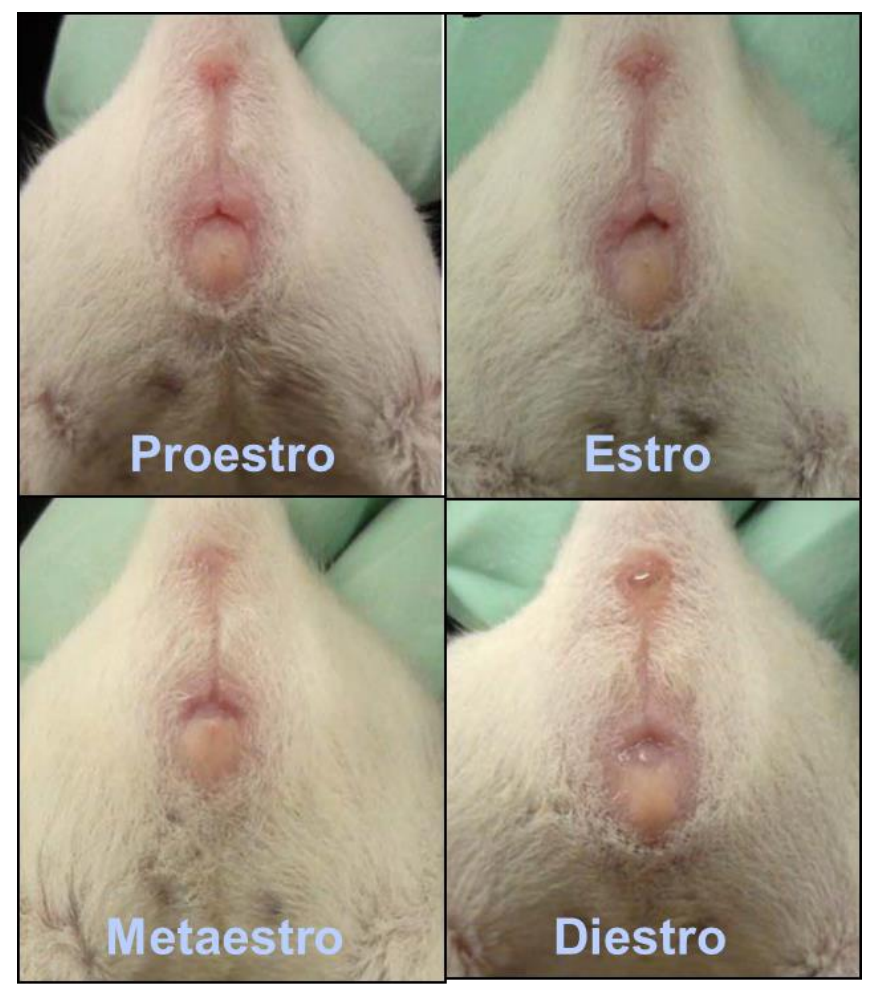

Fig. 6. Ejemplo de los 4 estadios del ciclo estral, tomado de (Byers et al., 2012).

El apareamiento se confirmó por la presencia de tapón de vaginal y el día que se detectó el tapón vaginal se definió como el día 1 de gestación y las hembras se mantuvieron separadas individualmente.

El día de nacimiento de las crías fue asignado como el día 1, y en el día 7 postnatal las crías fueron sexadas, las camadas se ajustaron a 7-9 crías de la siguiente manera 6-8 hembras y 1 macho, las crías excedentes se sacrificaron. Las crías que se emplearon para el estudio permanecieron con la madre hasta el día del sacrificio y la madre se regresaba a la caja de unidad reproductiva para aparearse nuevamente.

\section{Administración del PFOS}

Para observar el efecto del PFOS sobre la vía de señalización de la esteroidogénesis se emplearon las hembras prepúberes de la cepa CD1 obtenidas a partir de las unidades reproductivas. Los animales fueron dosificados vía oral 
con una cánula acoplada a una jeringa de $1 \mathrm{ml}$ diariamente durante 8 días a partir del día 13 postnatal, las dosis empleadas fueron $1.4,10$ y $21 \mu \mathrm{mol} / \mathrm{kg}$ de peso corporal equivalente a $0.75,5.38 \circ 11.3 \mathrm{mg} / \mathrm{kg}$ (Johansson et al., 2008b). Las hembras se pesaron diariamente a partir del día 13 (inicio de tratamiento) y hasta el día 21 postnatal (día de sacrificio), en el día 13 se descartaron a las hembras con un peso menor a $6 \mathrm{~g}$ y cada dosis se ajustó por el peso corporal de cada individuo diariamente.

El sulfonato de perfluorooctano (sal de potasio de PFOS de pureza 98\%), se mezcló con lecitina de soya y aceite de cacahuate (Óleum arachidis) en proporción 1:10. De esta mezcla se tomaron 4 volúmenes y se adicionó 1 volumen de agua, para obtener la emulsión se sonicó por 10 minutos. Se preparó una solución stock $21 \mu \mathrm{mol}$ y a partir de esta se elaboraron las soluciones de trabajo (Johansson et al., 2008b). En la tabla 3 se muestran los grupos utilizados.

Para estimular el desarrollo folicular de los animales en el día 19 postnatal se administraron 5 U.I. de Gonadotropina coriónica equina (eCG; FOLLIGON®) de forma subcutánea y $48 \mathrm{~h}$ después de la estimulación se sacrificaron por dislocación cervical, inmediatamente después se obtuvieron el útero y los ovarios (Hinojosa et al., 1999).

Tabla 3 Grupos y dosis empleadas en la administración de PFOS a ratones hembras

\begin{tabular}{|ccc|}
\hline Grupo & Dosis PFOS $\mu \mathrm{mol} / \mathrm{kg}$ & $\mathrm{N}$ \\
\hline Control & 0 & 9 \\
\hline Experimental 1 & 1.4 & 12 \\
\hline Experimental 2 & 10 & 12 \\
\hline Experimental 3 & 21 & 13 \\
\hline
\end{tabular}




\section{Obtención de úteros y ovarios}

Los ovarios y úteros de los individuos administrados se obtuvieron de manera aséptica y se colocaron en una caja Petri con $5 \mathrm{ml}$ de amortiguador de fosfatos salino (PBS) y se limpió la grasa. Se colocaron en PBS nuevo y se separó el útero de los ovarios. Los ovarios se colocaron en una caja Petri que contenía $2 \mathrm{ml}$ de medio Leibovitz L- 15, se observaron en el microscopio estereoscópico (Zeiss, Stemi DV4, Alemania) y se obtuvieron imágenes digitales con cámara (Nikon, Japón) con los aumentos de 12 y 20 X. Las imágenes obtenidas fueron analizadas con el programa ImageJ (Schneider et al., 2012) para medir la longitud de los ovarios. Los úteros fueron fijados en formol y posteriormente fueron pesados en balanza analítica.

\section{Obtención de células de la granulosa y de la teca}

En el medio Leibovitz L- 15 se eliminó la bursa que cubren los ovarios. Se trasladaron a una caja Petri que contenía $2 \mathrm{ml}$ de medio Dulbecco modificado por Eagle, mezcla de nutriente HAM- F12 (DMEM/F-12 vol. 50/50) ajustado a pH 7.6, suplementado con $10 \%$ de suero fetal bovino (GIBCO), $1 \%$ de antibiótico mezcla de penicilina- estreptomicina, $10 \mu \mathrm{g} / \mathrm{ml}$ de insulina y $1 \mathrm{mM}$ de piruvato de sodio. Posteriormente se puncionaron los ovarios con una aguja de calibre $27 \mathrm{~g}$ (BectonDickinson, EUA) y por aspiración con una pipeta se colectaron el medio y los fragmentos de tejido.

\subsection{Células de la granulosa}

El medio colectado se centrifugó a $68 \times$ X por 10 minutos, se retiró el sobrenadante y el paquete celular se resuspendió nuevamente con $1 \mathrm{ml}$ de DMEM-F12, se incubó a $37{ }^{\circ} \mathrm{C}$ y $5 \% \mathrm{CO}_{2}$, por una hora hasta que se realizó la extracción de proteínas. 


\subsection{Células de la teca}

Los fragmentos colectados por aspiración se colocaron en una mezcla de digestión compuesta por colagenasa $4 \mathrm{mg} / \mathrm{ml}(200 \mu \mathrm{l})$, albumina sérica bovina (BSA, $100 \mu \mathrm{l}) 10 \mathrm{mg} / \mathrm{ml}$, DNAsa $10 \mu \mathrm{g} / \mathrm{ml}(100 \mu \mathrm{l})$ y Medio $199(300 \mu \mathrm{l})$.

Los fragmentos se incubaron a $37^{\circ} \mathrm{C}$, con $95 \%$ de aire y $5 \%$ de $\mathrm{CO}_{2}$ y humedad a saturación por un lapso de $60 \mathrm{~min}$. Cada $20 \mathrm{~min}$ los fragmentos fueron homogenizados pasándolos repetidamente por la punta de una micropipeta hasta que se desintegraron.

En un tubo cónico de $10 \mathrm{ml}$ se preparó un gradiente de Percoll con dos fases:

$\star$ Percoll pesado $(2000 \mu \mathrm{l})$ compuesto por la mezcla de Percoll $(880 \mu \mathrm{l})$, medio $199(920 \mu \mathrm{l})$, Hepes $250 \mathrm{mM}(200 \mu \mathrm{l})$.

$\star$ Percoll ligero (1995.6 $\mu \mathrm{l})$ formado por Percoll $(75.6 \mu \mathrm{l})$, Hepes $250 \mathrm{mM}(200$ $\mu \mathrm{l}), \mathrm{BSA} 10 \mathrm{mg} / \mathrm{ml}(20 \mu \mathrm{l}), \mathrm{M} 199$ con $150 \mathrm{mM}$ de $\mathrm{NaCl}(1.7 \mathrm{ml})$. Se vertió el Percoll ligero sobre el pesado evitando que se mezclaran, al final se agregó el homogenado celular y se centrifugó a 29 X G por 25 min.

Con ayuda de una pipeta se retiraron las células de la teca ubicadas en la interfaz entre el Percoll ligero y pesado procurando extraer la menor cantidad de Percoll. Posteriormente se lavaron las células colocándolas en un tubo Eppendorf con $1 \mathrm{ml}$ de DMEM- F12, se centrifugó a $64 \times$ G por 5 min, se eliminó el sobrenadante y se resuspendió el paquete celular en medio fresco. Se mantuvieron en incubación a $37^{\circ} \mathrm{C}$ y $5 \% \mathrm{CO}_{2}$ hasta que se realizó la extracción de proteínas.

\subsection{Extracción de las proteínas de las $C G$ y $C T$}

A partir de las células de la teca y de la granulosa, se obtuvieron los extractos proteínicos, se agregó amortiguador de lisis, se homogenizó la muestra a $4{ }^{\circ} \mathrm{C}$ y se incubó 20 min a $4{ }^{\circ} \mathrm{C}$. Posteriormente se centrifugó en frío a 350 × G durante 20 min, se recuperó el sobrenadante y se realizó la cuantificación de proteínas por el método de Bradford. 


\subsection{Aislamiento de las células de la granulosa y de la teca}

Para confirmar que se había estandarizado la técnica de la separación celular por: punción ovárica (CG) y gradiente de Percoll (CT), se eligió hacer una inmunodetección para la proteína aromatasa que tiene un PM de $55 \mathrm{kDa}$ aproximadamente, ya que es una proteína que se detecta únicamente en las CG; para la inmunodetección se utilizó el anticuerpo antiaromatasa (Abcam, Reino Unido). Para la verificación de las CT se empleó inmunodetección de la proteína StAR, ya que se encuentra en mayor cantidad en las CT.

\section{Inmunodetección de las proteínas fosforiladas $y$ totales de EGFR, ERK $1 / 2$ y STAR}

A los extractos proteínicos se les agregó amortiguador de muestra (agua desionizada, $0.5 \mathrm{M}$ Tris-HCL pH 6.8, glicerol, $10 \%$ SDS y $0.5 \%$ azul de Bromofenol) y fueron separados por electroforesis en geles de poliacrilamidadodecilsulfato de sodio (SDS-PAGE).

El EGFR al ser una proteína de masa molecular alta se corrió en geles de SDSPAGE al $7 \%$. Las proteínas ERK 1/2 y StAR por tener bajos pesos moleculares se corrieron en geles al $12 \%$.

Después de la electroforesis se realizó la transferencia de proteínas a membranas de nitrocelulosa (Bio-Rad EUA), por $1 \mathrm{~h}$ a $4{ }^{\circ} \mathrm{C}$ posteriormente, las membranas se bloquearon con leche al 5\% en PBS-Tween 20 (PBS- T20) durante $2 \mathrm{~h}$, transcurrido este tiempo se lavaron con PBS- T20 y se incubaron a $4{ }^{\circ} \mathrm{C}$ toda la noche con el anticuerpo primario correspondiente a cada proteína en PBS-T20 más BSA. Las membranas respectivas se lavaron con PBS-T20 tres veces, se incubaron durante $2 \mathrm{~h}$ a temperatura ambiente con el anticuerpo secundario correspondiente (Bio Care Medical, EUA) en PBS-T20 - leche y se lavaron tres veces con PBS-T20. Por último, se trataron con luminol (Millipore, EUA) para visualizar las proteínas en el fotodocumentador (KODAK Gel Logic 100 System) (Evaul y Hammes, 2008). 
Para evaluar el efecto del PFOS sobre las proteínas primero se incubaron las membranas con los anticuerpos fosforilados de las proteínas p- EGFR ( $p$ Tyr1173) y p- ERK 1/2 (ERK1: p- Thr202/Tyr 204 y ERK2: p- Thr185/Tyr 187). Las muestras se analizaron en el fotodocumetador y se constató que la marca del anticuerpo se encontraba en la masa molecular relativa apropiada para cada proteína, se realizó el desnudamiento de las membranas y se continuó con el análisis para las proteínas totales de EGFR, ERK 1/2 y StAR. Se realizó el mismo procedimiento del western blot; para finalizar el análisis, las membranas fueron tratadas con el anticuerpo de actina para realizar la normalización de las proteínas.

\subsection{Desnudamiento de membranas de nitrocelulosa ("stripping")}

Para realizar el desnudamiento de las membranas, éstas se incubaban en $10 \mathrm{ml}$ de la solución de desnudamiento (15 g de glicina, 1 SDS, $10 \mathrm{ml}$ de Tween 20, ajustado a pH 2.2, cbp $1 \mathrm{~L}$ ), a temperatura ambiente por 10 min y agitación constante, se retiró la solución y se agregaron nuevamente $10 \mathrm{ml}$ y se repitió nuevamente este paso, se retiró la solución de desnudamiento y se lavó por 10 min con PBS 2 veces, posteriormente se lavó 2 veces con TBS por 5 min y la membrana estuvo en condiciones para bloquearse nuevamente.

\section{Análisis de resultados}

Los resultados obtenidos fueron analizados con el análisis de varianza. Para analizar la comparación entre los grupos experimentales del peso de las ratonas y longitud de ovarios se realizó una prueba de Duncan para la diferencia de medias. Los datos obtenidos de las densitometrías de las inmunodetecciones se analizaron por una prueba de ANOVA, una prueba de Bonferroni para la diferencia de medias y prueba de Fisher (LSD) para la diferencia mínima significativa. El valor de $p$ considerado como significativo fue $<0.05$, se utilizaron los programas NCSS, 2007 e IBM, SPSS Statistics, 2011. 


\section{Resultados}

\section{EL PFOS no afecta el peso corporal de las hembras tratadas}

El peso de las hembras del grupo control y de los tres grupos experimentales durante la administración del PFOS fue similar, lo que indica que la administración del compuesto durante 8 días no alteró significativamente el peso corporal de las hembras. En la tabla 4, se presenta el promedio del peso durante los 9 días del estudio.

Tabla 4. Peso de las hembras tratadas con el perfluorado PFOS \pm D.S.

\begin{tabular}{|ccccc}
\hline Edad (días) & \multicolumn{4}{c}{ PFOS $(\mu \mathrm{mol} / \mathrm{kg})$} \\
\hline $\mathbf{1 3}$ & 0 & 1.4 & 10 & 21 \\
$\mathbf{1 4}$ & $7.47 \pm 2.3$ & $7.69 \pm 1.0$ & $7.53 \pm 1.2$ & $7.58 \pm 0.9$ \\
$\mathbf{1 5}$ & $8.04 \pm 1.8$ & $8.28 \pm 1.1$ & $8.13 \pm 1.2$ & $8.18 \pm 0.9$ \\
$\mathbf{1 6}$ & $8.34 \pm 1.8$ & $8.76 \pm 1.2$ & $8.59 \pm 1.0$ & $8.53 \pm 0.8$ \\
$\mathbf{1 7}$ & $8.77 \pm 1.9$ & $9.31 \pm 1.3$ & $9.22 \pm 1.2$ & $9.13 \pm 1.0$ \\
$\mathbf{1 8}$ & $10.31 \pm 1.9$ & $10.52 \pm 1.2$ & $10.35 \pm 1.1$ & $10.10 \pm 0.9$ \\
$\mathbf{1 9}$ & $11.24 \pm 2.6$ & $11.65 \pm 2.0$ & $11.42 \pm 1.3$ & $11.45 \pm 1.4$ \\
$\mathbf{2 0}$ & $12.05 \pm 2.5$ & $12.74 \pm 1.5$ & $12.60 \pm 1.5$ & $12.36 \pm 1.0$ \\
$\mathbf{2 1}$ & $13.20 \pm 1.6$ & $14.07 \pm 1.7$ & $14.14 \pm 1.8$ & $14.00 \pm 1.2$ \\
\hline
\end{tabular}

PFOS: sulfonato de perfluorooctano. Peso en gramos \pm la desviación estándar (D.S.), $p=0.980984$. Hembras utilizadas $N=46$, Control: $N=9,1.4 \mu \mathrm{mol} / \mathrm{kg} N=12,10 \mu \mathrm{mol} / \mathrm{kg} N=12$ y $21 \mu \mathrm{mol} / \mathrm{kg}: N=$ 13. 


\section{Evaluación de los ovarios y úteros de animales expuestos al PFOS}

Se detectó que los ovarios de las hembras a las que se les administró la dosis de $10 \mu \mathrm{mol} / \mathrm{kg}$ de PFOS tenían un tamaño mayor que los del grupo control y los grupos experimentales. En la figura 7 y 8 se muestran imágenes representativas de estas observaciones.

Los ovarios de los animales a los que se les administró la dosis de $10 \mu \mathrm{mol} / \mathrm{kg}$ presentaron una longitud promedio de $15.65 \mathrm{~mm}$, con una diferencia significativa con respecto a los grupos, control, 1.4 y $21 \mu \mathrm{mol} / \mathrm{kg}$. En la tabla 5 se muestran los promedios de los datos obtenidos de los ovarios derecho e izquierdo de las hembras.

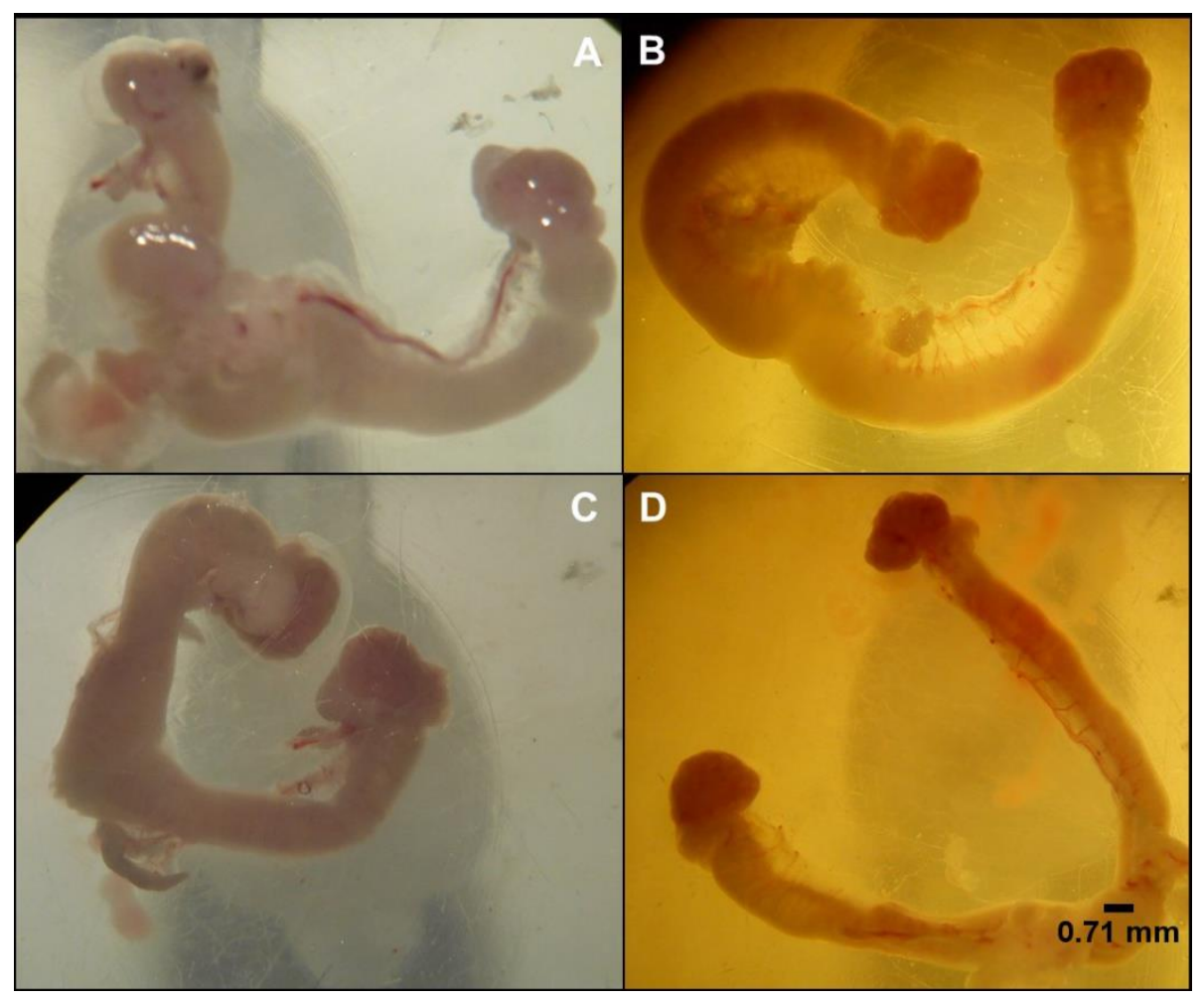

Fig. 7. Observación al microscopio estereoscópico $(12 X)$ de ovarios y úteros de hembras administradas con las dosis del PFOS: A) Control; B) 1.4; C) 10 y D) $21 \mu \mathrm{mol} / \mathrm{kg}$. 
Tabla 5. Longitud de ovarios de ratones hembras tratadas con PFOS en dosis única por 8 días.

\begin{tabular}{cc|}
\hline PFOS $(\mu \mathrm{mol} / \mathrm{kg})$ & Longitud \\
$\mathbf{0}$ & $12.49 \pm 1.7$ \\
$\mathbf{1 . 4}$ & $12.27 \pm 1.4$ \\
$\mathbf{1 0}$ & $15.65 \pm 1.0^{*}$ \\
$\mathbf{2 1}$ & $12.75 \pm 1.0$ \\
\hline
\end{tabular}

Longitud de ovarios en $\mathrm{mm} \pm$ D.S. $p=0.001255^{*}$. $P$ Prueba de Duncan: Alfa $=0.05$, y Error de cuadrados mínimos $(E C M)=1.603673$. Hembras: $N=22$. Control: $N=5,1.4 \mu \mathrm{mol} / \mathrm{kg} N=5,10$ $\mu \mathrm{mol} / \mathrm{kg} \mathrm{N}=6$ y $21 \mu \mathrm{mol} / \mathrm{kg}: \mathrm{N}=6$.

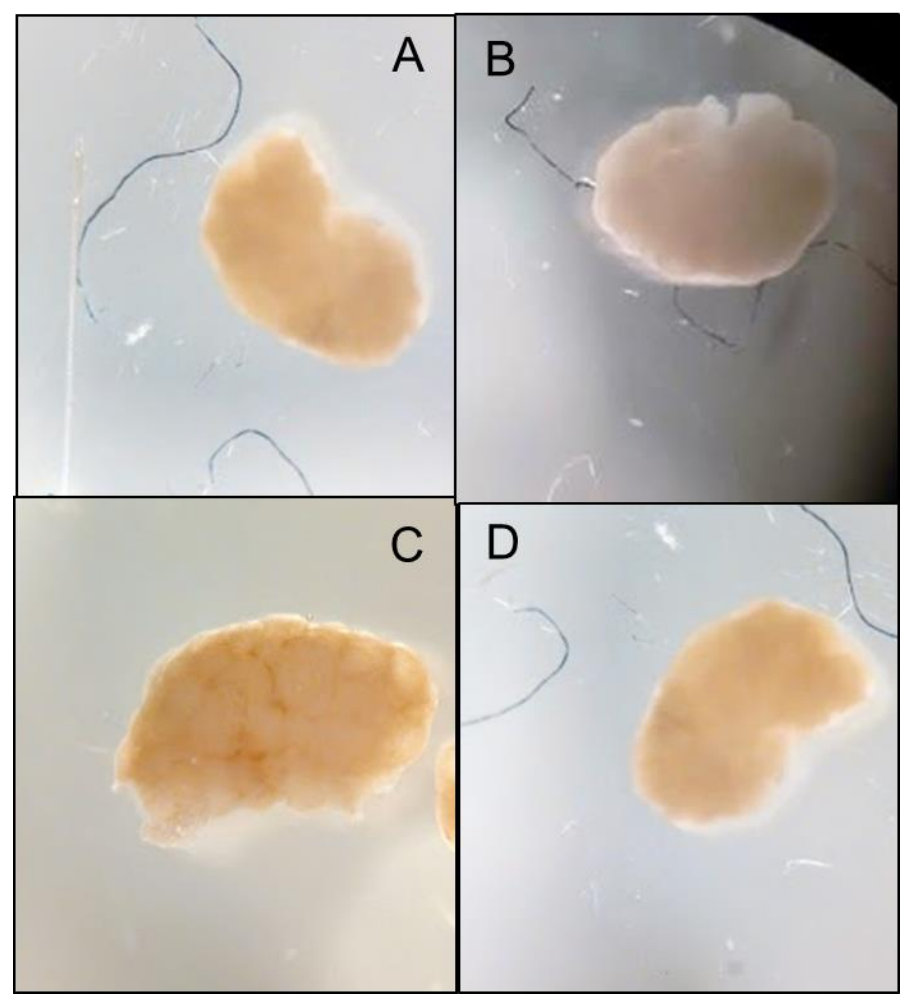

Fig. 8. Ovarios frescos de hembras tratadas con PFOS, observados al microscopio estereoscópico a 20 X. A) Control; B) 1.4; C) 10 y D) $21 \mu \mathrm{mol} / \mathrm{kg}$.

El peso de los úteros fijados en formol no tuvo diferencias entre los grupos, sólo se observó un ligero pero no significativo incremento en el peso de los úteros de los individuos tratados con la dosis de $21 \mu \mathrm{mol} / \mathrm{kg}$. En la tabla 6 se muestra el promedio del peso en gramos. 
Tabla 6. Peso de úteros de hembras tratadas por 8 días con el perfluorado PFOS.

\begin{tabular}{|cc|}
\hline PFOS $\mu \mathrm{mol} / \mathrm{kg}$ & Peso (g) \\
$\mathbf{0}$ & $0.0574 \pm 0.0210$ \\
$\mathbf{1 . 4}$ & $0.0596 \pm 0.0354$ \\
$\mathbf{1 0}$ & $0.0677 \pm 0.0173$ \\
$\mathbf{2 1}$ & $0.0709 \pm 0.0142$ \\
\hline
\end{tabular}

Peso en gramos de úteros fijados \pm D.S. $p=0.864621$

Prueba de Duncan: Alfa $=0.05, E C M=5.909475 E-04$

Úteros: $N=17$, Control: $N=4 ; 1.4 \mu \mathrm{mol} / \mathrm{kg} N=5 ; 10 \mu \mathrm{mol} / \mathrm{kg} N=4$ y $21 \mu \mathrm{mol} / \mathrm{kg}: \mathrm{N}=4$.

\section{Aislamiento de las células de la granulosa y de la teca}

En la figura 9 se observa las imágenes obtenidas de las inmunodetecciones de las proteínas antiaromatasa y antiStAR y se comprobó que la técnica empleada para la separación celular fue la adecuada y se realizó correctamente.

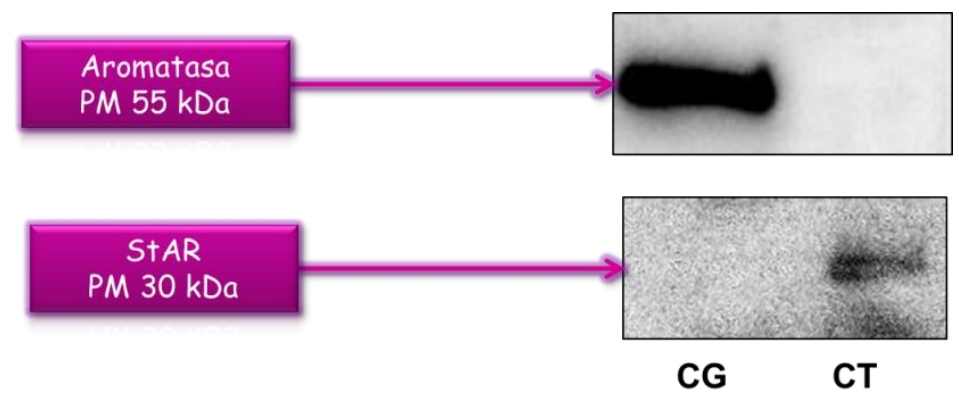

Fig.9. Inmunodetección representativa de la proteína aromatasa (arriba) y de StAR (abajo) en proteínas de células de la granulosa y de la teca, aisladas por el método de gradiente de Percoll, de ratones hembras sin tratar. El ensayo se realizó por duplicado. Carril izquierdo: extracto proteínico de las células de la granulosa (CG); carril derecho: extracto proteínico de las células de la teca $(C T)$. 


\section{Actividad de proteínas involucradas en la vía de señalización de la esteroidogénesis}

\subsection{Diferencias entre el efecto del PFOS sobre la presencia de EGFR en las $C T$ y $C G$}

En las CG el PFOS provocó una disminución en la presencia del EGFR en todos los grupos experimentales en comparación con el control, esta disminución fue mayor en las dosis 1.4 y $21 \mu \mathrm{mol} / \mathrm{kg}$, en la dosis $10 \mu \mathrm{mol} / \mathrm{kg}$ la disminución fue menor en comparación con los otros grupos experimentales, sin embargo, no se encontró diferencia significativa. En las CT el comportamiento observado fue diferente, ya que la presencia de EGFR aumentó en 10 y $21 \mu \mathrm{mol} / \mathrm{kg}$, mientras que en $1.4 \mu \mathrm{mol} / \mathrm{kg}$ disminuyó, aunque no se encontró diferencia significativa con el control ni entre los grupos experimentales (Tabla 7, Gráfica 1). En las CT se observó que las D.O. de las dosis 10 y $21 \mu \mathrm{mol} / \mathrm{kg}$ fueron mayores en comparación con las de las CG.

Tabla 7. Densitometría de la inmunodetección sobre membrana de EGFR normalizada contra el control de carga (actina) $\pm D$.S., de los extractos proteínicos de células de la granulosa (CG) y células de la teca (CT) obtenidas de hembras expuestas al PFOS.

$\begin{array}{ccc}\text { PFOS } \mu \mathrm{mol} / \mathrm{kg} & \text { CG } & \text { CT } \\ \mathbf{0} & 1 \pm 0 & 1 \pm 0 \\ \mathbf{1 . 4} & 0.46 \pm 0.27 & 0.71 \pm 0.79 \\ \mathbf{1 0} & 0.80 \pm 0.60 & 1.54 \pm 0.99 \\ \mathbf{2 1} & 0.43 \pm 0.45 & 1.39 \pm .60\end{array}$

D.O: Densidad óptica, CG: células de la granulosa, CT: células de la teca. D.O. de EGFR D.S. Para: PFOS el valor de $p$ en las $C G$ fue de 0.18 y para $C T$ fue de 0.37 . $N$ total $=32$, CG y $C T N=16$; $\mathrm{N}=4$, para control 1.4, 10, $21 \mu \mathrm{mol} / \mathrm{kg}$. Alfa 0.050 . 


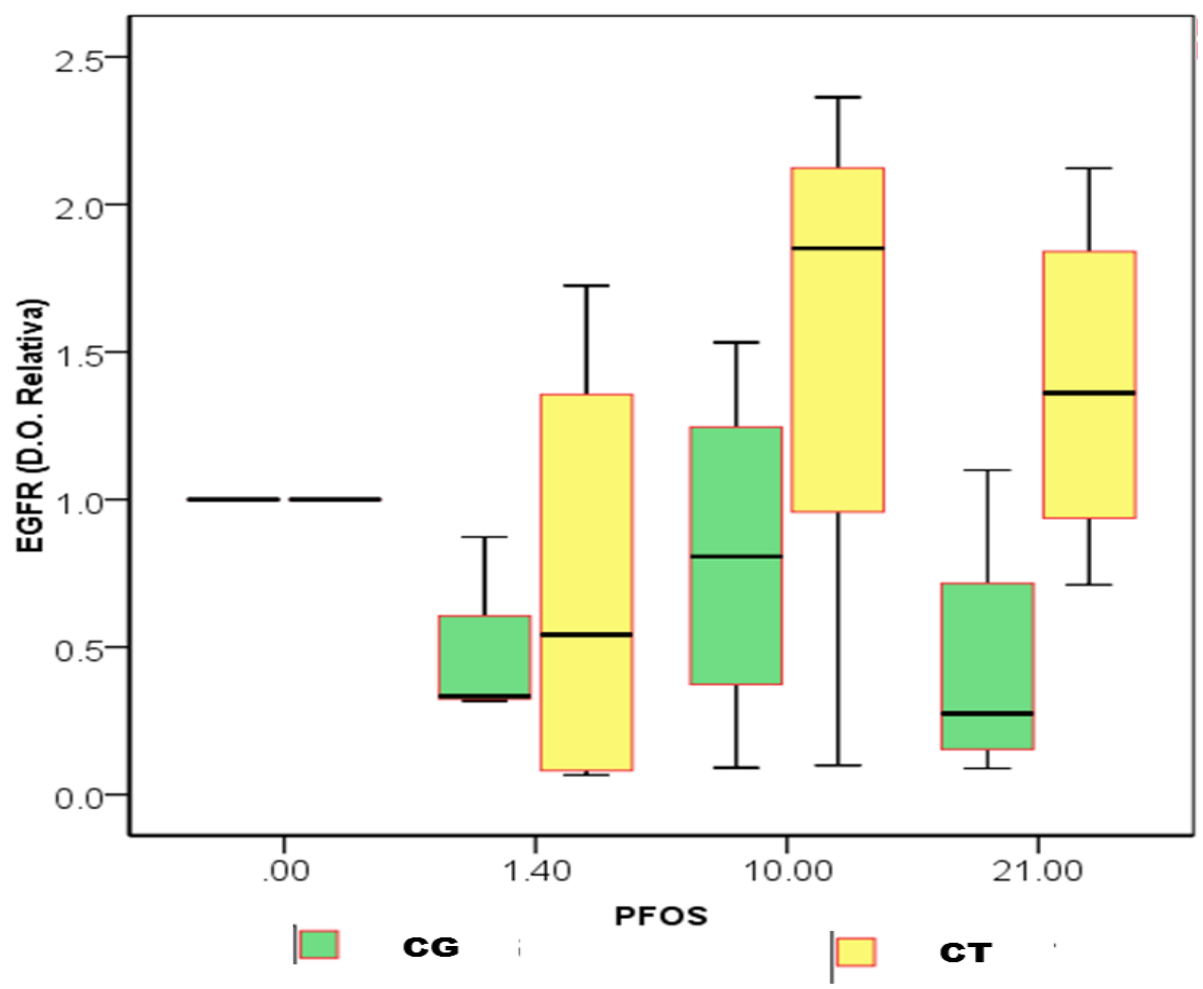

Gráfica 1. Media de la densitometría de la inmunodetección de EGFR de los extractos proteínicos de las CG (cajas verdes) y de las CT (cajas amarillas) de hembras tratadas con el PFOS.

\subsection{Diferencias entre el efecto del PFOS sobre la presencia de p- EGFR en las $C T$ y $C G$}

En cuanto al efecto del PFOS sobre el p-EGFR en el sitio Tyr1173, en las CG se observó que el PFOS provocó un aumento en la presencia de p-EGFR en la dosis de $1.4 \mu \mathrm{mol} / \mathrm{kg}$ que fue menor con las dosis 10 y $21 \mu \mathrm{mol} / \mathrm{kg}$, pero ninguna de las dosis presentó diferencia significativa en comparación con el grupo control y los grupos experimentales. En las CT se apreció un aumento en la presencia de pEGFR en todos los grupos experimentales, siendo mayor en $10 \mu \mathrm{mol} / \mathrm{kg}$, seguida de 21 y $1.4 \mu \mathrm{mol} / \mathrm{kg}$, aunque no se encontró diferencia significativa entre los grupos experimentales y el control. En la tabla 8 se encuentran los datos obtenidos de las D.O. de los experimentos realizados de las inmunodetecciones del p-EGFR en las CG y CT.

En las CG con la dosis de $1.4 \mu \mathrm{mol} / \mathrm{kg}$ se observó un ligero aumento en $\mathrm{p}$-EGFR en comparación con las CT, mientras que, con las dosis de 10 y $21 \mu \mathrm{mol} / \mathrm{kg}$ se 
obtuvieron valores menores en comparación con los datos obtenidos de las CT. En la gráfica 2 se observa un diagrama de caja y bigote de los valores obtenidos de las D.O. de las CG y las CT.

Tabla 8. Densitometría de la inmunodetección sobre membrana de p-EGFR normalizada contra el control de carga (actina) \pm D.S. de los extractos proteínicos de células de la granulosa (CG) y células de la teca (CT) de hembras expuestas al PFOS.

\begin{tabular}{|ccc|}
\hline PFOS umol/kg & CG & CT \\
\hline $\mathbf{0}$ & $1 \pm 0$ & $1 \pm 0$ \\
$\mathbf{1 . 4}$ & $1.85 \pm 1.31$ & $1.69 \pm 1.41$ \\
$\mathbf{1 0}$ & $1.03 \pm 0.72$ & $2.97 \pm 2.99$ \\
$\mathbf{2 1}$ & $1.23 \pm 0.77$ & $2.41 \pm 1.60$ \\
\hline
\end{tabular}

D.O: Densidad óptica, CG: células de la granulosa, CT: células de la teca. D.O. de p-EGFR \pm D.S. Para PFOS el valor de $p$ en las CG y CT fue de 0.48. $N$ total =32, C.G: $N=16$ y CT $N=16 ; N=4$, para control 1.4, 10, $21 \mu \mathrm{mol} / \mathrm{kg}$. Alfa $=0.050$.

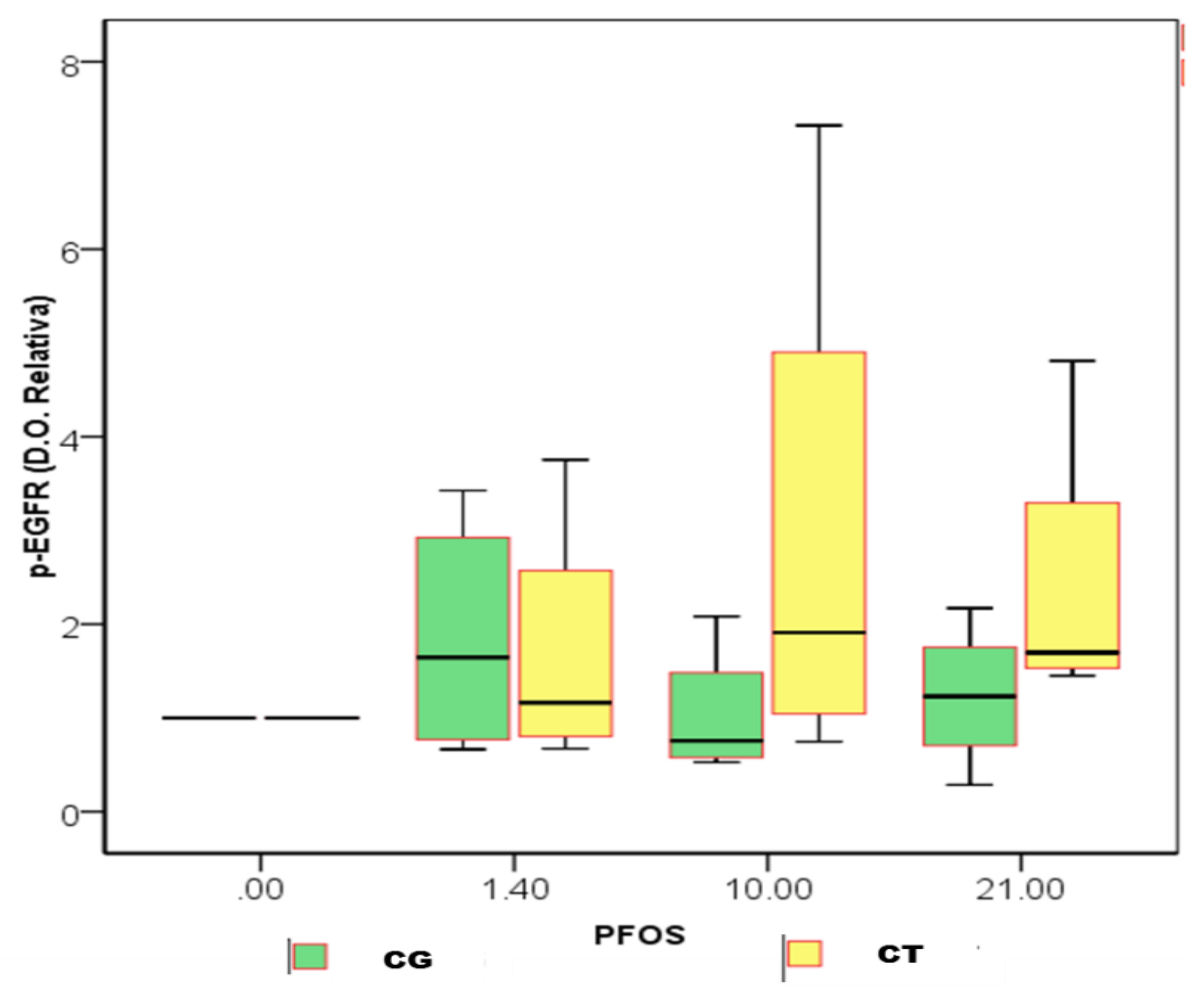

Gráfica 2. Densitometría de la inmunodetección de p-EGFR de las células de la granulosa (cajas verdes) y de la teca (cajas amarillas) obtenidas de las hembras con dosis de 0, 1.4, 10 y 21 $\mu \mathrm{mol} / \mathrm{kg}$ de PFOS. 


\subsection{Efecto del PFOS sobre la relación de p-EGFR / EGFR en las $C G$ y $C T$}

En las CG, la relación p-EGFR / EGFR incrementó la presencia de la proteína fosforilada en los grupos experimentales con respecto al control, que fue mayor en $21 \mu \mathrm{mol} / \mathrm{kg}$, presentando significativa con respecto al control. En las CT también se observó un aumento en la relación de p-EGFR / EGFR en los grupos experimentales con respecto al control, en $21 \mu \mathrm{mol} / \mathrm{kg}$ se presentó menor relación entre p-EGFR / EGFR en comparación con los grupos experimentales, sin embargo, no se encontró diferencia significativa (Tabla 9). En las CT el aumento de la relación de entre p-EGFR / EGFR fue menor en comparación con el de las CG.

En la gráfica 3 se observa un diagrama de caja y bigote de la relación de p-EGFR / EGFR. En la figura 10 se muestran las inmunodetecciones del p-EGFR, el EGFR total y el control de carga actina en los extractos proteínicos de células de la teca y de la granulosa.

Tabla 9. Relación de p-EGFR / EGFR, obtenida a partir de las inmunodetecciones de p-EGFR y EGFR, de los extractos proteínicos de células de la granulosa (CG) y células de la teca (CT) de hembras expuestas al PFOS.

\begin{tabular}{|ccc|}
\hline PFOS $\mu \mathrm{mol} / \mathrm{kg}$ & $\mathrm{CG}$ & $\mathrm{CT}$ \\
$\mathbf{0}$ & $1 \pm 0$ & $1 \pm 0$ \\
$\mathbf{1 . 4}$ & $4.04 \pm 2.51$ & $2.81 \pm 3.20$ \\
$\mathbf{1 0}$ & $3.13 \pm 4.39$ & $3.31 \pm 3.17$ \\
$\mathbf{2 1}$ & $6.00 \pm 6.59^{\mathrm{a}}$ & $1.76 \pm 0.73$ \\
\hline
\end{tabular}

D.O: Densidad óptica, CG: células de la granulosa, CT: células de la teca. D.O. de la relación de pEGFR y EGFR \pm D.S. Para PFOS en las CG el valor de $p$ fue de 0.42 y en las CT de 0.40. $N$ total= 32, CG y CT N=16; $N=4$, para control 1.4, 10, $21 \mu \mathrm{mol} / \mathrm{kg} .{ }^{a}$ diferente significativamente del control (Prueba de Fisher LSD). Alfa $=0.050$. 


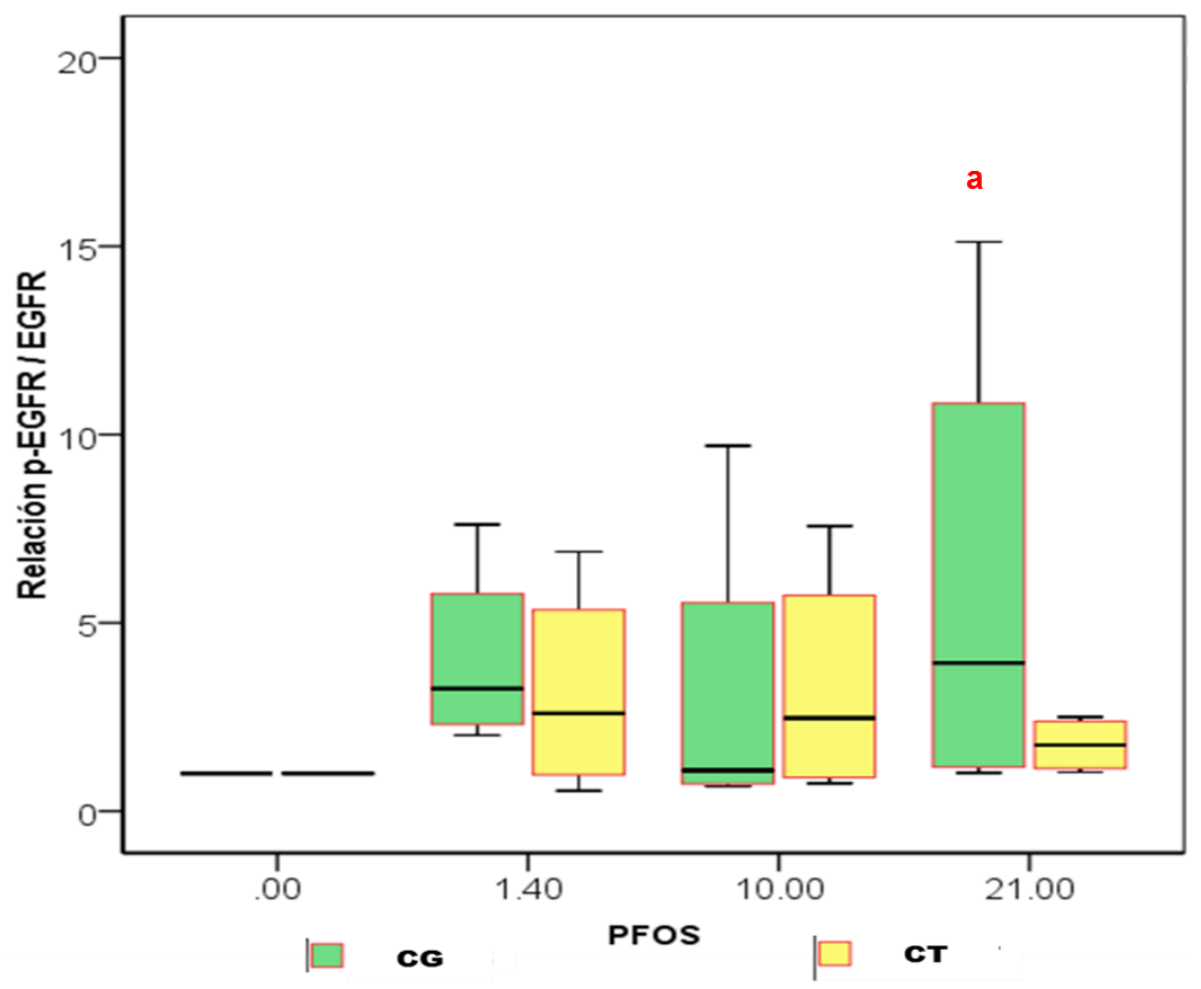

Grafica 3. Relación entre $p$-EGFR y EGFR obtenida a partir de las inmunodetecciones de $p$-EGFR y EGFR, de los extractos proteínicos de las células de la granulosa (cajas verdes) y células de la teca (cajas amarillas) de hembras expuestas a 0,1.4, 10 y $21 \mu \mathrm{mol} / \mathrm{kg}$ de PFOS.
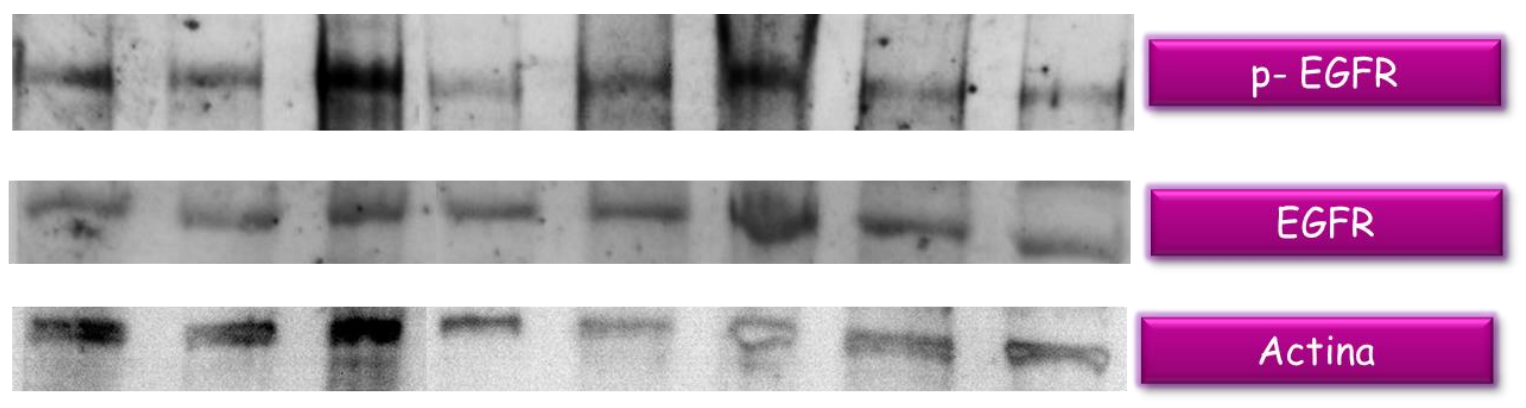

\section{Actina}

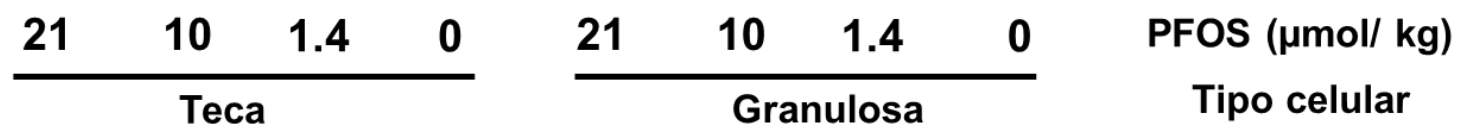

Fig. 10. Inmunodetección de la proteína EGFR, fosforilada (p-EGFR), total (EGFR) y el control de carga de actina en los extractos proteínicos de células de la teca (izquierda) y células de la granulosa (derecha) obtenidos de hembras expuestas a dosis de 0, 1.4, 10 y $21 \mu \mathrm{mol} / \mathrm{kg}$. 


\subsection{Diferencias entre el efecto del PFOS sobre la presencia la Cinasa regulada extracelularmente (ERK 1/2) en las $C G$ y $C T$}

En las CG a pesar de que no se encontraron diferencias significativas entre los grupos experimentales y el control se observó una tendencia de aumento en las dosis 1.4 y $10 \mu \mathrm{mol} / \mathrm{kg}$. En las CT en la dosis de $10 \mu \mathrm{mol} / \mathrm{kg}$, se observó una disminución de la D.O. con respecto al control (0.85 vs 1.0). En las dosis 1.4 y 21 $\mu \mathrm{mol} / \mathrm{kg}$ se detectó una tendencia de aumento. No hubo diferencia significativa entre los grupos experimentales ni con el control (Tabla 10).

En las D.O. obtenidas de las inmunodetecciones de la cinasa ERK 1/2 no se observaron cambios significativos, entre las CG y las CT, sólo se detectó una ligera disminución en la dosis de $10 \mu \mathrm{mol} / \mathrm{kg}$ de las CT con respecto a los demás grupos experimentales y con los grupos de las CG. (Gráfica 4 y Tabla 10).

Tabla 10. Densitometría de la inmunodetección en membrana de ERK 1/2 normalizadas contra el control de carga actina $\pm D$.S. de los extractos proteínicos de células de la granulosa (CG) y células de la teca (CT) obtenidas de hembras expuestas al PFOS.

\begin{tabular}{|ccc|}
\hline PFOS $\mu \mathrm{mol} / \mathrm{kg}$ & $\mathrm{CG}$ & $\mathrm{CT}$ \\
$\mathbf{0}$ & $1 \pm 0$ & $1 \pm 0$ \\
$\mathbf{1 . 4}$ & $1.39 \pm 0.79$ & $1.24 \pm 0.55$ \\
$\mathbf{1 0}$ & $1.04 \pm 0.41$ & $0.85 \pm 0.44$ \\
$\mathbf{2 1}$ & $1.03 \pm 0.83$ & $1.03 \pm 0.43$ \\
\hline
\end{tabular}

D.O: Densidad óptica, CG: células de la granulosa, CT: células de la teca. D.O. relativa de ERK 1/2 \pm D.S. Para PFOS el valor de $p$ en las CG fue de 0.62 y para las CT 0.46. $N$ total $=48, C G$ y CT: $N=$ 24, $N=6$ para control, 1.4, 10 y $21 \mu \mathrm{mol} / \mathrm{kg}$. Alfa=0.050. 


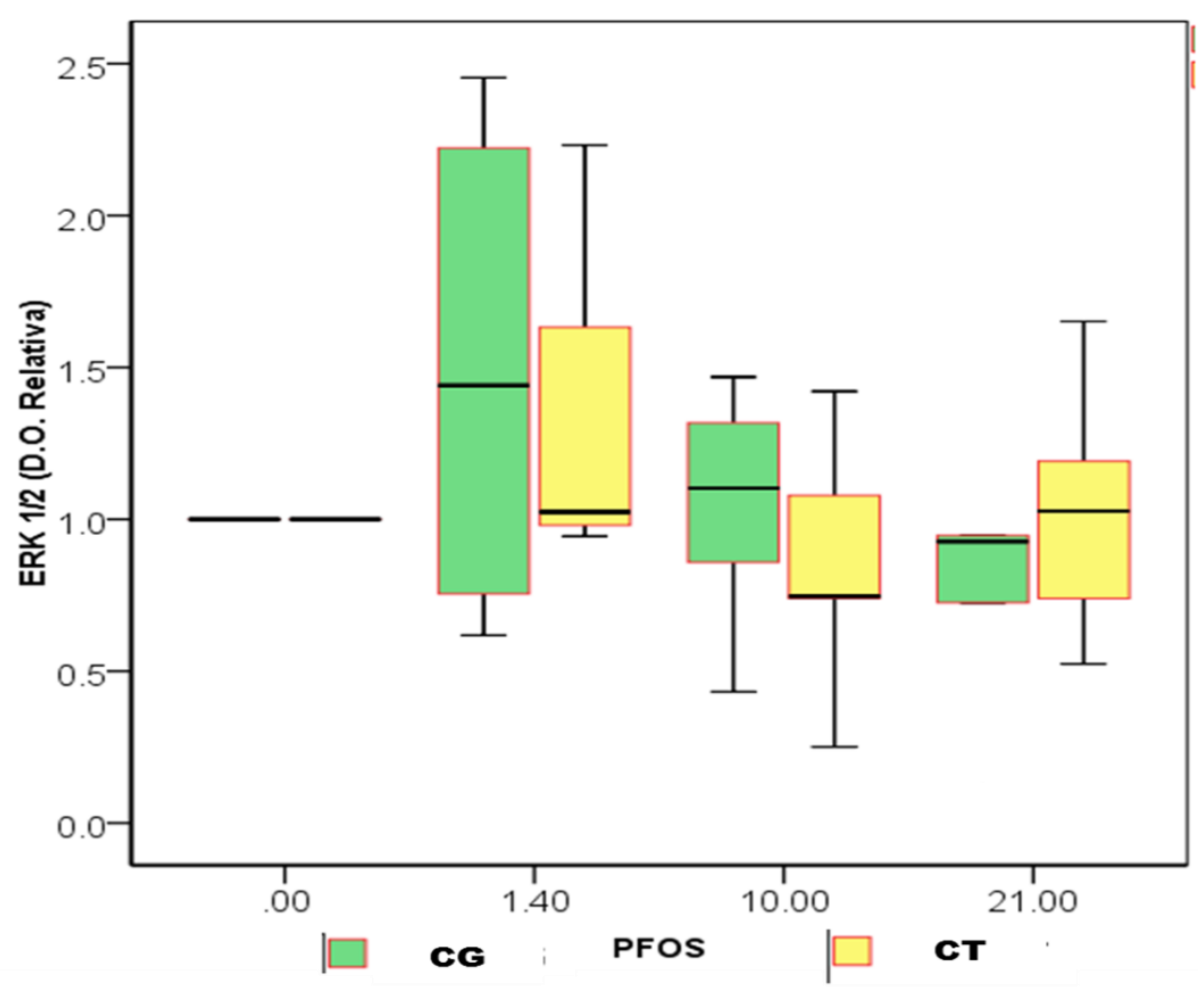

Gráfica 4. Media de la densitometría de la inmunodetección de ERK 1/2 de los extractos proteínicos de las CG (cajas verdes) y de las CT (cajas amarillas) de hembras tratadas con el PFOS. No se encontraron diferencias significativas.

\subsection{Diferencias entre el efecto del PFOS sobre la presencia de p- ERK $1 / 2$ en las $C G$ y $C T$}

La presencia de PFOS provocó cambios significativos en la fosforilación de ERK 1/2 en los sitios de fosforilación ERK1: p- Thr202/ Tyr 204 y ERK2: p- Thr185/ Tyr 187. En las CG la dosis de PFOS $10 \mu \mathrm{mol} / \mathrm{kg}$ mostró un incremento significativo en la presencia de p-ERK 1/2 con respecto a todos los grupos. En tanto que la de 21 $\mu \mathrm{mol} / \mathrm{kg}$ tuvo el efecto contrario y su disminución fue significativa con respecto a los otros grupos (Tabla 11). Por otro lado, en las CT se encontró que el PFOS tuvo una tendencia a reducir la presencia de p-ERK 1/2, la disminución fue mayor en 10 $\mu \mathrm{mol} / \mathrm{kg}$ seguida de 21 con diferencia significativa entre el control y $1.4 \mu \mathrm{mol} / \mathrm{kg}$ (Tabla 11).

La dosis de PFOS $10 \mu \mathrm{mol} / \mathrm{kg}$ tuvo un efecto contrario en los dos tipos celulares ya que tanto en la actividad de ERK $1 / 2$ como en la de $p$-ERK 1/2 en las CG se 
presentó un incremento y en las CT una disminución. En la dosis de $21 \mu \mathrm{mol} / \mathrm{kg}$ la D.O. en las CG fue doble en comparación con las CT. La dosis $1.4 \mu \mathrm{mol} / \mathrm{kg}$ no mostró efecto diferente en los dos tipos de células (Gráfica 5).

Tabla 11 Densitometría de la inmunodetección en membrana de p- ERK 1/2 normalizadas contra el control de carga actina \pm D.S. de los extractos proteínicos de las células de la granulosa y de la teca obtenidos de hembras expuestas al PFOS.

$\begin{array}{ccc}\text { PFOS } \mu \mathrm{mol} / \mathrm{kg} & \mathrm{CG} & \mathrm{CT} \\ \mathbf{0} & 1 \pm 0 & 1 \pm 0 \\ \mathbf{1 . 4} & 1.03 \pm 0.79 & 0.99 \pm 0.55 \\ \mathbf{1 0} & 1.89 \pm 0.41^{\mathrm{a}} & 0.17 \pm 0.44 \\ \mathbf{2 1} & 0.67 \pm 0.83 & 0.33 \pm 0.43^{*}\end{array}$

D.O: Densidad óptica, CG: células de la granulosa, CT: células de la teca. D.O. relativa de $p$ - ERK $1 / 2 \pm$ D.S. Para PFOS el valor de $p$ en las CG fue de $0.000009^{*}$ y en las CT de $0.000008^{*}$. N total= 48, CG y CT: $N=24, N=6$ para control, $1.4,10$ y $21 \mu \mathrm{mol} / \mathrm{kg} .{ }^{a}$ fue diferente del control (Prueba de Bonferroni). " fueron diferentes del control (Prueba de Bonferroni y Prueba de Fisher LSD). Alfa $=0.050$.

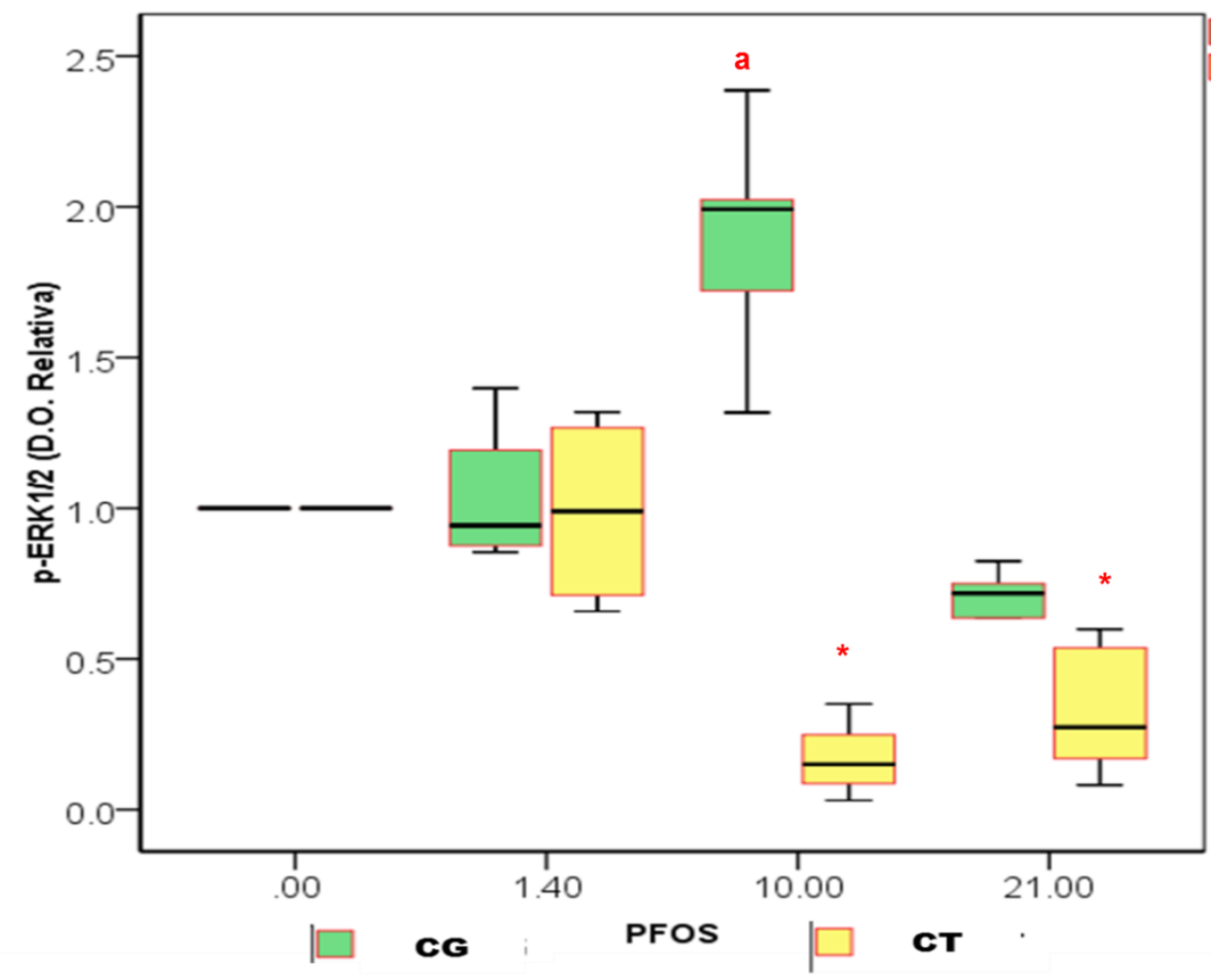

Gráfica 5. Densitometría de la inmunodetección de $p$-ERK 1/2 de las células de la granulosa (cajas verdes) y de la teca (cajas amarillas) obtenidas de las hembras con dosis de 0,1.4, 10 y 21 $\mu \mathrm{mol} / \mathrm{kg}$ de PFOS. 


\subsection{Efecto del PFOS sobre la relación de p-ERK $1 / 2$ / ERK $1 / 2$}

En la figura 11 se muestran las inmunodetecciones sobre membrana del $p$-ERK $1 / 2$, ERK $1 / 2$ total y el control de carga actina en los extractos proteínicos de la granulosa y células de la teca. En las CG el PFOS provocó un incremento en la relación de p-ERK 1/2 sobre ERK 1/2 en todas las dosis con respecto al control, aunque únicamente la dosis de $10 \mu \mathrm{mol} / \mathrm{kg}$ mostró un aumento significativo. Por otro lado en las CT en las dosis de 10 y $21 \mu \mathrm{mol} / \mathrm{kg}$ hubo un ligero incremento con respecto al control pero ninguna de las dosis mostró una diferencia significativa (Tabla 12).

En las CG se encontró un aumento en la relación de p-ERK 1/2 sobre ERK 1/2 en comparación con los grupos experimentales de las CT. En la gráfica 6 se observa un diagrama de caja y bigote de la relación de p-ERK 1/2 sobre ERK 1/2.

Tabla. 12. Relación de p-ERK 1/2 / ERK 1/2, hecha a partir de las inmunodetecciones de $p$ - ERK 1/2 y ERK 1/2, de los extractos proteínicos de células de la granulosa (CG) y células de la teca (CT) obtenidos de hembras expuestas al PFOS.

$\begin{array}{ccc}\text { PFOS } \mu \mathrm{mol} / \mathrm{kg} & \mathrm{CG} & \mathrm{CT} \\ \mathbf{0} & 1 \pm 0 & 1 \pm 0 \\ \mathbf{1 . 4} & 3.24 \pm 1.45 & 0.98 \pm 0.84 \\ \mathbf{1 0} & 4.27 \pm 3.74^{\mathrm{a}} & 1.43 \pm 0.85 \\ \mathbf{2 1} & 2.31 \pm 1.21 & 1.17 \pm 0.50\end{array}$

D.O: Densidad óptica, CG: células de la granulosa, CT: células de la teca. Relación p-ERK 1/2ERK 1/2 \pm D.S. $N$ total= 48, CG y CT: $N=24, N=6$ para control, 1.4, 10 y $21 \mu \mathrm{mol} / \mathrm{kg}$. El valor de $p$ para las CG fue de 0.14 y para las CT 0.67. " fue diferente del control (Prueba de Fisher LSD); Alfa $=0.050$. 


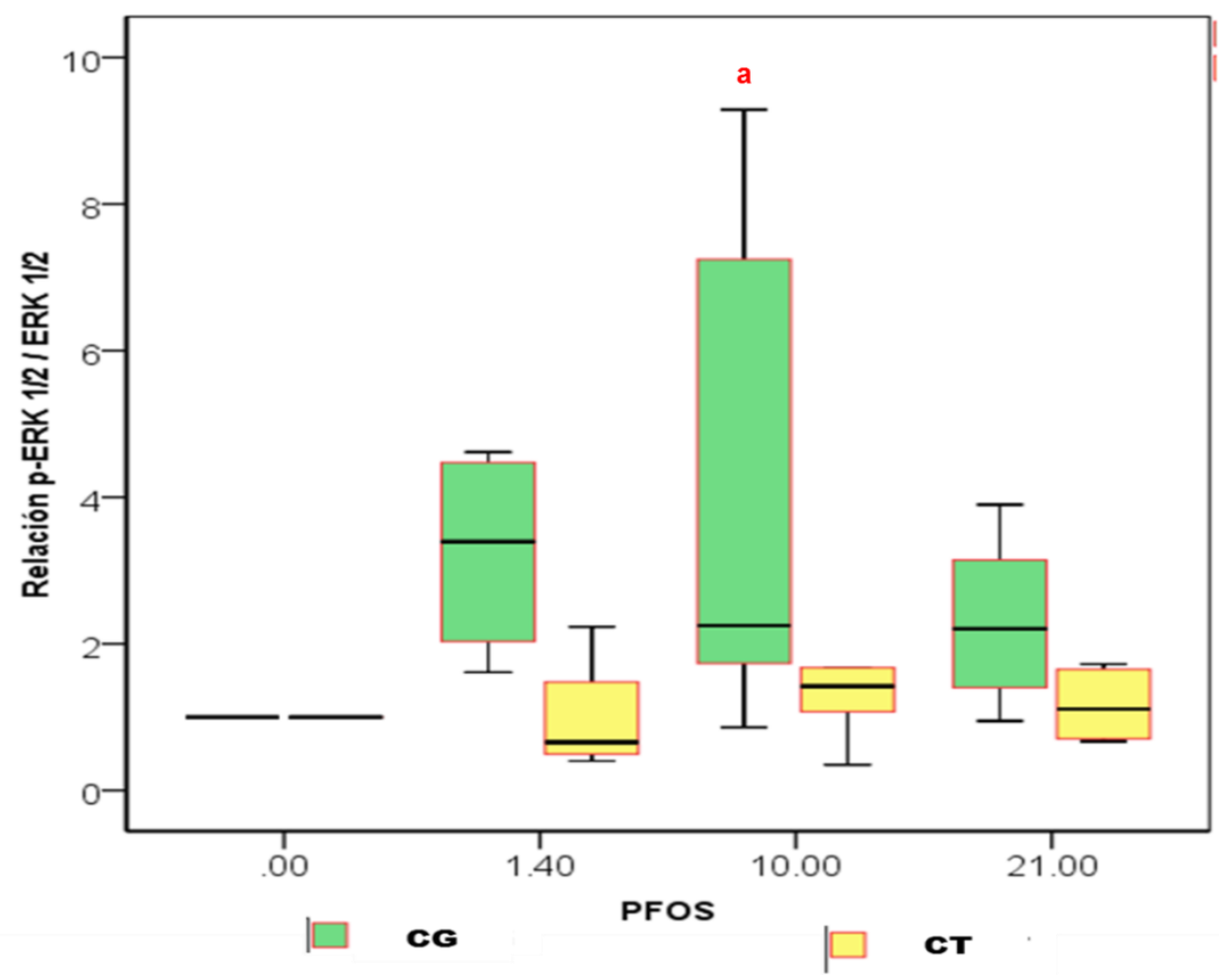

Gráfica 6. Relación de p-ERK 1/2 / ERK 1/2, hecha a partir de las inmunodetecciones de p- ERK 1/2 y ERK 1/2, de los extractos proteínicos de células de la granulosa (CG cajas verdes.) y células de la teca (CT cajas amarillas) que se obtuvieron de hembras administradas con 0, 1.4, 10 y 21 $\mu \mathrm{mol} / \mathrm{kg}$ de PFOS.
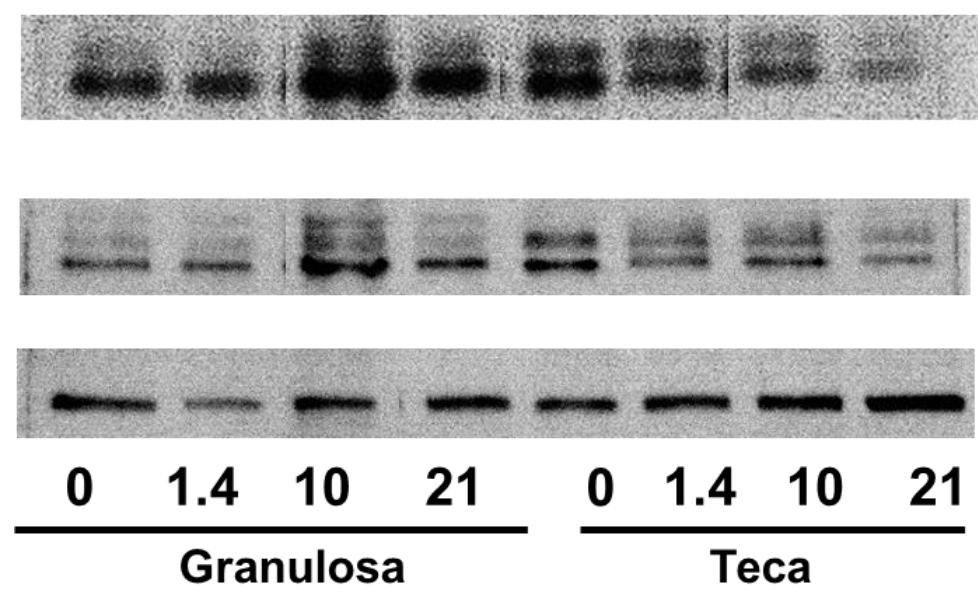

\section{p-ERK $1 / 2$}

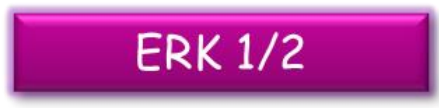

Actina

PFOS $(\mu \mathrm{mol} / \mathrm{kg})$ Tipo celular

Fig. 11. Inmunodetección de la proteína ERK, fosforilada (p-ERK 1/2) y total (ERK 1/2) en los extractos proteínicos de células de la granulosa (izquierda) y células de la teca (derecha) obtenidos de hembras expuestas a 0, 1.4, 10 y $21 \mu \mathrm{mol} / \mathrm{kg}$. 


\subsection{Efecto del PFOS sobre la presencia de la proteína reguladora de la esteroidogénesis aguda (StAR)}

Los individuos tratados con las dosis 1.4 y $21 \mu \mathrm{mol} / \mathrm{kg}$, presentaron un aumento en la actividad de la proteína StAR, sin embargo, los individuos de la dosis 10 $\mu \mathrm{mol} / \mathrm{kg}$ tuvieron una disminución, a pesar de que no se encontró diferencia significativa (Tabla 13).

En la gráfica 7 se observan un diagrama de caja y bigote de las medias de las D.O. obtenidas a partir de las inmunodetecciones sobre membrana del StAR total y el control de carga actina en los extractos proteínicos de células de la teca (Figura 12).

Tabla 13. Densitometría de la inmunodetección en membrana de StAR normalizada contra el control de carga actina $\pm D$.S. de los extractos proteínicos de las células de la teca obtenidos de hembras expuestas al PFOS.

\begin{tabular}{cc} 
PFOS $\mu \mathrm{mol} / \mathrm{kg}$ & Células de la teca \\
$\mathbf{0}$ & $1 \pm 0$ \\
$\mathbf{1 . 4}$ & $1.15 \pm 1.06$ \\
$\mathbf{1 0}$ & $0.82 \pm 0.96$ \\
$\mathbf{2 1}$ & $1.39 \pm 2.09$ \\
\hline
\end{tabular}

D.O: Densidad óptica, CT: células de la teca. D.O. relativa de StAR $\pm D$.S. Para PFOS $p=0.910073$. $N$ total=20, $C T, N=5$ para cada grupo experimental. Prueba de Bonferroni, $E C M=1.60$, valor crítico $=$ 2.67. 


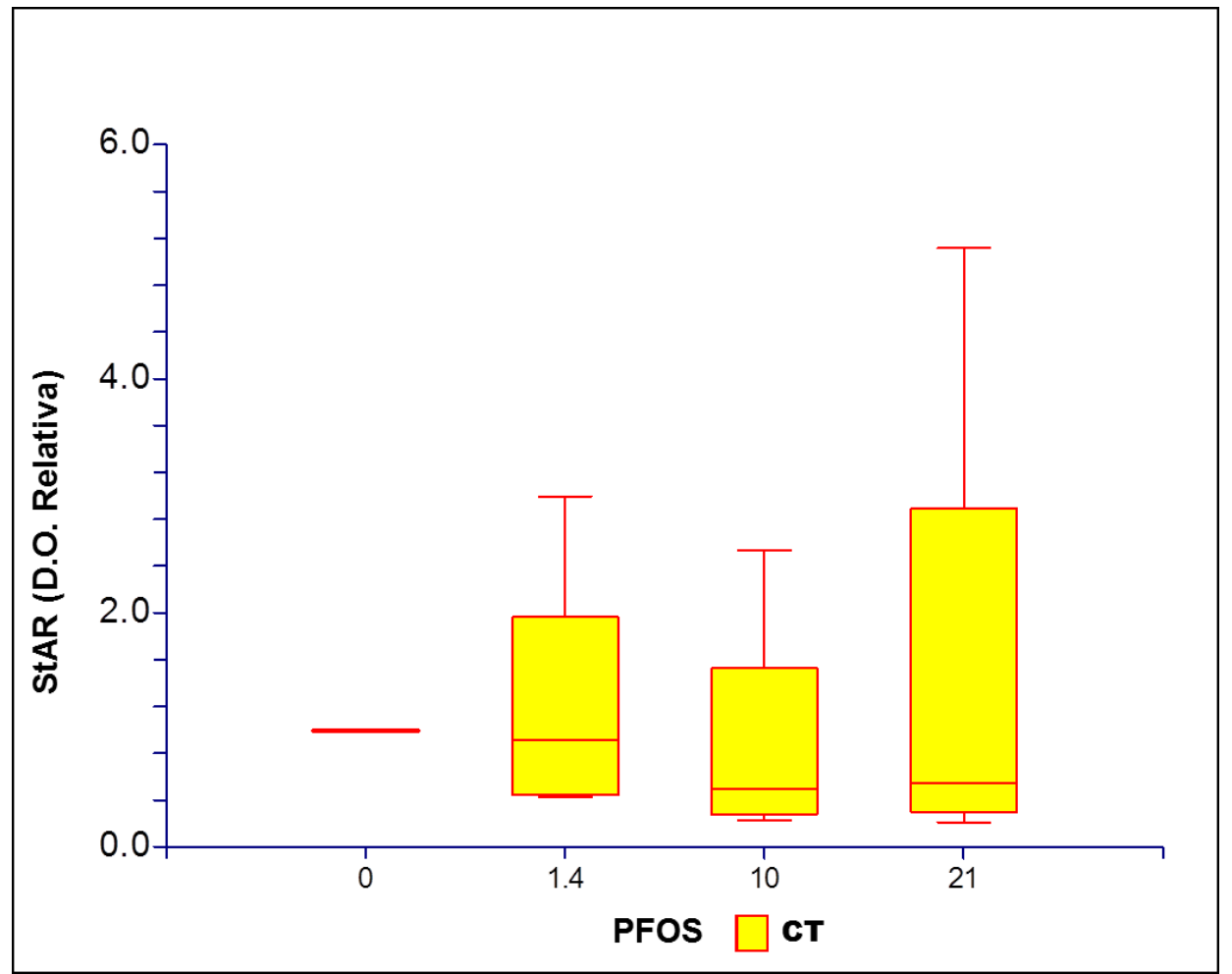

Grafica 7. Densitometría de la inmunodetección de StAR en células de la teca, obtenidas de hembras expuestas a 0, 1.4, 10 y $21 \mu \mathrm{mol} / \mathrm{kg}$ de PFOS. No hay cambios significativos; sin embargo, en la concentración de $21 \mu \mathrm{mol} / \mathrm{kg}$ hay una tendencia al incremento causado por la exposición de PFOS.
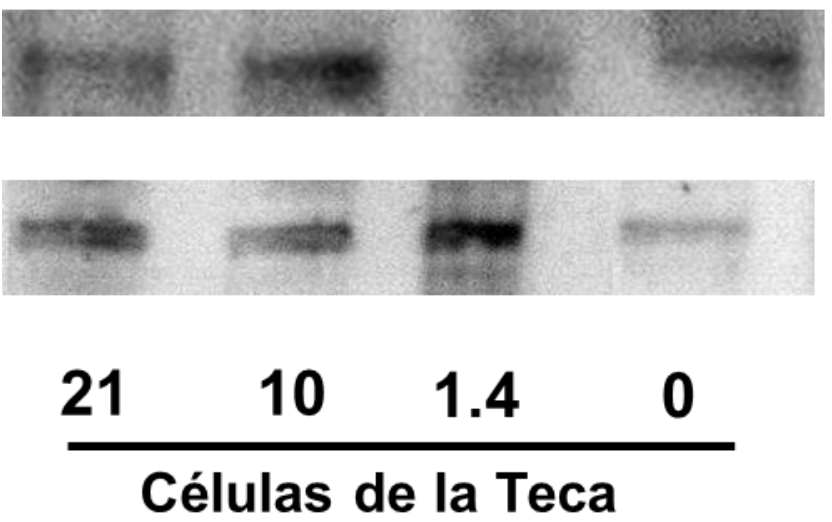

\section{StAR}

Actina

PFOS $(\mu \mathrm{mol} / \mathrm{kg})$ Tipo celular

Fig. 12. Inmunodetección de la proteína StAR en células de la teca obtenidas de las hembras tratadas con el PFOS, como control de carga se empleó la actina No se observaron cambios significativos entre los tratamientos empleados. 


\section{Discusión}

\section{EL PFOS no afecta el peso corporal de las hembras tratadas}

En este trabajo se estudió la respuesta de las células de la granulosa y de la teca al compuesto perfluorado PFOS y su efecto en las proteínas involucradas en la vía de señalización de la esteroidogénesis.

Se administraron un total de 10 camadas, de las que se obtuvo una $N=46$, dispuestas de la siguiente manera:

$\star$ Grupo Control $n=9$

$\star$ Grupo $[1.4 \mu \mathrm{mol} / \mathrm{kg}]=12$

$\star$ Grupo $[10 \mu \mathrm{mol} / \mathrm{kg}]=12$

$\star$ Grupo $[21 \mu \mathrm{mol} / \mathrm{kg}]=13$

El peso de los ratones hembra expuestas por 8 días a PFOS no varió en ninguno de los 4 grupos experimentales, lo que coincide con los datos reportados en ratones macho expuestos a PFOS vía oral por periodos de 10 y 7 días (Johansson et al., 2009, Johansson et al., 2008a, Johansson et al., 2008b, Wan, 2011). El hecho de que no haya alteraciones en el peso corporal de las hembras indica que los efectos observados en la morfología de útero y ovarios, así como los cambios bioquímicos no se deben a la alteración del peso corporal. Sin embargo se sabe que exponer por más de 14 días a los individuos, los hace perder peso (Austin et al., 2003, Wan, 2011).

\section{Evaluación macroscópica de los úteros y ovarios de animales expuestos al PFOS}

En modelos experimentales in vivo en los que se emplearon ratas y carpitas cabezonas expuestas a PFOS se observó un aumento en el peso de los ovarios 
en dosis y concentraciones de $10 \mathrm{mg} / \mathrm{kg}$ y $1 \mathrm{mg}$ de $\mathrm{PFOS} / \mathrm{L}$ respectivamente (Ankley et al., 2005, Austin et al., 2003), nosotros encontramos aumento longitudinal en los ovarios y un aumento en el peso de los úteros de hembras expuestas a la dosis de $10 \mu \mathrm{mol} / \mathrm{kg}$, equivalente a $5.38 \mathrm{mg} / \mathrm{kg}$, lo que quiere decir que el incremento de los ovarios se presenta a partir de dosis más pequeñas.

El aumento de peso en los ovarios podría deberse a la acción de los PPARs específicamente de los PPAR $\gamma$ en los ovarios y su activación por el PFOS. Los PPARs son una familia de factores de transcripción que comparten una estructura común con los receptores de hormonas esteroides, que son activados por un ligando. Los PPARs tienen un papel esencial en el control del metabolismo de lípidos, diferenciación y proliferación celular (Kowalewski et al., 2009, Takacs y Abbott, 2007). Posterior a la activación de los PPARs se activan los mecanismos de genes de transcripción para diversa proteínas, una de ellas ERK 1/2 y su fosforilación (Seto-Young et al., 2007, Takacs y Abbott, 2007).

Los PPAR juegan un papel en el control inflamatorio, se expresan fuertemente en las células de la granulosa, en menor cantidad en las células de la teca y en el cuerpo lúteo. Se detecta en la foliculogénesis temprana, en el folículo primario y su expresión incrementa progresivamente en el estado ovulatorio, pero disminuye después del pico de LH, lo que sugiere que juega un papel importante durante la esteroidogénesis (Petro et al., 2014, Scaramuzzi et al., 2010, Takacs y Abbott, 2007). Los activadores de los PPAR $\gamma$ incluyen los agentes sensibilizantes a la insulina tales como tiazolidinedionas (TZD), rosiglitazona (RSG), pioglitazona y los ligandos naturales: los eicosanoides, ácidos grasos y prostaglandinas (Kowalewski et al., 2009, Scoditti et al., 2009). Sin embargo estudios in vitro e in vivo han demostrado que el PFOS puede activar al PPAR $\gamma$ en el cultivo de células madre neuronales expuestas a $50 \mathrm{nM}$ (Wan Ibrahim et al., 2013).

Por lo que sería importante evaluar la actividad de los PPAR $\gamma$ de los ratones hembra tratadas con PFOS y poder elucidar si estos receptores influyen en el 
crecimiento y diferenciación de los folículos y sus estados de desarrollo, y esto, sea la causa de que encontremos un aumento en el peso y longitud de los ovarios.

\section{Actividad de proteínas involucradas en la vía de señalización de la esteroidogénesis.}

\subsection{Efecto del PFOS sobre la presencia del Receptor del factor de crecimiento epidérmico (EGFR)}

EL EGFR es un receptor de superficie celular que media la diferenciación y proliferación celular. En porcinos se ha detectado la presencia de EGFR fundamentalmente en la células de la granulosa y en menor cantidad en las células de la teca, también se ha demostrado que el EGFR y la FSH pueden inducir la expansión de las células del cúmulo en murinos (Volodymyr, 2004), sin embargo, en otras especies de roedores la expresión y actividad del EGFR es mayor en las CT y en las CG depende del estado de desarrollo folicular, ya que es menor su presencia en el folículo primario y aumenta en los folículos antrales (Garnett et al., 2002). Los efectos del PFOS sobre la actividad del EGFR han sido escasamente estudiados, se ha reportado el efecto de PFOS sobre el EGFR en corazones de ratas Sprague-Dawley, expuestas prenatalmente. Xia et al. (2011) observaron que PFOS indujo un incremento en la actividad de EGFR a 2.0 $\mathrm{mg} / \mathrm{kg} / \mathrm{d}$, la expresión de EGFR en concentraciones más bajas fue normal. Nosotros encontramos en las células de la teca un aumento en la presencia de EGFR $10 \mu \mathrm{mol} / \mathrm{kg}(5.38 \mathrm{mg} / \mathrm{kg})$, el hecho de encontrar el aumento en una concentración mayor puede deberse a diversos factores; en el estudio de Xia et al. (2011) se empleó un órgano diferente, las ratas fueron expuestas por 19 días en edad prenatal. El tiempo de exposición empleado por este grupo de investigación fue mayor al de este estudio y encontraron que con la dosis empleada se producía un efecto tóxico; puede ser que en esta edad los animales sean más susceptibles al efecto tóxico de PFOS, ya que nosotros no detectamos un efecto tóxico y por último, a pesar de que son especies de roedores, su cinética de eliminación es 
diferente, la vida media del PFOS en ratas hembras es de 71 días aproximadamente y en ratones hembras de 30 (Chang et al., 2012).

El EGFR disminuyó su actividad en las CG y aumentó en las CT. Encontrar menor actividad de esta proteína en las CG indica que existe un menor número de folículos en estados avanzados de desarrollo, esto podría indicar una alteración en los procesos de crecimiento y proliferación celular en ambos tipos celulares.

Se detectó un aumento en la presencia de p-EGFR no significativo en las células de la granulosa en la dosis de $1.4 \mu \mathrm{mol} / \mathrm{kg}(0.75 \mathrm{mg} / \mathrm{kg})$, sin embargo los valores obtenidos en los grupos experimentales son valores cercanos al control. El hecho de encontrar valores cercanos al control en las CG podría indicar que el PFOS no altera la activación de p-EGFR en éstas, por otro lado, en las células de la teca se detectó un aumento en 10 y $21 \mu \mathrm{mol} / \mathrm{kg}(5.38,11.3 \mathrm{mg} / \mathrm{kg})$. La presencia de pEGFR, al ser mayor que en las CG, al igual que el EGFR podría corroborar la idea de que los procesos de diferenciación y proliferación celular son alterados, sin embargo los resultados obtenidos en esta parte del estudio son difíciles de contrastar, ya que no existen referencias de otros estudios que se hayan realizado para evaluar el efecto del PFOS sobre la actividad y presencia de p-EGFR y también se debe considerar que en algunos de los valores los datos obtenidos a partir de las D.O. presentan desviaciones estándar mayores o muy cercanos a los valores de las medias, lo que indica que nuestros datos se encuentran dispersos, por lo que es necesario realizar más experimentos para ampliar nuestra muestra y obtener así una muestra homogénea.

El mecanismo por el que la señalización del receptor de LH desencadena la activación del EGFR es controversial, sin embargo estudios in vitro de receptores acoplados a proteínas G (GPCRs) han demostrado que éstas pueden activar el EGFR a través de las metaloproteasas de matriz (MMP) aunque otros estudios sugieren que la activación del EGFR puede ocurrir independiente de las MMP y se puede activar por factores como el AMPc y/ o la cinasa Src (Evaul y Hammes, 2008), por otro lado, estudios en folículos de ratón han demostrado que los inhibidores de MMP bloquean la fosforilación de EGFR inducida por la LH, la 
maduración de ovocitos y la esteroidogénesis, lo que sugiere que la señalización extracelular es esencial para la activación de EGFR y su fosforilación (Carbajal et al., 2011). Las metaloproteasas de la matriz MMP-2 y MMP-9 facilitan la remodelación de la membrana basal durante el crecimiento folicular, en el momento de la ovulación y durante la formación del cuerpo lúteo (McCaffery et al., 2000).

El aumento en la presencia del EGFR y p-EGFR en las células de la teca podría indicarnos que el PFOS altera los procesos de crecimiento y proliferación celular, sin embargo es importante evaluar si ocurre una alteración en los factores que activan el EGFR y su consecuente fosforilación. Por lo que sería importante determinar la actividad de las metaloproteasas MMP-2 y MMP-9 y así obtener mayor información acerca del aumento en la actividad del EGFR en las células de la teca y su posible disminución en las células de la granulosa, también sería importante realizar cortes histológicos de los ovarios para contabilizar el número de folículos, así como el estadio en el que se encuentran y detectar la presencia de EGFR total y fosforilado en las células de la granulosa y de la teca mediante un análisis de inmunohistoquímica.

\subsection{Efecto del PFOS sobre la presencia de la Cinasa regulada extracelularmente (ERK 1/2)}

La vía de señalización de la cinasa ERK 1/2 juega un papel importante, ya que regula la redistribución de proteínas de unión; en las células de la granulosa es activada en respuesta a las gonadotropinas, esta cinasa es importante en la regulación de la esteroidogénesis ovárica inducida por gonadotropinas, regula la transcripción de genes involucrados en la esteroidogénesis, se requiere para la detención del ciclo celular en las células de la granulosa durante la maduración, la expansión de las células del cúmulo, la inducción de la meiosis en el ovocito y la ovulación (Karlsson et al., 2010, Paul et al., 2010, Qiu et al., 2013b).

Los resultados obtenidos en este estudio acerca de la presencia de ERK 1/2 en las células de la granulosa y de la teca no presentaron diferencias entre los grupos experimentales y el control, sin embargo encontramos que en la dosis de 10 
$\mu \mathrm{mol} / \mathrm{kg}$ en las CT existe una tendencia a disminuir la presencia de ERK $1 / 2$. Por otro lado, en las CG detectamos una tendencia al aumento en la presencia de ERK $1 / 2$ y en su fosforilación en el grupo de $10 \mu \mathrm{mol} / \mathrm{kg}(5.38 \mathrm{mg} / \mathrm{kg})$ y en las CT encontramos valores menores al control, sin embargo estos valores no tuvieron diferencias significativas, la disminución en la presencia de p-ERK 1/2 en las células de teca, puede deberse al hecho de que en estas células la cantidad de esta cinasa es menor en comparación con la presente en las CG (Paul et al., 2010). Los datos obtenidos del aumento en la presencia de p-ERK $1 / 2$ en 10 $\mu \mathrm{mol} / \mathrm{kg}$ concuerdan con estudios publicados que hablan del aumento en la fosforilación de la cinasa ERK 1/2 en modelos in vitro e in vivo expuestos a PFOS, uno de ellos es el de las células de Sertoli de ratón macho, en este estudio se observó un aumento significativo en la fosforilación de ERK 1/2 con la dosis de 25 $\mathrm{mg} / \mathrm{kg} / \mathrm{d}$ (Qiu et al., 2013a). Cabe destacar que en este modelo se emplearon ratones adultos tratados por 28 días, en el presente estudio se encontró un aumento en la presencia de ERK $1 / 2$ en la dosis de $10 \mu \mathrm{mol} / \mathrm{kg}(5.38 \mathrm{mg} / \mathrm{kg})$, la diferencia entre los resultados obtenidos por Qu et al. (2013a) y nosotros puede deberse a las diferencias entre machos y hembras en la biodistribución y eliminación del compuesto (Chang et al., 2012).

En los trabajos de Lee et al. (2012) y Lee et al. (2013) se ha estudiado el efecto de PFOS en la vía de señalización de las MAPKs en cultivos de células granulares del cerebelo; las células tratadas con PFOS por $24 \mathrm{~h}$ en concentraciones de 3 y 30 $\mu \mathrm{M}$ producen una inducción en la translocación de PKC de una manera dependiente de la concentración, lo que produce una alteración en la fosforilación de PKC, un paso clave para la vía de señalización de las MAPKs (Lee et al., 2012). Se detectó que se produce un aumento en la fosforilación de ERK 1/2 en $10 \mu \mathrm{mol} / \mathrm{kg}$, los datos de Lee et al. (2012), Lee et al. (2013) y Qiu et al. (2013a) son similares a los datos obtenidos en este estudio, sin embargo sería importante evaluar la actividad de PPAR y y ERK $1 / 2$ ya que como se sabe los PPAR $\gamma$ están involucrados en la activación del gen de transcripción de ERK 1/2 (Seto-Young et al., 2007, Takacs y Abbott, 2007) y no se ha estudiado el efecto del PFOS sobre éstos. También se debe evaluar la actividad de PKC porque se sabe que la 
activación de los PPAR $\gamma$ por RSG disminuye la translocación de la PKC en el endotelio humano (Scoditti et al., 2009), PFOS provoca un aumento en las translocación de la PKC en el cultivo de células granulares del cerebelo (Lee et al., 2013), sería interesante evaluar si esta alteración en la translocación de la PKC también se observa en la activación de los PPAR por PFOS en las células de la teca y de la granulosa y que ésto sea lo que provocó el aumento en la presencia de p-ERK 1/2 que hemos encontrado; también se deben estudiar los efectos del PFOS en las células de la granulosa y de la teca, sobre la ERK 1/2 con un inhibidor de la cinasa (SB4315545, U0126, ALK41517) y dilucidar su efecto en la vía de señalización del EGFR- ERK 1/2-StAR.

\subsection{Efecto del PFOS sobre la presencia de la proteína reguladora de la esteroidogénesis aguda (STAR)}

La cascada de señalización más estudiada en la esteroidogénesis es la mediada por la cinasa de proteínas dependiente del AMPc la vía de la PKA. El efecto agudo de las hormonas tróficas incrementa el contenido intracelular de AMPc activando a la PKA, que fosforila proteínas involucradas en la vía de señalización (EGFR, ERK 1/2) para la activación de las proteínas que se encargan del transporte de colesterol hacia la mitocondria, como es el caso de la proteína StAR (GómezChang et al., 2012), La proteína StAR se considera un paso importante para que se lleve a cabo la esteroidogénesis, ya que es una proteína transportadora de colesterol de la membrana externa de la mitocondria hacia la interna para que pueda empezar la biosíntesis de progesterona, andrógenos y, posteriormente, los estrógenos (Fan et al., 2009, Gyles et al., 2001, Stocco et al., 2005).

En estudios in vivo en ratones macho tratados por 21 días con 5 y $10 \mathrm{mg} / \mathrm{kg}$ de PFOS se ha detectado que hay una disminución en la expresión del RNAm de StAR (Wan, 2011) y en células de Leydig expuestas prenatalmente por 8 días, también se encontró una disminución significativa en la expresión del RNAm de StAR así como en la presencia de la proteína en la dosis de $20 \mathrm{mg} / \mathrm{kg}$ (Zhao et al., 2014). En el presente trabajo se demostró que en las células de la teca existe una ligera tendencia al aumento en la actividad de StAR en las concentraciones de 1.4 
y $21 \mu \mathrm{mol} / \mathrm{kg}(0.75$ y $11.3 \mathrm{mg} / \mathrm{kg})$, sin embargo, los datos obtenidos son cercanos al control, por lo que no son significativamente diferentes, por otro lado, se detectó una tendencia a la disminución en la concentración de $10 \mu \mathrm{mol} / \mathrm{kg}(5.38 \mathrm{mg} / \mathrm{kg})$, este efecto se puede comparar con los datos obtenidos en otros estudios (Wan, 2011, Zhao et al., 2014), sin embargo, se recomienda realizar más experimentos para poder contrastar los resultados obtenidos en la concentración de $10 \mu \mathrm{mol} / \mathrm{kg}$.

La vía de señalización de ERK 1/2 induce la expresión de genes esenciales para la maduración del ovocito, esteroidogénesis, ovulación y luteinización de las células de la granulosa, dentro de los genes que se codifican bajo la influencia de la cinasa ERK 1/2 se mencionan Ptgs2, Pgr y StAR (Fan et al., 2009). Existen sitios de unión para la regulación de la transcripción del gen de StAR, tales como el factor esteroidogénico 1 (SF-1), el activador de la proteína 1 (AP-1) que tienen actividad transcripcional dependiente de fosforilación. La ERK 1/2 está implicada en la regulación y fosforilación de los factores transcripcionales SF-1, AP-1 y la proteína fijadora de los elementos de respuesta a AMPc (CREB), una vez fosforilados estos factores se activará la región del promotor y se lleva a cabo la transcripción de StAR (Fan et al., 2009, Gyles et al., 2001, Stocco et al., 2005). Los resultados obtenidos nos pueden indicar que a pesar de que existe un aumento en la presencia de ERK 1/2 y p-ERK 1/2 ésta podría producir una disminución en la actividad sobre los factores de transcripción como CREB o SF-1 que son esenciales para la transcripción de StAR. Por lo que sería interesante evaluar el efecto del PFOS sobre la expresión de CREB y SF-1 y así poder ampliar los conocimientos de la vía de señalización en las células de la teca. También se debe ampliar este trabajo incluyendo en futuros experimentos la evaluación por inmunodetección de p-StAR. 


\section{Conclusiones}

El presente estudio demostró que:

* La exposición a PFOS en la etapa prepuberal de hembras de ratón no altera el peso en gramos por 8 días de tratamiento, pero si aumenta la longitud de los ovarios obtenidos en la dosis de $10 \mu \mathrm{mol} / \mathrm{kg}$.

$\star$ En las CT en la dosis $21 \mu \mathrm{mol} / \mathrm{kg}$ hay una tendencia al aumento en la presencia de EGFR y que éste podría deberse a diversos factores uno de ellos podría ser el entrecruzamiento que se requiere con la actividad de las MMPs.

$\star$ Se presentan cambios significativos en el aumento de la actividad y fosforilación de la cinasa ERK 1/2 en las CG.

$\star$ Se detectó una alteración en la presencia de StAR en la dosis de 10 $\mu \mathrm{mol} / \mathrm{kg}$ igual que en ERK 1/2 en las CT. 


\section{Perspectivas}

* Realizar cortes histológicos para evaluar el tamaño y número de los folículos, así como el número de capas de las células de la granulosa y de la teca.

* Evaluar la actividad de los PPAR $\gamma$ en el ovario y en las células de la teca, para determinar si este tiene influencia en el desarrollo de las células de la granulosa.

* Realizar inmunohistoquímica de todas las proteínas analizadas en los cortes histológicos para detectar su exacta presencia.

$\star$ Evaluar la actividad de las metaloproteasas MMP-2 y MMP-9, para esclarecer el aumento en la actividad del EGFR en las células de la teca y su posible disminución en las células de la granulosa.

$\star$ Evaluar la actividad del RNAm del PPAR $\gamma$, ERK 1/2, CREB y SF-1

* Valorar la actividad de la PKC en las células de la granulosa y células de la teca y su posible aumento en su translocación

$\star$ Evaluar la actividad de ERK 1/2 ante un inhibidor de cinasa (SB4315545, U0126, ALK41517).

$\star$ Realizar inmunodetección de la p-StAR. 


\section{Referencias bibliográficas}

1. Amsterdam A, Plehn-Dujowich D y Suh BS (1992). Structure-function relationships during differentiation of normal and oncogene-transformed granulosa cells. Biol Reprod 46(4): 513-522.

2. Ankley GT, Kuehl DW, Kahl MD, Jensen KM, Linnum A, Leino RL y Villeneuvet DA (2005). Reproductive and developmental toxicity and bioconcentration of perfluorooctanesulfonate in a partial life-cycle test with the fathead minnow (Pimephales promelas). Environ Toxicol Chem 24(9): 2316-2324.

3. Austin ME, Kasturi BS, Barber M, Kannan K, MohanKumar PS y MohanKumar SM (2003). Neuroendocrine effects of perfluorooctane sulfonate in rats. Environ Health Perspect 111(12): 1485-1489.

4. Basavarajappa MS, Hernandez-Ochoa I, Wang W y Flaws JA (2012). Methoxychlor inhibits growth and induces atresia through the aryl hydrocarbon receptor pathway in mouse ovarian antral follicles. Reprod Toxicol 34(1): 16-21.

5. Benninghoff AB, WH; Koch, DC; Ehresman, DJ; Kolluri, SK; Williams, DE; (2011). Estrogen-like activity of perfluoroalkyl acids in vivo and interaction with human and rainbow trout estrogen receptors in vitro. Toxicol Sci 120: 42-58.

6. Bethencourt J (2004). Ciclo ovárico: Regulación y Endocrinología, correlaciones Hipotálamo- Hipófisis- Ovario. Obstetricia y Ginecología. R Comino and G López. Barcelona, Editorial Ariel, S. A.: 13-22.

7. Biegel LB, Liu RC, Hurtt ME y Cook JC (1995). Effects of ammonium perfluorooctanoate on Leydig cell function: in vitro, in vivo, and ex vivo studies. Toxicol Appl Pharmacol 134(1): 18-25.

8. Bijland S, Rensen PC, Pieterman EJ, Maas AC, van der Hoorn JW, van Erk MJ, Havekes LM, Willems van Dijk K, Chang SC, Ehresman DJ, Butenhoff JL y Princen HM (2011). Perfluoroalkyl sulfonates cause alkyl chain length-dependent 
hepatic steatosis and hypolipidemia mainly by impairing lipoprotein production in APOE*3-Leiden CETP mice. Toxicol Sci 123(1): 290-303.

9. Byers SL, Wiles MV, Dunn SL y Taft RA (2012). Mouse estrous cycle identification tool and images. PLoS One 7(4): e35538.

10. Carbajal L, Biswas A, Niswander LM, Prizant H y Hammes SR (2011). GPCR/EGFR cross talk is conserved in gonadal and adrenal steroidogenesis but is uniquely regulated by matrix metalloproteinases 2 and 9 in the ovary. Mol Endocrinol 25(6): 1055-1065.

11. Cohen S (1962). Isolation of a mouse submaxillary gland protein accelerating incisor eruption and eyelid opening in the new-born animal. J Biol Chem 237: 1555-1562.

12. Chang SC, Noker PE, Gorman GS, Gibson SJ, Hart JA, Ehresman DJ y Butenhoff JL (2012). Comparative pharmacokinetics of perfluorooctanesulfonate (PFOS) in rats, mice, and monkeys. Reprod Toxicol 33(4): 428-440.

13. Chen $\mathrm{MH}, \mathrm{Ha}$, E; et al. (2012). Perfluorinated compounds in umbilical cord blood and adverse birth outcomes. PLoS One 7(8): e42474.

14. Díaz J, García M, Martin G y García R (1998). Crecimeinto normal y patólogico. Avances en el deficit de hormona del crecimiento. Aspectos clínicos, evolutivos y psicológicos. R Gracia and J Portellano. Madrid, Ediciones Díaz de Santos: 3-68.

15. Du G, Hu J, Huang H, Qin Y, Han X, Wu D, Song L, Xia Y y Wang X (2012). Perfluorooctane sulfonate (PFOS) affects hormone receptor activity, steroidogenesis, and expression of endocrine-related genes in vitro and in vivo. Environ Toxicol Chem 32(2): 353-360.

16. Evaul K y Hammes SR (2008). Cross-talk between G protein-coupled and epidermal growth factor receptors regulates gonadotropin-mediated steroidogenesis in Leydig cells. J Biol Chem 283(41): 27525-27533. 
17. Fan HY, Liu Z, Shimada M, Sterneck E, Johnson PF, Hedrick SM y Richards JS (2009). MAPK3/1 (ERK1/2) in ovarian granulosa cells are essential for female fertility. Science 324(5929): 938-941.

18. Fei C, McLaughlin JK, Lipworth L y Olsen J (2009). Maternal levels of perfluorinated chemicals and subfecundity. Hum Reprod 24(5): 1200-1205.

19. Froment P, Gizard F, Defever D, Staels B, Dupont J y Monget P (2006). Peroxisome proliferator-activated receptors in reproductive tissues: from gametogenesis to parturition. J Endocrinol 189(2): 199-209.

20. Garnett K, Wang J y Roy SK (2002). Spatiotemporal expression of epidermal growth factor receptor messenger RNA and protein in the hamster ovary: follicle stage-specific differential modulation by follicle-stimulating hormone, luteinizing hormone, estradiol, and progesterone. Biol Reprod 67(5): 1593-1604.

21. Gómez-Chang E, Larrea F y Martínez-Montes F (2012). Vías de señalización asociadas a la esteroidogénesis. Revista especializada en ciencias Químico-Biológicas 15(1): 24-26.

22. Gorrochategui E, Perez- Albaladejo E, Casas J, Lacorte S y Porte C (2014). Perfluorinated chemicals: differential toxicity, inhibition of aromatase activity and alteration of cellular lipids in human placental cells. Toxicol Appl Pharmacol 277(2): 124-130.

23. Gyles SL, Burns CJ, Whitehouse BJ, Sugden D, Marsh PJ, Persaud SJ y Jones PM (2001). ERKs regulate cyclic AMP-induced steroid synthesis through transcription of the steroidogenic acute regulatory (StAR) gene. J Biol Chem 276(37): 34888-34895.

24. Halldorsson T, Rytter D, Haug L y Olsen S (2012). Prenatal exposure to perfluorooctanoate and risk of overweight at 20 years of age: a prospective cohort study. Environ Health Perspect 120(5): 668-673. 
25. Hampl R, Kubatova J y Starka L (2014). Steroids and endocrine disruptorsHistory, recent state of art and open questions. J Steroid Biochem Mol Biol, S09600760(14)00099-5 [pii] 10.1016/j.jsbmb.2014.04.013.

26. Hatzirodos N, Hummitzsch K, Irving-Rodgers HF y Rodgers RJ (2014). Transcriptome profiling of the theca interna in transition from small to large antral ovarian follicles. PLoS One 9(5): e97489.

27. Heath J, Abdelmageed Y, Braden TD, Williams CS, Williams JW, Paulose T, Hernandez-Ochoa I, Gupta R, Flaws JA y Goyal HO (2011). Genetically induced estrogen receptor alpha mRNA (Esr1) overexpression does not adversely affect fertility or penile development in male mice. J Androl 32(3): 282-294.

28. Hinojosa L, Chavira R, Dominguez R y Rosas P (1999). Effects of thymulin on spontaneous puberty and gonadotrophin-induced ovulation in prepubertal normal and hypothymic mice. J Endocrinol 163(2): 255-260.

29. Hunter T, Ling N y Cooper J (1984). Protein kinase $\mathrm{C}$ phosphorylation of the EGF receptor at a threonine residue close to the cytoplasmic face of the plasma membrane. Nature 311(5985): 4-10.

30. Jamnongjit M y Hammes S (2006). Ovarian Steroids: The Good, the Bad, and the Signals that Raise Them. National Institutes of Health 5(11): 1178-1183.

31. Johansson N, Eriksson P y Viberg $H$ (2009). Neonatal exposure to PFOS and PFOA in mice results in changes in proteins which are important for neuronal growth and synaptogenesis in the developing brain. Toxicol Sci 108(2): 412-418.

32. Johansson N, Fredriksson A y Eriksson $P$ (2008a). Neonatal exposure to perfluorooctane sulfonate (PFOS) and perfluorooctanoic acid (PFOA) causes neurobehavioural defects in adult mice. Neurotoxicology 29(1): 160-169.

33. Johansson N, Viberg H, Fredriksson A y Eriksson P (2008b). Neonatal exposure to deca-brominated diphenyl ether (PBDE 209) causes dose-response 
changes in spontaneous behaviour and cholinergic susceptibility in adult mice. Neurotoxicology 29(6): 911-919.

34. Karlsson AB, Maizels ET, Flynn MP, Jones JC, Shelden EA, Bamburg JR y Hunzicker- Dunn M (2010). Luteinizing hormone receptor-stimulated progesterone production by preovulatory granulosa cells requires protein kinase A-dependent activation/dephosphorylation of the actin dynamizing protein cofilin. Mol Endocrinol 24(9): 1765-1781.

35. Kjeldsen LS y Bonefeld-Jorgensen EC (2013). Perfluorinated compounds affect the function of sex hormone receptors. Environ Sci Pollut Res Int 20(11): 8031-8044.

36. Komar CM, Braissant O, Wahli W y Curry TE, Jr. (2001). Expression and localization of PPARs in the rat ovary during follicular development and the periovulatory period. Endocrinology 142(11): 4831-4838.

37. Kowalewski MP, Dyson MT, Manna PR y Stocco DM (2009). Involvement of peroxisome proliferator-activated receptor gamma in gonadal steroidogenesis and steroidogenic acute regulatory protein expression. Reprod Fertil Dev 21(7): 909922.

38. Kraugerud M, Zimmer KE, Ropstad E y Verhaegen S (2005). Perfluorinated compounds differentially affect steroidogenesis and viability in the human adrenocortical carcinoma (H295R) in vitro cell assay. Toxicol Lett 205(1): 62-68.

39. Lau C, Lindstrom AB y Seed J (2009). Perfluorinated chemicals 2008: PFAA Days II meeting report and highlights. Reprod Toxicol 27(3-4): 429-434.

40. LaVoie HA, Whitfield NE, Shi B, King SR, Bose HS y Hui Y (2014). STARD6 is expressed in steroidogenic cells of the ovary and can enhance de novo steroidogenesis. Exp Biol Med (Maywood) 239(4): 430-435. 
41. Lee HG, Lee YJ y Yang JH (2012). Perfluorooctane sulfonate induces apoptosis of cerebellar granule cells via a ROS-dependent protein kinase C signaling pathway. Neurotoxicology 33(3): 314-320.

42. Lee YJ, Lee HG y Yang JH (2013). Perfluorooctane sulfonate-induced apoptosis of cerebellar granule cells is mediated by ERK $1 / 2$ pathway. Chemosphere 90(5): 1597-1602.

43. Light A y Hammes SR (2013). Membrane receptor cross talk in steroidogenesis: recent insights and clinical implications. Steroids 78(6): 633-638.

44. Liu C, Du Y y Zhou B (2007). Evaluation of estrogenic activities and mechanism of action of perfluorinated chemicals determined by vitellogenin induction in primary cultured tilapia hepatocytes. Aquat Toxicol 85(4): 267-277.

45. Lopez- Doval S, Salgado R, Pereiro N, Moyano R y Lafuente A (2014). Perfluorooctane sulfonate effects on the reproductive axis in adult male rats. Environ Res 134C: 158-168.

46. Manna P, Dyson M y Stocco D (2009). Regulation of the steroidogenic acute regulatory protein gene expression: present and future perspectives. Mol Hum Reprod 15(6): 321-333.

47. Manna P y Stocco D (2011). The Role of Specific Mitogen-Activated Protein Kinase Signaling Cascades in the Regulation of Steroidogenesis. Journal of signal Transduction 2011: 1-13.

48. Maras M, Vanparys C, Muylle F, Robbens J, Berger U, Barber JL, Blust R y De Coen W (2006). Estrogen-like properties of fluorotelomer alcohols as revealed by mcf-7 breast cancer cell proliferation. Environ Health Perspect 114(1): 100-105.

49. McCaffery FH, Leask R, Riley SC y Telfer EE (2000). Culture of bovine preantral follicles in a serum-free system: markers for assessment of growth and development. Biol Reprod 63(1): 267-273. 
50. Miller WL y Auchus RJ (2011). The molecular biology, biochemistry, and physiology of human steroidogenesis and its disorders. Endocr Rev 32(1): 81-151.

51. Paul S, Kundu S, Pramanick K, Bandyopadhyay A y Mukherjee D (2010). Regulation of ovarian steroidogenesis in vitro by gonadotropin in common carp Cyprinus carpio: interaction between calcium- and adenylate cyclase-dependent pathways and involvement of ERK signaling cascade. J Mol Endocrinol 45(4): 207218.

52. Petro EM, D' Hollander W, Covaci A, Bervoets L, Fransen E, DeNeubourg D, DePauw I, Leroy JL, Jorssen EP y Bols PE (2014). Perfluoroalkyl acid contamination of follicular fluid and its consequence for in vitro oocyte developmental competence. Science of the Total Environment 496: 282-288.

53. Programa de las Naciones Unidas para el Medio Ambiente (2006), Informe del Comité de Examen de los Contaminantes Orgánicos Persistentes sobre la labor realizada en su segunda reunión, Adición: Perfil de riesgos del sulfonato de perfluorooctano. Ginebra. Naciones Unidas. UNEP/POPS/POPRC.2/17/Add.5.

54. Qiu L, Zhang X, Zhang X, Gu J, Chen M, Zhang Z, Wang X y Wang S (2013a). Sertoli cell is a potential target for perfluorooctane sulfonate(PFOS)induced reproductive dysfunction in male mice. Toxicological Sciences TOXSCI13-0108.R2: 1-39.

55. Qiu M, Liu J, Han C, Wu B, Yang Z, Su F, Quan F y Zhang Y (2013b). The Influence of Ovarian Stromal/Theca Cells During In Vitro Culture on Steroidogenesis, Proliferation and Apoptosis of Granulosa Cells Derived from the Goat Ovary. Reprod Domestic Anim, 10.1111: 170-176.

56. Rajkovic A, Pangas S y Matzuk M (2006). Follicular Development: Mouse, Sheep, and Human Models. Knobil and Neill's Physiology of Reproduction. J Neill. Amsterdam, Elsevier: 383- 410. 
57. Rosell R (2004). Regulación neuroendocrina del ciclo estral en los animales domésticos. REDVET 5(1): 1-25.

58. SAGARPA SdA, Ganadería, Desarrollo Rural, Pesca y Alimentación (2001), NOM-062-ZOO-1999, Especificaciones técnicas para la producción, cuidado y uso de los animales de laboratorio. México. Diario Oficial de la Federación.

59. Sahmani M, Najafipour R, Farzadi L, Sakhinia E, Darabi M, Shahnazi V, Mehdizadeh A, Shaaker M y Noori M (2012). Correlation between PPARgamma protein expression level in granulosa cells and pregnancy rate in IVF program. Iran J Reprod Med 10(2): 149-154.

60. Sanderson JT (2006). The steroid hormone biosynthesis pathway as a target for endocrine-disrupting chemicals. Toxicol Sci 94(1): 3-21.

61. Sasseville M, Ritter LJ, Nguyen TM, Liu F, Mottershead DG, Russell DL y Gilchrist RB (2010). Growth differentiation factor 9 signaling requires ERK1/2 activity in mouse granulosa and cumulus cells. J Cell Sci 123(Pt 18): 3166-3176.

62. Scaramuzzi R, Brown H y Dupont J (2010). Nutritional and metabolic mechanisms in the ovary and their role in mediating the effects of diet on folliculogenesis: a perspective. Reprod Domest Anim 45 Suppl 3: 32-41.

63. Scoditti E, Massaro M, Carluccio MA, Distante A, Storelli C y De Caterina R (2009). PPARgamma agonists inhibit angiogenesis by suppressing PKCalpha- and CREB-mediated COX-2 expression in the human endothelium. Cardiovasc Res 86(2): 302-310.

64. Schneider CA, Rasband WS y Eliceiri KW (2012). NIH Image to ImageJ: 25 years of image analysis. Nature Methods 9: 671-675.

65. Seto-Young D, Avtanski D, Strizhevsky M, Parikh G, Patel P, Kaplun J, Holcomb K, Rosenwaks Z y Poretsky L (2007). Interactions among peroxisome proliferator activated receptor-gamma, insulin signaling pathways, and 
steroidogenic acute regulatory protein in human ovarian cells. J Clin Endocrinol Metab 92(6): 2232-2239.

66. Stocco DM, Wang X, Jo Y y Manna PR (2005). Multiple signaling pathways regulating steroidogenesis and steroidogenic acute regulatory protein expression: more complicated than we thought. Mol Endocrinol 19(11): 2647-2659.

67. Takacs M y Abbott A (2007). Activation of Mouse and Human Peroxisome Proliferator-Activated Receptors $(\alpha, \beta / \delta, \gamma)$ by Perfluorooctanoic Acid and Perfluorooctane Sulfonate. Toxicol Sci 95(1): 108-117.

68. Trejo R, Betancourt M y Casas E (2005). Óvulo: la célula reproductora femeninia. Los gametos: células reproductoras de los mamíferos. R Trejo. México, Manual Moderno: 47-72.

69. Volodymyr D (2004). Efectos del factor de crecimiento epidérmico (egf) sobre los procesos implicados en la fecundación "in vitro". Doctorado Tesis Doctoral, Universidad Complutense de Madrid.

70. Wan HZ, Y; Wong, K; Lee, K; Yeung, W; Giesy, J; Wong, C; (2011). Testicular Signaling Is the Potential Target of Perfluorooctanesulfonate-Mediated Subfertility in Male Mice. Biology of Rerpoduction 84: 1016-1023.

71. Wan Ibrahim WN, Tofighi R, Onishchenko N, Rebellato P, Bose R, Uhlen P y Ceccatelli S (2013). Perfluorooctane sulfonate induces neuronal and oligodendrocytic differentiation in neural stem cells and alters the expression of PPARgamma in vitro and in vivo. Toxicol Appl Pharmacol 269(1): 51-60.

72. Woods DC, Haugen MJ y Johnson AL (2007). Actions of epidermal growth factor receptor/mitogen-activated protein kinase and protein kinase $\mathrm{C}$ signaling in granulosa cells from Gallus gallus are dependent upon stage of differentiation. Biol Reprod 77(1): 61-70. 
73. Xia W, Wan Y, Li YY, Zeng H, Lv Z, Li G, Wei Z y Xu SQ (2011). PFOS prenatal exposure induce mitochondrial injury and gene expression change in hearts of weaned SD rats. Toxicology 282(1-2): 23-29.

74. Zhao B, Li L, Liu J, Li H, Zhang C, Han P, Zhang Y, Yuan X, Ge RS y Chu Y (2014). Exposure to perfluorooctane sulfonate in utero reduces testosterone production in rat fetal Leydig cells. PLoS One 9(1): e78888.

75. Zheng L, Dong GH, Jin YH y He QC (2009). Immunotoxic changes associated with a 7-day oral exposure to perfluorooctanesulfonate (PFOS) in adult male C57BL/6 mice. Arch Toxicol 83(7): 679-689. 